\title{
Clasificación Sachs-Hornbostel de instrumentos musicales: una revisión y aplicación desde la perspectiva americana
}

\author{
The Sachs-Hornbostel Classification System of Musical \\ Instruments: a Review and Application from an American \\ Perspective
}

por

José Pérez de Arce

Museo Chileno de Arte Precolombino, Chile

jperezdearce@museoprecolombino.cl

Francisca Gili ${ }^{1}$

Universidad Católica del Norte y Universidad de Tarapacá, Chile frangili@hotmail.com

\begin{abstract}
El sistema de clasificación de instrumentos musicales ideado por Curt Sachs y Erich Moritz von Horbonstel en 1914 es universalmente usado hasta hoy. En este artículo se analizan las razones de esta permanencia y se revisa en general la historia de los distintos criterios usados para clasificar los instrumentos musicales. Igualmente se explica, de acuerdo con nuestra experiencia, el porqué el sistema de Sachs-Hornbostel nos parece el más apropiado para la realidad americana, con énfasis en la época prehispánica. Se discuten las fortalezas del sistema, junto con sus debilidades, la metodología de clasificación y la de ordenamiento, de modo de clarificar su utilidad como herramienta metodológica. Nuestra posición se sustenta en una experiencia de más de treinta años de investigación en la organología americana, la que permite precisar las posibilidades que ofrece este sistema para futuras investigaciones. Además se contrastan las características del sistema con las necesidades metodológicas que plantea el material organológico americano, en especial el arqueológico. Finalmente se propone una actualización del sistema completo, en la que se incluyen nuevas variedades organológicas del área surandina. Se ha respetado la estructura original del sistema propuesta por sus autores, para que continúe siendo efectivo como sistema de referencia universal y compatible con el amplio uso que se le ha dado en todo el mundo.

Palabras clave: organología, clasificación de instrumentos musicales, metodología organológica, música prehispánica, área surandina.
\end{abstract}

The classification system of musical instruments created by Curt Sachs and Erich Moritz von Hornbostel in 1914 is still the most widely used around the world. In this article the reasons of the permanence of this system are analyzed along with a brief revision of the history of other systems of classifying musical instruments. On the basis of our

1 Becaria MECESUP del programa de Postgrado en Antropología de la Universidad Católica del Norte y la Universidad de Tarapacá.

Revista Musical Chilena, Año LXVII, enero-junio, 2013, Nº 219, pp. 42-80 
experience we explain the reasons for considering the Sachs-Hornbostel system as the most appropriate for the study of the American musical instruments, especially those from the pre-Columbian period. The strengths and weaknesses of the system along with its methodological structure are discussed so as to clarify its usefulness as a methodological tool. After thirty years studying the organology of the American instruments we feel in condition to delineate the possibilities of this system in future research studies. The main characteristics of this system are contrasted with the requirements of the organology of the American instruments especially those found in pre Hispanic archaeological sites. Finally an updating of the whole system is proposed in which new organological varieties of the South Andean zone are included. A special care has been taken to maintain the original structure established by the authors, so that the system will remain useful as a universal tool compatible with the wide use that has had around the world.

Key words: organology, classification of musical instruments, organological methodology, pre Hispanic music, South Andean area

Este artículo revisa los sistemas de clasificación de instrumentos musicales aplicados a la realidad americana, con énfasis en la realidad prehispánica, en que su utilidad es mayor según nuestra experiencia. La primera parte discute brevemente los sistemas usados históricamente. Se concentra en el sistema ideado por SachsHornbostel (en adelante $\mathrm{SH}$ ), que es el más utilizado en la región. Se analizan sus fortalezas, debilidades y su metodología de clasificación y de ordenamiento.

La segunda parte está dedicada al sistema SH. Profundiza en la discusión de sus características, las que se contrastan con las necesidades metodológicas que se enfrentan en el estudio del material organológico americano, en especial el arqueológico. Finalmente se propone una actualización de este sistema adaptado a estas necesidades ${ }^{2}$. Se ha tenido cuidado de respetar la estructura original propuesta por sus autores, para que de este modo siga siendo efectivo como sistema de referencia universal y compatible con el amplio uso que se le ha dado en todo el mundo.

El artículo expone los resultados de un trabajo desarrollado durante los últimos 25 años de investigación en organología por parte de José Pérez de Arce, quien se nutrió de los sistemas de clasificación expuestos para guiar metodológicamente el registro de los diferentes instrumentos musicales que ha estudiado. En los últimos años se incorporó al trabajo Francisca Gili ${ }^{3}$, quien colaboró en la recopilación de antecedentes y en la revisión de la sistematización desarrollada por Pérez de Arce.

La aplicación de este sistema como una herramienta metodológica para el estudio de piezas de tradición no occidental significa un gran aporte. Mediante su análisis y aplicación hemos podido observar cualidades que definen algunas tendencias y permanencias en las tradiciones musicales propias del continente americano.

2 La versión completa, aumentada y corregida del sistema Sachs-Hornbostel realizada por los autores de este trabajo se puede consultar en la versión electrónica www.SciELO.cl de este número de la $R M C h$ o en www.revistamusicalchilena.uchile.cl .

3 Trabajo realizado en el marco del proyecto de título: Documentación digital para colecciones de instrumentos musicales arqueológicos. Fue realizado a base de la colección del Museo Chileno de Arte Precolombino durante los años 2004-2007, para optar al grado de Licenciado en Artes con mención en Restauración en la Pontificia Universidad Católica de Chile. 


\section{LOS SISTEMAS DE CLASIFICACIÓN}

En la búsqueda por organizar los elementos que rodean al ser humano a lo largo de la historia ha surgido la necesidad de clasificarlos. Se han ideado sistemas para clasificar las especies naturales y lo mismo ha ocurrido con los objetos hechos por el hombre. El caso de los instrumentos musicales no escapa a esta aproximación. Con el tiempo se han desarrollado diversos sistemas que buscan aproximarse a la naturaleza de los instrumentos musicales y a las divisiones jerárquicas que mejor definen las diferencias entre ellos. La idea de clasificar es difícil por el dinamismo y diversidad ante la cual nos enfrentamos. La clasificación no ha sido una tarea fácil, toda vez que es estática y busca la semejanza entre los elementos. Es por ello que se han generado diversas propuestas, las que brevemente se describirán a continuación.

El más antiguo sistema de clasificación de instrumentos de música conocido fue usado por los chinos 4.000 años antes de Cristo. Consideraba ocho "sonidos", según los materiales de construcción: metal, seda, piedra, bambú, calabaza, arcilla, cuero, madera (Biot 1803-1850).

Los primeros sistemas de clasificación europeos son muy posteriores al sistema chino. Los de Martin Agrícola (Musica instrumentalis deudsch, 1529), Pierre Trichet (Traité des instruments de musique, ca.1640, 1957) y del padre Marin Mersenne (Traité de l'harmonie universelle, 1627), reconocieron cuatro grupos de instrumentos: de cuerda, de viento, de percusión y "varios". Esta forma de clasificar se explica porque en los conjuntos orquestales europeos de la época los instrumentos de "cuerdas" y los de "vientos" eran esenciales, la percusión no era importante y se conocían algunos pocos inclasificables. No obstante estas divisiones eran incongruentes, ya que no había un único criterio de subdivisión. En el caso de la cuerda y el viento se realiza una división de acuerdo con los componentes que entran en vibración para producir el sonido; en el caso de la percusión, de acuerdo con la técnica de tañido y en la categoría "varios" según los instrumentos que no caben en las categorías anteriores. La subdivisión de estos grupos se hace según el material del cual están hechos, lo que resulta operativo en el caso de los instrumentos de vientos, de madera y los de bronce de la orquesta de la época.

A partir de 1880 Víctor Mahillon ${ }^{4}$ idea un nuevo modo de clasificación, luego de la exploración de la amplia colección de instrumentos europeos y exóticos del Museo del Conservatorio de Bruselas. Este sistema intenta unificar los criterios de clasificación para lograr una mayor consistencia. Para este efecto mantiene la primera división según el elemento que entra en vibración (cuerda y viento). No obstante, se diferencia según los otros elementos que entran en vibración, membrana en el caso de los tambores, o la masa entera del instrumento, como es el caso de los platillos, las castañuelas o un gong. Para una mayor precisión de

4 Cf. Mahillon 1880. En Vega 1946 se hace referencia a otras publicaciones de Mahillon sobre el tema aparecidas en 1900, 1909, 1922 y 1939. 
su nomenclatura, Mahillon toma como referencia la palabra griega "fono", que significa sonido. Sobre esta base denomina las divisiones como membranófonos (instrumentos en los cuales el material que entra en vibración es una membrana); cordófonos (cuando el material que entra en vibración es una cuerda); aerófonos (si lo que entra en vibración es el viento) y autófonos (aquellos instrumentos en los cuales el material que entra en vibración es el mismo que compone a la pieza). Las subdivisiones que plantea para continuar la clasificación están determinadas por la manera con la que el ejecutante hace vibrar el cuerpo del instrumento, punto sobre el que no entraremos en su detalle.

El primer intento de contar con un sistema que se pudiera aplicar a las regularidades y patrones universales con una metodología basada en la compleja realidad organológica del panorama mundial, más que solamente en criterios teóricos, es el de Erich Moritz von Hornbostel, director del Berlin Phonogram Archiv y Curt Sachs, quien trabajaba en la Staatliches Instrumenten Samlung de Berlín. Ellos incorporaron el conocimiento de la gran gama de nuevos instrumentos que aportó el auge de la etnografía y el nacimiento de la musicología comparada. Publicaron en 1914 su sistema bajo el título "Systematik der Musikinstrumente". Adoptaron los cuatro principios de clasificación iniciales de Mahillon, ya que permitía incorporar las nuevas especies exóticas a las que se les comenzaba a prestar atención. No obstante, cambiaron la denominación de autófonos por idiófonos, al asumir la raíz griega "idio" como lo propio, en vez de "auto" que significa "por sí mismo", ya que podría confundirse con que el instrumento suena por sí mismo, como es el caso de un instrumento automático.

Respecto de las subdivisiones, cambiaron el modelo Mahillon por uno más sencillo y reconocible a simple vista tanto por los etnólogos como por los exploradores o por los conservadores de museos. Detectaron la inconveniencia de mantener encabezamientos consistentes para todos los rubros, ya que el número de subdivisiones es tan amplio que no resulta manejable sin ingresar encabezamientos superfluos e insignificantes. Además el sistema debe dejar espacio para futuras divisiones, a fin de abarcar casos especiales y permitir el aumento de las subdivisiones. En lugar de dividir los distintos grupos de acuerdo con un principio uniforme, Sachs y Hornbostel establecieron que el principio de la división fuese dictado por la naturaleza del grupo mismo (Vega 1946), según detallaremos más adelante.

Para concretar esta idea, Sachs y Hornbostel adoptaron el sistema de numeración de Dewey, el que permite ampliar infinitamente las subdivisiones de clasificación. Para aplicarlo enumeraron inicialmente las cuatro divisiones principales: (1) idiófonos, (2) membranófonos, (3) cordófonos, (4) aerófonos y luego continuaron sucesivamente con las subdivisiones. De este modo, al clasificar un instrumento de acuerdo con este método, se obtiene un número de clasificación que puede ser descifrado siguiendo el sistema Sachs-Hornbostel. Por ejemplo, si se parte del número (3), que significa cordófonos, este se subdivide según el siguiente principio: 


\section{(3) CORDÓFONOS}

(31) Sin mango

(311) de palo

(312) de tubo

(313) de balsa

(314) de tabla

(315) de valvas

(316) de marco

(32) Con mango

(321) Laúdes

(322) Arpas

(323) Laúdes-arpas

Es así como se puede saber que el número (311) corresponde a un instrumento cuyo sonido es emitido por la vibración de una cuerda (cordófono), de estructura simple, sin mango, y que su cuerpo corresponde a un palo. A su vez la clasificación 311 tiene otras subdivisiones:

(311.1) Arcos musicales

(311.11) Idiocordes

(311.12) Heterocordes

(311.121) Monoheterocordes

(311.122) Poliheterocordes

(311.122.1) Sin corredera vocal.

(311.122.2) Con corredera vocal.

(311.2) Palos musicales (que a su vez se extiende como la anterior subdivisión).

Estas subdivisiones informan que 311.122.2 corresponde a un cordófono/sin marco/de palo/heterocorde/poliheterocorde/con corredera vocal. Siguiendo la traducción al español hecha por Carlos Vega, se encuentra una breve explicación de cada una de estas subdivisiones:

\begin{tabular}{|l|l|}
\hline (3) CORDÓFONOS & Una o varias cuerdas están tendidas entre puntos fijos. \\
\hline $\begin{array}{l}\text { (31) CORDÓFONOS SIMPLES O } \\
\text { CÍTARAS }\end{array}$ & $\begin{array}{l}\text { El instrumento consiste en un portacuerdas solo, o en } \\
\text { un portacuerdas y un cuerpo de resonancia en cohesión } \\
\text { inorgánica, separables sin destrucción del aparato musical. }\end{array}$ \\
\hline (311) DE PALOS & $\begin{array}{l}\text { El portacuerdas tiene forma de palo; también las tablas } \\
\text { puestas de filo pertenecen a esta. }\end{array}$ \\
\hline (311.1) Arcos musicales & El portacuerdas es flexible (y curvo). \\
\hline (311.12) Heterocordes & La cuerda es de otra materia que el arco. \\
\hline
\end{tabular}




\begin{tabular}{|l|l|}
\hline (311.122) Poliheterocordes & El arco tiene varias cuerdas de otra materia que el cuerpo. \\
\hline (311.122.2) Con corredera vocal & \\
\hline
\end{tabular}

De este modo, con un número de clasificación se puede tener la información organológica de los instrumentos, lo que permite en poco espacio tener una nomenclatura universal e informar acerca de los instrumentos.

Posteriormente, se plantearon otros sistemas de clasificación. Los más importantes son el de Nicholas Bessarabof (1941) y el de André Schaeffner (1936). Bessarabof incorporó dos clases: los instrumentos electrónicos y los accesorios, junto con reinterpretar las subdivisiones. Por su parte André Schaeffner, etnomusicólogo del Museo del Hombre de París, desarrolló un nuevo modelo de clasificación, inspirado en el precedente. Dividió los instrumentos en aquellos de cuerpo sólido vibrante (idiófonos, cordófonos y membranófonos) y los de aire vibratorio (aerófonos), junto con corregir las debilidades teóricas del sistema SH. En definitiva, es un sistema que pone más énfasis en su formulación teórica que en la realidad de los instrumentos musicales del mundo. Si bien en términos lógicos es más perfecto y coherente, resulta menos representativo de la realidad y por lo tanto es menos útil.

Los investigadores posteriores Dräger (1948), Hood (1971) y en general la musicología hacia los años 60, experimentó la influencia de la antropología. Promovieron una mirada centrada en la función social del instrumento musical, en su identidad cultural, y por lo tanto en la diversidad regional y temporal, opuesta al criterio universal propuesto por SH. Los intentos de clasificación de Reinecke (1974), Malm (1974), Stockmann (1979) y Heyde (1975) usan los nuevos lenguajes y métodos para tratar de hacer más operativa esa tendencia. Sin embargo el nivel de antecedentes que se vinculan se acrecienta, lo que lleva a lenguajes cada vez más complejos y crípticos. Para la realidad americana, y específicamente precolombina, sin embargo, ninguno de estos sistemas sirve, porque justamente el ámbito antropológico (uso y función) es la variable desconocida de los instrumentos musicales precolombinos ${ }^{5}$.

Actualmente el sistema de clasificación de instrumentos musicales más aceptado y utilizado universalmente como herramienta metodológica sigue siendo el creado por Sachs y Hornbostel. Recientemente, el año 2011, una nueva versión de este sistema ha sido publicada en la web sobre la base de modificaciones propuestas por Jeremy Montagu el año 2009. Esta adaptación ha sido revisada a nivel

\footnotetext{
5 El enfoque nuestro se centra en las necesidades de la arqueomusicología americana, en la que la ausencia de datos respecto de los instrumentos es notable. Otros autores, como Hickmann (1990: 340 y 463, citado en Mendívil 2002: 5), han hecho notar este punto. Las causas se deben a la gran cantidad de objetos provenientes de excavaciones no registradas y a la falta de conocimiento musicológico por parte de los arqueólogos.
} 
europeo por diferentes investigadores asociados a los principales museos que albergan colecciones de instrumentos musicales en el marco del proyecto MIMO. $\mathrm{Su}$ objetivo es registrar instrumentos musicales de diversas colecciones en una base de datos unificada. ${ }^{6}$

En relación con nuestro continente, su amplia aceptación por parte de investigadores en la región latinoamericana se basa en los trabajos de Gustav Izikowitz ${ }^{7}$, quien lo tradujo al inglés y lo adoptó para clasificar instrumentos americanos. Posteriormente Carlos Vega ${ }^{8}$ lo tradujo al español. La tarea de traducción no les resultó fácil a ambos estudiosos, ya que se hacía muy complejo hacer coincidir la traducción del alemán con las nomenclaturas que ofrecían los diversos idiomas. En palabras del mismo Vega (1946: 27): "La versión alemana original establece el significado de la especie que cada cifra representa, añadiendo generalmente al nombre de la clase, el de la subclase, el del orden etc., y articulando con ellos sólo una o dos palabras compuestas. No he podido hacer lo mismo en castellano por razones de índole idiomática”.

Sobre la base de la traducción de Vega, diversos organólogos de la región latinoamericana han aplicado este sistema a instrumentos arqueológicos o etnográficos de distintas localidades del continente. Se pueden destacar los trabajos de Fernando Ortiz (1952) en Cuba, Isabel Aretz (1967) en Venezuela, Bolaños y otros (1978) en Perú, Gudemos (1988) en Argentina y Ernesto Cavour (1994) en Bolivia, entre otros.

\subsection{Comentarios acerca del sistema de clasificación $\mathrm{SH}$}

La necesidad de clasificar el material organológico debe nacer de la metodología usada en cada caso particular. Por ejemplo, todo trabajo etnomusicológico serio debiera tomar en consideración la clasificación de los instrumentos musicales como la concibe la cultura que estudia. En la mayoría de estos casos no encontramos una intención de clasificar propiamente, pero sí la de organizar el material organológico de acuerdo con patrones determinados, como es el caso por ejemplo del calendario anual en las culturas andinas de Perú y Bolivia ${ }^{9}$. Desgraciadamente los trabajos en este sentido son escasos. El único intento específico que conocemos en esta dirección para América Latina fue hecho por Julio Mendívil (2002) respecto

6 Revision of the Hornbostel-Sachs Classification of Musical Instruments by the MIMO Consortium. http://www.music.ed.ac.uk/euchmi/cimcim/uymhs02.pdf (recuperado el 16 de octubre de 2012).

7 Inicialmente este trabajo fue presentado como una tesis de grado en la Universidad de Göteborg, Suecia. Incorpora piezas vernáculas americanas que fueron incluidas en este sistema de clasificación. Se concentra mayoritariamente en la zona de Sudamérica, especialmente en la región del Amazonas, el Chaco y Perú.

8 Este libro ofrece un tratado organológico de los instrumentos vernáculos de Argentina y sus países limítrofes incorporados al sistema de clasificación Sachs-Hornbostel.

9 Una discusión de este tema se halla en Baumann 2001: 826. 
de la clasificación de instrumentos Incas, el que no ha sido publicado. Por otra parte existen excelentes revisiones que se mueven en esa dirección, como es el caso de Stevenson (1976).

Actualmente hay un mayor interés en estudiar los contextos culturales de la producción musical. Cynthia Adams Hoover (1996: 4) considera que el sistema SH corresponde a la tendencia taxonómica de algunos coleccionistas del siglo XX, quienes "se dedicaron a descubrir las semejanzas entre distintos tipos de instrumentos, en vez de registrar las tradiciones singulares de una cultura". De acuerdo con Gunji (1996: 6), hay quienes consideran que este es un sistema adecuado para instrumentos musicales occidentales, y que los demás han de interpretarse de distinto modo -por ejemplo de acuerdo con un origen etnográfico o folclóricopara reflejar sus características singulares. Es evidente que, según los objetivos de cada investigación, el sistema utilizado será más o menos adecuado y sin duda el sistema SH no fue diseñado para distinguir singularidades culturales.

Para la realidad organológica de América prehispánica, en cambio, el sistema SH es el más adecuado, porque se basa en la única herramienta metodológica existente que sea confiable y estable para toda la muestra. Esto no significa que sea perfecta. Como cualquier sistema que intenta agrupar, definir y catalogar objetos culturales, el sistema SH presenta una serie de problemas, ya que la realidad exhibe una ductilidad, variación y plasticidad que hace imposible su encasillamiento a cualquier sistemática. La misma lógica que permite agrupar y relacionar puede, en otros casos, tender a separar y disociar elementos. Para este efecto se repasará desde una perspectiva crítica dos características fundamentales de este sistema: la metodología de árbol filogenético y los criterios de subdivisión, para luego revisar sus ventajas comparativas.

El gran hallazgo metodológico del sistema SH es a la vez su mayor problema estructural; la organización en familias y subfamilias, al modo del "árbol filogenético", el gran descubrimiento científico del siglo XIX, basado en la evolución biológica y en la filogenia de los seres vivos, con líneas de parentesco con ancestros comunes. Al aplicar este criterio a los instrumentos musicales se revela (como en todo objeto cultural) una serie de problemas, como son las filogenias paralelas (como los tambores semejantes, inventados independientemente en África y América), los casos intermedios (como las flautas que no son cerradas ni abiertas sino "semicerradas"), los mestizajes entre dos tipos filogenéticamente diferentes (como el tambor-sonajero ${ }^{10}$, ver Figura 1 ), los casos que no caben cómodamente en ninguna clasificación (como los "aerófonos de vibración") o un mismo instrumento que, según como se tañe, suena como un instrumento diferente (un violín

10 Aparte de la invención explícita de híbridos (ver, por ejemplo, Cavour 2003) existen muchos ejemplos tradicionales de mestizaje en cuyo caso $\mathrm{SH}$ recomienda definir su doble filiación, como en las flautas traversas de Asia oriental (421.121), cuyo agujero lateral obturado con una membrana pegada actúa como mirlitón de tubos (241). 
pulsado, frotado o percutido en la caja ${ }^{11}$ ). Los autores Sachs y Hornbostel trataron estos casos programando soluciones tales como la división común final, que se añade con el signo (-) al final, o con el signo (+) para añadir dobles filiaciones.

\section{FIGURA 1}

Kultrún ("timbal" SH211.11) mapuche (sur de Chile) con objetos mágicos adentro, en ocasiones es sacudido usándolo como "timbal-sonaja" (SH212.1). (Museo Chileno de Arte Precolombino [MCHAP] - ex-MAVI 3403)

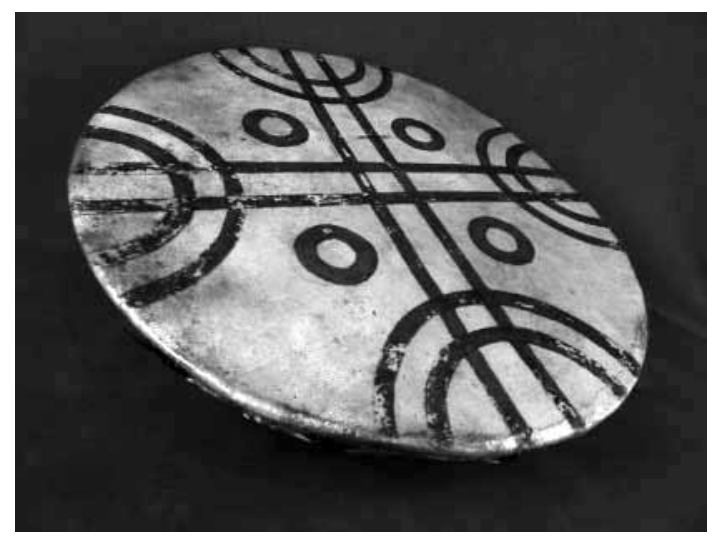

Los criterios de subdivisión son el problema central de todo sistema de clasificación. El mayor desafío que debió afrontar la creación del sistema SH fue, sin duda, el decidir caso a caso qué criterio debía primar sobre los otros. Su decisión se basó en criterios simples. El principio organizador lo escogieron, en cada caso, atendiendo a la naturaleza del grupo mismo. Este tipo de decisión es bastante arbitraria. A modo de ejemplo, definir si es más importante que un tambor sea abierto o cerrado, que tenga una o dos membranas, o que su cuerpo tenga una geometría determinada puede variar de un investigador a otro. La decisión, sea cual sea, repercute en todas las categorías posteriores e influye en la utilización del sistema. Probablemente el peso de los argumentos en pro de una u otra decisión varía de una zona geográfica a otra. La decisión que tomaron Sachs y Hornbostel fue dejar abierto este punto. Definieron una forma de reordenar las categorías de acuerdo con las necesidades, haciendo uso de símbolos como (:) y (]). Esta parte del sistema $\mathrm{SH}$ es bastante engorrosa y además plantea cambios al sistema universalmente aceptado, por lo que ha sido poco usado. Los comentarios a este problema se detallarán en notas para cada caso más adelante.

$11 \mathrm{SH}$ recomienda definir cada caso por separado. 
A pesar de los problemas descritos, dentro de sus márgenes y limitaciones de naturaleza operativa, el sistema opera metodológicamente en forma muy eficiente, lo que se expresa de diversos modos.

En primer lugar, permite entender un instrumento musical como parte de un sistema de diseños acústicos empleados en diferentes épocas y lugares para lograr resultados sonoros semejantes ${ }^{12}$. La ventaja de esto es que el sistema de clasificación hace más comprensible la descripción de la especificidad acústica de cada tipo organológico, incluso para el lector no habituado al conocimiento acústico, sonoro y musical. Existen casos en que ese diseño acústico es muy sencillo, pero de difícil descripción, como en la flauta. Por su misma sencillez estructural algunas flautas son difíciles de identificar, como los "aerófonos de ruido", descubiertos por Roberto Velázquez en colecciones arqueológicas de México, las que hasta entonces habían pasado inadvertidos (Velásquez 2003).

En segundo lugar, permite utilizar los conceptos de grupo, familia o parentesco organológico y definir de acuerdo con parámetros estudiables las tendencias estético-sonoras de un área cultural. Esto ayuda a identificar casos de convergencia, mestizaje, difusión, evolución, parentesco, divergencia e incluso las ausencias (como es el caso de la ausencia de los cordófonos en América prehispánica o de los idiófonos en la Europa Clásica). Esta utilidad se complementa con el concepto de tendencia, según veremos posteriormente.

En tercer lugar, el sistema SH permite la identificación del principio organológico con independencia de las características no sonoras. El hacer esta distinción entre las características que no intervienen en la producción del sonido (como en el uso de la ornamentación, por ejemplo) de aquellas características relacionadas con el sonido, permite detectar tipos organológicos que de otro modo permanecen ocultos tras distintas apariencias estilísticas. Este punto se desarrollará al tratar la permanencia.

En cuarto lugar, este sistema de clasificación está realizado sobre una plataforma que permite hoy su sistematización en medios digitales. Toda la organización del sistema se podría eventualmente programar en un software, mediante el que se podrían obtener diversas ventajas. Se podría generar una herramienta activa alojada en la web, en la que distintos investigadores registraran los diferentes instrumentos que han analizado. Al tener un sistema poblado de datos, se podrían generar búsquedas de datos específicos y estadísticas de la información relevada, lo que aportaría una herramienta muy significativa para posteriores estudios organológicos correlacionales.

12 En este sentido, y haciendo caso al concepto de tendencia, nos hacemos cargo de la posibilidad de tener datos útiles respecto de las culturas sonoras del pasado a base del análisis acústico del objeto. No creemos, sin embargo, que ese análisis por sí mismo sea útil, como postula Hickmann (1990: 413-450, citado en Mendívil 2000: 17), teniendo en cuenta los problemas que se destacarán respecto del tañido. 
En quinto y último lugar, el sistema SH permite abordar los instrumentos musicales según los estándares internacionales que existen para la documentación de bienes patrimoniales. En el desarrollo de la normalización de la información para el registro de colecciones y bienes patrimoniales, diversas instituciones (Getty Institute $^{13}$, Centro de Documentación de Bienes Patrimoniales [CDBP] de la Dirección de Bibliotecas, Archivos y Museos [DIBAM] ${ }^{14}$, Instituto del Patrimonio Andaluz ${ }^{15}$ ) han aportado con la generación de tesauros con el fin de normalizar el vocabulario que describe los distintos elementos que componen el patrimonio. Para estos tesauros se han generado jerarquías que dividen los universos patrimoniales y que buscan una sistematización de la información en bases de datos. El sistema SH se presenta como una metodología que, planteada hace décadas, satisface estas necesidades de sistematización y que, además, es un sistema ya resuelto, aprobado por un universo disciplinario y que ha sido traducido a diferentes idiomas.

En este sentido cabe destacar varias propuestas para generar bases de datos y fichas para instrumentos musicales en colecciones que han recomendado el uso de este sistema, tanto a nivel nacional (Pérez de Arce 1985) como a nivel internacional. Lo proponen miembros del Comité Internacional de Museos y Colecciones de Instrumentos Musicales [CIM-CIM] del Consejo Internacional de Museos [ICOM] (Myers 1989; Barclay 1992). Importante en tal sentido es el desarrollo de una base de datos para registrar instrumentos musicales online MIMO [Musical Instrument Museums Online] ${ }^{16}$, iniciativa en la que se está alojando la información de instrumentos musicales que provienen de diversas partes del mundo y que están albergados principalmente en colecciones europeas. En esta instancia se han generado modificaciones al sistema Sachs-Hornbostel que se utiliza como dato en el registro de las piezas. Sin embargo no está integrada en la aplicación web, de modo de poder correlacionar datos y generar búsquedas de instrumentos definidas por las cualidades tecnológicas determinadas por el sistema de clasificación que nos convoca, alternativa que consideramos de gran utilidad en vista del análisis del sistema que a continuación se exhibirá.

\section{NUEVA PROPOSICIÓN DEL SISTEMA SH}

A continuación se presenta una discusión del sistema SH sobre la base de las modificaciones que proponemos, para hacerlo más comprensible, por una parte, a un público de habla española, y por otra parte como herramienta metodológica que acoja las variables propias de América. En virtud de los antecedentes expuestos la presente propuesta toma como base la traducción de Vega a la cual se le han integrado algunos cambios de índole idiomática con la finalidad de clarificar los significados propuestos en el original de Sachs y Hornbostel. Además se han incluido nuevas

\footnotetext{
13 http://www.getty.edu/research/tools/vocabularies/aat/about.html

$14 \mathrm{http}: / /$ www.tesauroregional.cl/trp/publico/buscar.htm

15 http://www.iaph.es/web/canales/conoce-el-patrimonio/tesauro-pha/

16 http://www.mimo-db.eu/MIMO/Infodoc/
} 
categorías que han sido registradas para nuestro continente con un especial énfasis e interés en los fenómenos organológicos desarrollados en el área Sur Andina.

En primer lugar se discutirán los criterios principales sobre los cuales se fundamenta nuestro trabajo. Para este efecto se definirá lo que se entiende por instrumento musical, los criterios metodológicos básicos que se consideran necesarios para su estudio y las relaciones entre instrumentos musicales en tiempo y espacio que se consideran relevantes al presente estudio. En segundo lugar se revisarán las características del material organológico mundial conocido hasta ahora para identificar las características con que el sistema $\mathrm{SH}$ opera en relación con el panorama planteado en el punto anterior, y en tercer lugar se presentará nuestra versión revisada del sistema $\mathrm{SH}$.

\subsection{Temas generales: discusión}

\subsubsection{El instrumento musical como diseño de sonidos}

La construcción de un instrumento musical tiene por objetivo la producción de un tipo de sonido específico. El constructor tiene en mente una música producida por ese instrumento, que despliega una gama de timbres, melodías, ritmos e intenciones musicales, y fabrica el instrumento de acuerdo con esa idea. Esta área la denominamos “diseño sonoro". Se puede definir el diseño sonoro como la elección, manipulación y elaboración de objetos con el fin de obtener determinados sonidos. Ese diseño implica tanto la elección de materiales, de técnicas de construcción y de aspectos estructurales tales como técnicas de tañido ${ }^{17}$. Queda fuera de esta definición el rango de los diseños naturales, como el uso de la voz, o el sonido producido por el picoteo en el árbol del pájaro carpintero o el aleteo en el agua de patos en celo. Esta exclusión es muy útil metodológicamente, ya que se refiere el estudio de los diseños naturales, ya sea orgánico como inorgánico, los que se agrupan en un área complementaria (que puede tener una gran importancia), sobre todo en el caso de las culturas con contacto directo con la naturaleza, en las que el diseño sonoro se nutre del diseño natural. En cambio el suelo golpeado con los pies desnudos durante los rituales de guerra mapuches del siglo XVI, por ejemplo, queda dentro de esta definición. Si el diseño natural queda excluido por su cualidad anterior a la cultura, en el otro extremo de la cultura se deja fuera el diseño electrónico musical, ya que no utiliza las propiedades físicas del objeto para producir sonidos, sino que las crea artificialmente mediante la electrónica ${ }^{18}$.

17 Otros autores han agrupado los instrumentos musicales según los criterios de la importancia de la función sonora, como Lund (citado en Mendívil: 2002: 2): un instrumento puede producir sonido; podría supuestamente producir sonido; puede tener funciones diversas, una de las cuales es producir sonido; puede no estar construido para producir sonido, pero puede ser usado con ese fin; puede tener una función desconocida, la que probamente sea producir sonido. Esta clasificación no es útil para la realidad arqueológica americana porque presupone conocer la función y el uso del instrumento, temas acerca de los cuales, según se ha visto, no cuenta con antecedentes.

18 El sacar el instrumento electrónico de esta clasificación tiene que ver con nuestra opción y necesidad metodológica, asociada a las tradiciones culturales vernáculas del mundo. En todo caso, 
El producto del diseño sonoro, tal como se ha definido, es el instrumento musical ${ }^{19}$. Se puede definir el instrumento musical como un objeto producido culturalmente para obtener un resultado sonoro determinado. Debido a que el término "música" no existe en muchas culturas (las andinas, por ejemplo), algunos autores han propuesto el término "objeto sonoro", ya que es más amplio e inespecífico $^{20}$. Pero esta misma inespecificidad deja de lado el énfasis en la función de un "instrumento", es decir, un objeto diseñado específicamente con un propósito, que es una "música". Son precisamente estos los rasgos esenciales que marcan la tendencia del conjunto de estos objetos. Por ello preferimos hablar de "instrumento musical"21. Para superar el problema de la ausencia del término "música" en muchas culturas, se le dará a este término una dimensión semántica que abarca todo el ámbito del lenguaje estético sonoro humano, y que se diferencia del otro lenguaje lógico sonoro humano utilizado para hablar. Es interesante hacer notar que, acústicamente, ambos lenguajes se diferencian en la tendencia al uso de melodías (música) versus dinámicas y timbres (habla) como principal componente del discurso sonoro. Si bien ambos usan la voz, solo la música utiliza instrumentos musicales. El visualizar este conjunto permite entender la búsqueda organológica de la humanidad como un componente de su sistema de comunicación.

El estudio del diseño sonoro de un instrumento musical es lo que se entiende por organología ${ }^{22}$. El conjunto de características propias de un instrumento musical que le permiten crear sonidos se denominarán, de ahora en adelante, como "características organológicas" del objeto. Esta definición permite precisar los ámbitos sonoros de un objeto independientemente de los no sonoros. Estos

\footnotetext{
la aparición de este grupo importante de instrumentos en la tradición reciente, de origen urbano occidental, es una consecuencia de la tendencia propia de Occidente, basada en la extraordinaria incidencia que tuvo la tecnología en el diseño sonoro en el pasado, la que se revela en la invención del teclado, la cuerda de metal, los pedales y los instrumentos musicales mecánicos y automáticos. Se observa aquí una tendencia cultural que enlaza todos estos ejemplos en torno a una búsqueda tecnológica particular, pero aun así el salto que genera la invención del sonido electrónico es tan amplio y diferente a todo lo anterior que su separación conviene realizarse por necesidades prácticas. La reciente aparición del sonido electrónico nos permite considerar la etapa previa a su aparición como la habitual, mientras que el diseño electrónico se halla en una etapa expansiva, altamente exploratoria, que demorará en alcanzar un nivel de equilibrio y estabilidad que permitan aplicar un análisis de conjunto similar al alcanzado mediante $\mathrm{SH}$.

19 Mendívil (2002: 3) objeta la idea que las características acústicas de un instrumento sean las más importantes para la valoración cultural del mismo. Esta crítica es válida en la medida que se quiera entender el objeto como integrante de la cultura, poniendo el énfasis en otros valores. Nuestra posición no discute este tema, sino que atribuye al sonido la función central que diferencia el instrumento musical de los otros objetos construidos por el hombre.

20 Wachsmann y Kartomi 2001: 418. En alemán la palabra "Intrumentenkunde" y en inglés la palabra "Organology" soslayan este problema.

21 Se utiliza el concepto de "tendencia" para definir nuestra posición.

22 Bessaraboff (1941) introdujo este término para distinguir los aspectos científicos y técnicos del gran estudio de la música. Deriva del griego "organon" (instrumento) y del título del volumen de Praetorius De Organographia (1619), el segundo volumen de su Syntagma Musicum. Hood (1971: 124) distingue "Organology" (ciencia de los instrumentos musicales) de "Organography" (descripción).
} 
últimos incluyen los usos (aparte del tañido) y funciones (aparte de la música), así como sus características de ornamentación y la forma exterior ${ }^{23}$. Este es el ámbito propio de la organología: la práctica del diseño de sonidos, la que está conformada por un conjunto de conocimientos y habilidades artesanales y de tañido al servicio de una estética sonora particular.

Esta definición metodológica es operativamente muy útil, porque segmenta un sector de la cultura marcado por individuos con una sensibilidad particular (sonora), que por lo general conforman una subcomunidad definida dentro de la sociedad. Pero al mismo tiempo no se debe perder de vista que, como toda herramienta metodológica, al hacer esta segmentación se crea una falacia respecto de la realidad, en la que usos, funciones, ornamentaciones y contextos no sonoros influyen, retroalimentan y determinan continuamente muchos aspectos de la cultura musical de un pueblo.

La utilidad de hacer la distinción metodológica entre "lo sonoro" y "lo no sonoro" del instrumento musical es lo que permite detectar algunas características culturales notables. Una de ellas, ya mencionada, y a la que se volverá más adelante, es la independencia que se detecta al analizar una muestra amplia en el curso del tiempo y del espacio entre las características organológicas y las no organológicas. Mientras que las primeras exhiben, en muchos casos, una gran permanencia y estabilidad, las segundas muestran cambios y mutaciones constantes. Un ejemplo es el de las flautas de "tubo complejo", una invención que aparece en Paracas al sur de Perú hace 2300 años, y que mantiene hasta hoy su cualidad organológica intacta luego de haber pasado por las culturas Nazca, Tiwanaku, San Pedro, Diaguita y Aconcagua, en Chile Central, a pesar de que su aspecto exterior ha cambiado en cada traspaso (ver Figuras 2a y 2b). Otro rasgo notable, bastante frecuente, es que el diseño acústico produce objetos que se destacan por sobre la media artesanal de una determinada tradición cultural. Dos ejemplos de Chile Central ilustran este punto. Uno de ellos es la "antara" prehispánica, una flauta de Pan de tubo complejo, de piedra, que presenta un extraordinario nivel artesanal tanto formal como acústico muy por encima del resto de los de artefactos producidos por esa cultura ${ }^{24}$. El otro ejemplo es el guitarrón de 25 cuerdas, cuya complejidad de encordado lo ubica en un rango de diseño acústico sobresaliente, distinto a todo lo conocido regionalmente ${ }^{25}$ (ver Figura 3).

${ }^{23} \mathrm{El}$ tema de la iconografia puede ser irrelevante (cf. Myers 1989) o adquirir una gran importancia, como la que le atribuye Lund (ver Mendívil 2000: 7 para una discusión de este punto). Desde nuestro punto de vista lo central del estudio organológico es su siempre cualidad como instrumento musical productor de sonidos, aun cuando el análisis recurra a la iconografía o a menciones en fuentes secundarias (como el trabajo de Mendívil 2000).

24 Este tema es desarrollado en Pérez de Arce 2013.

${ }^{25}$ En ambos casos se ha postulado un origen foráneo a estos instrumentos. No obstante todos los antecedentes apuntan a su origen local (Pérez de Arce 1998, 2000, 2003). 


\section{FIGURA 2A}

"Antara sin asa" (SH421.112.211.121). Paracas (sur de Perú de hace 2300 años).

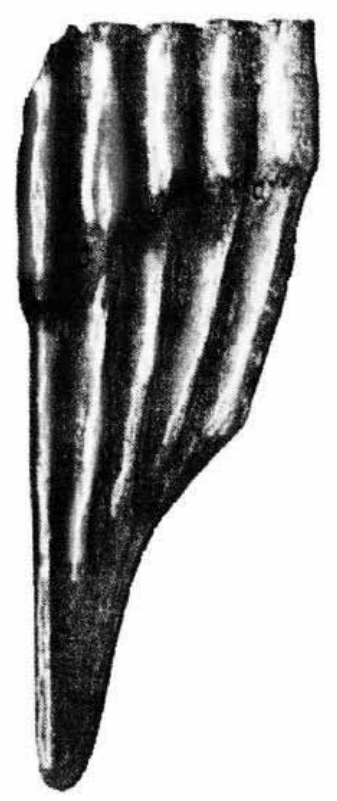

\section{FIGURA 2B}

Flauta de baile chino de San Roque, Chile central, actual ("pito longitudinal cerrado de tubo complejo", SH421.111.21).

A pesar de la distancia temporal y espacial, ambos comparten una misma organología (diseño sonoro) heredada a base de múltiples traspasos culturales.

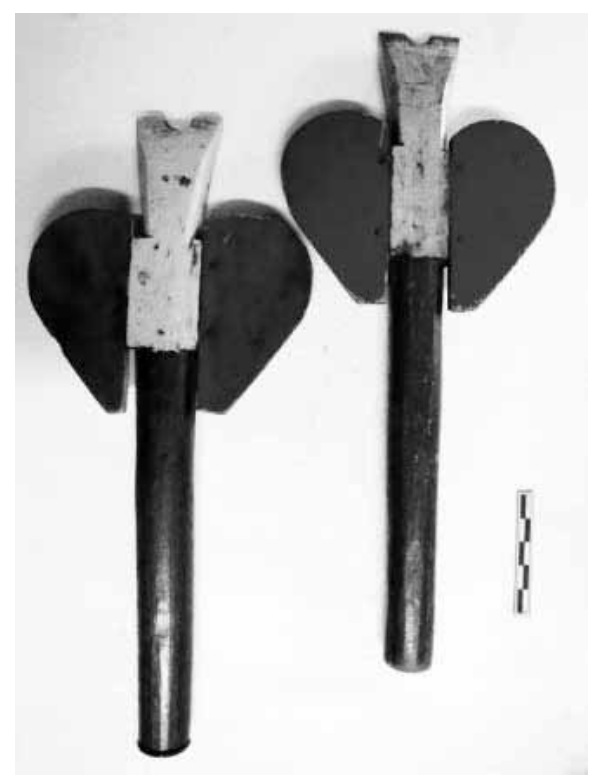

\section{FIGURA 3}

Guitarrón chileno de 25 cuerdas ("guitarra" SH321.322.1), cuyo diseño acústico del encordado, de origen local, lo hace único en su tipo, sin referentes conocidos a nivel mundial, y en un rango sobresaliente respecto de todas las artesanías conocidas regionalmente.

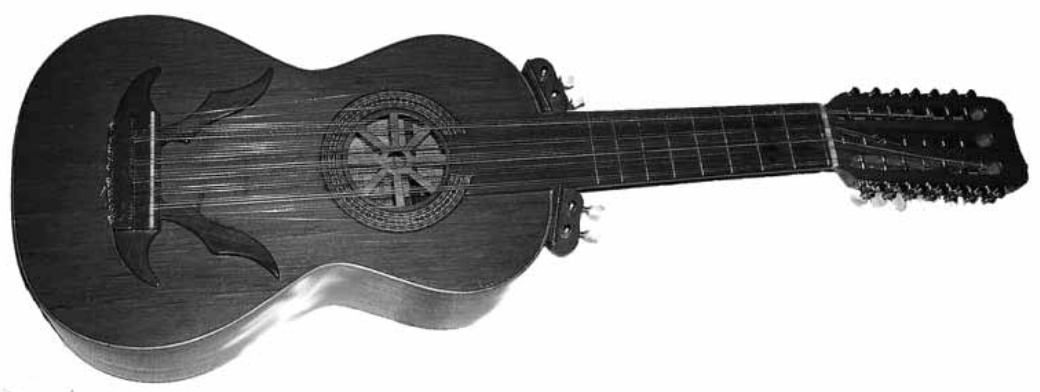


Esto indica que el diseño sonoro ilumina un sector privilegiado de la cultura en el que se unen el rigor del conocimiento con la habilidad artesanal. El diseño sonoro de un instrumento musical implica un gran conocimiento y un estricto aprovechamiento de las propiedades de los materiales tanto en sus cualidades estructurales, su flexibilidad y su respuesta acústica como en su relación ergonométrica con el cuerpo humano, todo lo cual requiere una exactitud de normas y patrones de fabricación por parte del constructor. Por otra parte los instrumentos musicales exigen una especialización en el sistema de tañido por parte del ejecutante que puede llegar a absorber toda una vida. Ambas especialidades, la del constructor y la del intérprete, comparten una finalidad estética que puede alcanzar un grado de extraordinaria rigurosidad. En las sociedades complejas se encuentran extremos de refinamiento y especialización que se han transformado en leyenda, como son los casos de Stradivarius y Paganini respecto del violín europeo. En definitiva, el instrumento musical opera como un sintonizador fino de la estética musical de una sociedad determinada. La importancia de la organología radica en que permite descubrir las bases materiales de esa sintonía.

\subsubsection{Principios metodológicos de la organología}

La organología, entendida como la herramienta metodológica que se ha descrito, opera con ciertos principios que definen su eficacia. El primero de ellos es la diferenciación entre función acústica y tañido. El segundo es el reconocimiento de los fenómenos de tendencia y permanencia subyacentes en el material organológico, mientras que el tercero es la detección de los factores que constriñen, delimitan y restringen el universo del diseño sonoro. En el caso específico de los instrumentos musicales arqueológicos, en que se carece de datos acerca del tañido e intención musical, la identificación organológica es una herramienta fundamental ${ }^{26}$. En tales casos, la organología y sus principios cobran una importancia prioritaria.

\subsubsection{Función acústica y tañido}

La función acústica del instrumento musical se refiere al potencial sonoro del objeto. Este potencial está determinado por su diseño, que le permite producir una respuesta sonora definida por una cierta gama de sonidos, con características precisas de rango tonal, timbre, dinámica, etc. El tañido se refiere al sonido del instrumento como objeto cultural. Son dos realidades diferentes que están separadas por las posibilidades estructurales y acústicas del objeto, por un lado, y

26 Tal como lo postula la teoría de la arqueoetnología, siempre se necesita recurrir a la comparación con instrumentos musicales actuales en uso, los cuales, en la medida que provengan de una línea cultural directamente vinculados con los arqueológicos, hacen más válida esa comparación (Ebert 1979; Lawson 2004; Pérez de Arce 2004). 
por la técnica de tañido y la intención musical por el otro 27 . Ambas realidades son complejas. Si bien es efectivo que cada instrumento musical fue hecho para servir a una música en particular, es posible usar ese mismo instrumento musical para tocar muchas otras músicas. Debido a esto es que es imposible hacer el camino al revés, esto es, deducir a partir de la potencialidad sonora del instrumento la música que se interpretaba originalmente en él. En otras palabras, es imposible acotar las posibilidades acústicas del instrumento musical al punto de poder definir la música que se hace habitualmente con él ${ }^{28}$. La arqueología musical, que trabaja desde el instrumento musical para entender la música del pasado, conoce bien esta limitante. Por otra parte la interpretación musical no tiene límites, varía de individuo a individuo, de una ocasión a otra.

\subsubsection{Las tres paradojas}

Un instrumento, inscrito en una tradición cultural determinada (sobre todo si es preindustrial), es tañido de una cierta manera de modo de proporcionar una respuesta restringida a ciertos parámetros acústicos determinados. Técnicamente se trata de una restricción, pero en la práctica esto se transforma en una ampliación de las posibilidades musicales del instrumento. Esta es una de las paradojas que plantea teóricamente la aplicación del tañido al instrumento musical. Pero no es la única, también lo es la ausencia de una aproximación neutra a este tema y la falsa ilusión de libertad y exploración, propia de nuestra cultura, la que no es sino una limitante cultural más.

Para ejemplificar la primera paradoja, que indica que la restringida gama de técnicas de tañidos tradicionales es más rica en resultados musicales que la búsqueda de "todos los modos posibles" de tañer, se puede considerar el kultrún (timbal mapuche). Se le puede tocar con un palo, con las manos, rasgarlo con las uñas, sobarlo, tamborilearlo con los dedos, etc., y producir efectos de gran interés sonoro en referencia a nuestra cultura. No obstante, por esa vía no vamos a llegar al dominio exquisito, a los mil matices que logran los mapuches tras años de práctica con la única modalidad de tañido culturalmente definida, que es golpearlo mediante un palo ${ }^{29}$. Otro ejemplo es lo que ocurrió en 1981, al estudiar unas “antaras” de la cultura Aconcagua y describir su sonido según "todas" las posibilidades de tañido

27 Gunji (1996: 6) diferencia entre la música propiamente dicha de los medios objetivos y materiales de su expresión. El aspecto creativo, artístico, y científico de la música lo llama musicología y el aspecto científico y técnico de los instrumentos de música lo llama organología. Nos parece que esta división teórica es demasiado rígida.

28 La única excepción a esto es el instrumento musical automático, el que es capaz de reproducir una música siempre igual.

29 Lo toca exclusivamente el o la especialista machi, chamán, quien excepcionalmente lo sacude durante momentos específicos de un ritual específico. Excepcionalmente también se tañe con dos palos para un baile específico. 
(escalas de sonidos y armónicos). Años más tarde, el mismo instrumento, al ser ejecutado por Claudio Mercado según la técnica específica del "sonido rajado", más acertada como recreación del sonido ancestral, demostró una función acústica totalmente diferente, de gran riqueza tímbrica y dinámica, además de insospechadas proyecciones musicales (Pérez de Arce 2000b, 2000c). Habría sido imposible llegar por prueba y error a producir esa riqueza instrumental, puesto que la técnica requiere de un aprendizaje preciso y equilibrado dentro de un rango de máximo esfuerzo y mucho control, que se adquiere tras años de práctica.

La segunda paradoja, relacionada con la anterior, es que no existe la aproximación "neutra" al tañido de un instrumento musical: el sonido que se le atribuye está siempre mediado por una fórmula cultural que implica tanto una técnica de tañido como una intención sonora. La investigación científica positivista propia de la cultura moderna se basa en la exploración del objeto de estudio desprejuiciada y sin límites preconcebidos, con una mirada "neutral". En el ejemplo mapuche antes mencionado, el mundo de riqueza artística que revela el manejo del instrumento por parte de esta etnia nada tiene que ver con una manera de tocar que podríamos utilizar al analizar un instrumento, influida por la búsqueda de una estética de lo neutro y de laboratorio. Al intentar explorar las posibilidades del arte, de la estética, inevitablemente introducimos una variable estilística de nuestro tiempo, de nuestra cultura. La búsqueda se halla inevitablemente teñida de pautas culturales; no existe en la estética la neutralidad.

Como consecuencia de lo anterior, surge la tercera paradoja, que es sólo un espejismo propio de la cultura urbana occidental. En esta cultura se considera que la correcta forma de investigar es explorar todas las posibilidades del instrumento musical. La paradoja consiste en que en esta tendencia a la mayor apertura imaginable, está inscrita una intención cultural precisa, que se basa en el concepto de exploración científica, nuestro gran paradigma cultural, el cual restringe las posibilidades de la búsqueda. Como ejemplo de la tendencia a explorar de la cultura occidental en el terreno de la música es posible mencionar las composiciones para piano de los años 60', en que se abordaron las posibilidades de su tañido al máximo. El instrumento se tocaba tirando dardos a las cuerdas (Toshi Ichiyanasi), introduciendo comida (1982, Ken Friedman), introduciendo un gato y un perro (1962, George Maciunas), destrozándolo con dos elefantes (1966, Robert Bozzi), desarmándolo y rearmándolo (1961, Jackson Mac Low) e incluso persiguiendo al pianista que arranca (1965, Ben Vautire), entre muchos otros. Este ejemplo de "libertad sin límites" es visto hoy como una anécdota histórica. Se puede percibir su signo como contrario a la tendencia cultural universal a restringir el uso sonoro del instrumento a un estilo de tañido que potencia una fracción seleccionada de sus funciones acústicas.

Frente a este conjunto de paradojas nos encontramos ante una encrucijada metodológica: si la búsqueda "neutra", "desprejuiciada", "abierta a todas las posibilidades" no es posible, solo se la puede resolver mediante el uso de algún 
patrón cultural existente. Normalmente esto se resuelve con los músicos nativos, conocedores del instrumento musical. En los casos en que esto no sea posible, como en los instrumentos musicales arqueológicos, hay que recurrir a símiles en la etnografía. Estas consideraciones siguen las normativas de la etnoarqueología (Hodder 1982; Ebert 1979). Afortunadamente, en el caso de la música, los fenómenos de tendencia y permanencia (que se desarrollan más adelante) permiten evaluar las técnicas de tañido, aun cuando su relación con la muestra no sea necesariamente muy cercana en términos de tiempo o espacio. Por ejemplo, en las trompetas de caracol prehispánicas mesoamericanas existen unas pocas con agujeros. La tendencia occidental es a ver en ellos agujeros de digitación y usarlos para ampliar la gama tonal (cualidad muy preciada en Occidente). Sin embargo, al revisar la tendencia estética mesoamericana presente en la organología, resulta muy sugerente ver en estos agujeros un artificio para modificar el timbre, que sí forma parte de esa tendencia, y no la búsqueda de amplitud tonal, ausente en el resto de las trompetas prehispánicas mesoamericanas ${ }^{30}$.

\subsubsection{El concepto de tendencia}

El concepto de "tendencia" es muy útil para articular el sistema. Tendencia indica dirección, la que puede ser muy precisa, pero con bordes indefinidos. Para usar criterios de clasificación de objetos culturales es preciso siempre tener en cuenta una tendencia que explica el grupo en su conjunto y que abarca las infinitas variaciones particulares. La tendencia permite definir, por ejemplo, la tipología del tambor cilíndrico que incluye las innumerables variaciones de forma de los troncos de árboles excavados, los que a veces se alejan del cilindro. Esos casos se entienden como excepciones no intencionales de un patrón cilíndrico. Existe otra aplicación para el concepto de tendencia. SH lo usa al ubicar el grupo (111.1), idiófonos de entrechoque, dentro de la división de golpe directo. En rigor, el entrechoque es un tipo de golpe indirecto, ya que no es la mano la que golpea, sino la que mueve el conjunto para que se entrechoquen las partes. Sin embargo la tendencia sonora de este grupo es a producir sonidos aislados, netos e inconfundibles (piénsese, por ejemplo en las claves, las castañuelas, los címbalos), propios del golpe directo.

Se puede señalar otro ejemplo de la aplicación del concepto de tendencia relativa al uso y tañido. En las campanas metálicas de la cultura prehispánica Santamariana (Noroeste argentino), existe la hipótesis que se tocaba asentada sobre su vértice (Puppo 1979). Esta tendencia está ausente en América, pero es conocida en el extremo Oriente, donde la base de las campanas es plana y ancha, apropiada para esa función. Las campanas Santamarianas, en cambio, presentan una superficie angosta, provista de agujeros y protuberancias. Asimismo, la hipótesis de que la misma campana se golpeaba (Gudemos 1998) se contradice con

30 Sobre un panorama de las trompetas prehispánicas de México ver Both (2001). 
el estudio de las huellas de uso, que confirma definitivamente su uso colgando, con varios badajos, lo que a su vez corresponde a una amplia y antigua tendencia regional presente en los cencerros de madera ${ }^{31}$ (ver Figura 4).

\section{FIGURA 4}

"Cencerro" (SH111.242.122.2) metálico Santamariano (noroeste argentino, de hace aproximadamente 700 años). Era tañido de acuerdo con la tendencia regional, con múltiples badajos, tal como lo revelan sus huellas de uso (MCHAP 957, badajos de madera reconstruidos).

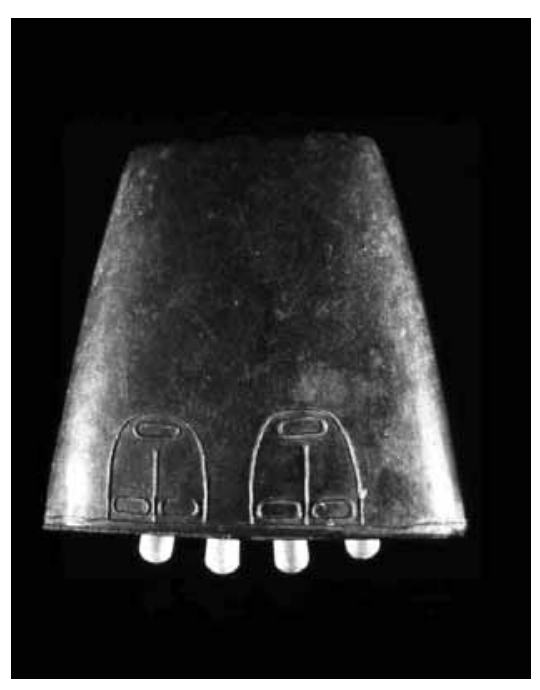

En cambio, no parece correcto usar el criterio de origen histórico como tendencia. Una nota de Vega (211.3) dice que el tambor militar europeo tiene su origen, aun en sus ejemplares más chatos, en el tambor cilíndrico, por lo que deben considerarse todos esos tambores como parte de ese grupo. Si se emplea el origen como criterio de clasificación, esto obliga a conocer siempre la historia del objeto, y a desechar todas las variedades posteriores a su origen, lo que hace altamente ineficiente el método.

Es dable observar que existen grandes tendencias organológicas a nivel mundial (África y los tambores, América y las flautas, Europa y las cuerdas, Asia y los idiófonos) así como tendencias a nivel regional (India y las cuerdas resonantes y enriquecidas tímbricamente, China y las cuerdas de sonidos secos, a modo de

31 Una amplia discusión de este tema se encuentra en Pérez de Arce 2001. 
ejemplo) ${ }^{32 .}$ A pesar de que en cada lugar se encuentran innumerables otras tendencias, la percepción de una tendencia estética regional es útil para dilucidar casos de pertenencia, como por ejemplo el guitarrón de Chile central. Carecemos de datos históricos y de parentesco organológico de este instrumento. No obstante sabemos que está íntimamente emparentado con las tendencias estéticas vernáculas de la región Sur Andina, como son la multivocalidad tímbrica, el énfasis en el enriquecimiento tímbrico, en la ejecución facilitada para duraciones largas, todo lo cual indica su pertenencia a una cultura musical local. Este es un buen ejemplo del traspaso de una tendencia estético-sonora entre dos familias organológicas muy distantes entre sí 33 .

Como en todo sistema cultural, hay una retroalimentación constante. La tendencia produce objetos que generan sonoridades que se adaptan a una cierta sensibilidad sonora específica y a su vez esas sonoridades definen una identidad sonora cultural específica, que redefine la tendencia.

\subsubsection{Permanencia}

La permanencia de los tipos organológicos en tiempo y espacio es un fenómeno que se encuentra con bastante frecuencia en diferentes partes del mundo ${ }^{34}$.

La quena andina, por ejemplo, se extiende con las mismas características desde el norte de Chile hasta Colombia por más de 4000 años (Izikowitz 1935; Stevenson 1976; Jiménez Borja 1951) (ver Figura 5). Existen otros instrumentos musicales que tienen pocas variaciones en su parte organológica, si bien externamente pueden adoptar muchas mutaciones a través del tiempo y del espacio. Por ejemplo, la botella silbadora se extiende desde el sur de Perú hasta México por más de 2000 años. Se ha adaptado a situaciones culturales muy diferentes, junto con adquirir miles de transformaciones exteriores sin perder sus características organológicas (Pérez de Arce 2004). Otro caso lo constituye la actual pifilka del sur de Chile, ya mencionada, que hereda su cualidad organológica (el "sonido rajado") del sur de Perú hace 2500 años (Pérez de Arce 2000).

Estos ejemplos nos revelan un alto grado de permanencia de los criterios estéticos sonoros frente a un frecuente cambio de los patrones estético visuales. Las razones radican principalmente en la relativa escasez de sistemas de producción de sonido, como es, a modo de ejemplo, la producción del sonido propio de la botella silbadora, comparada con la infinita variedad de formas y colores que pueden aplicarse a ese mismo objeto. También tiene que ver con la relativa restricción, especificidad y complejidad de su diseño organológico que satisface

32 Este tema está tratado parcialmente en Pérez de Arce 2005.

33 Para mayores detalles acerca de esta referencia, ver Pérez de Arce 2002a.

34 Merriam (1971) hace mención a esta cualidad del material sonoro, pero no ahonda en la explicación de este hecho. 
FIGURA 5

“Kena con agujeros de digitación” (SH421.111.12 ) prehispánica de Perú. La simplicidad de su diseño permite una permanencia casi inalterada por más de 4000 años en los Andes

(MCHAP 3506).

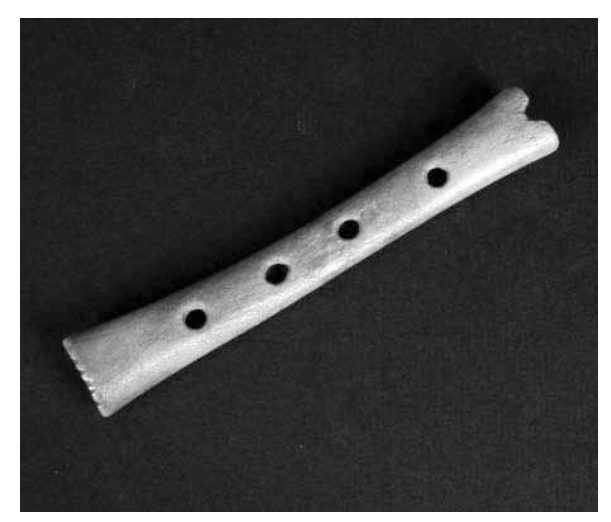

conceptos estéticos muy poco racionales y por lo mismo poco manipulables a nivel de conciencia. Para replicar el diseño sonoro se replica la fórmula artesanal que lo hace posible, lo que se traduce en una enorme estabilidad temporal.

La consecuencia es que en muchos casos se pueden encontrar instrumentos musicales etnográficos con cualidades organológicas semejantes, bastante alejados espacialmente. Al aplicar esta evidencia a la arqueología, se propone como hipótesis de trabajo que la similitud organológica mantenida en el tiempo es un argumento válido para suponer la similitud en el tañido y en el diseño sonoro durante ese período. Las flautas de Pan de la cultura Paracas, que existieron hace más de 2000 años en el sur de Perú, tienen símiles organológicos actuales ubicados a miles de kilómetros de distancia, en las flautas "de chinos" y pifilkas de Chile Central y Sur, las cuales son el mejor referente en términos de tañido para estudiar los sonidos de las flautas Paracas. Nos es imposible saber si en el pasado se tañían como ahora, pero sobre la base de la observación de las tendencias regionales se puede afirmar que esto es muy posible. A partir de los resultados sonoros de la experimentación se puede afirmar que este tañido saca un extraordinario aprovechamiento sonoro del instrumento Paracas de acuerdo con los patrones estéticos de esa tendencia. Los resultados confirman esta hipótesis ${ }^{35}$. Es precisamente este punto, la permanencia de rasgos organológicos, la herramienta más importante que entrega la organología para investigar el pasado musical.

35 Con Claudio Mercado se pudo testear esta hipótesis en el Museo Arqueológico de Lima, en 2005, gracias a la gentileza de Milano Trejo y su equipo, con resultados notables en términos de respuesta sonora. Antes se habían testeado de igual manera flautas Aconcagua, provenientes de Chile Central, con resultados semejantes (Pérez de Arce 2000, 2004). 


\subsection{Discusión de criterios organológicos}

A continuación se discutirán los criterios utilizados por SH para elaborar su sistema, con el aporte de nuestra visión al conjunto. Se revisarán las características del conjunto de instrumentos musicales mundiales que refleja el trabajo de $\mathrm{SH}$ en términos de las restricciones de diseño sonoro y en términos de la categorización utilizada por estos autores para producir la jerarquía de grupos en la clasificación.

\subsubsection{Las restricciones del material organológico}

Los criterios que usa el sistema $\mathrm{SH}$ para clasificar los instrumentos musicales son, como se ha señalado, un reflejo de la compleja realidad de todo un sector de la actividad humana. Al analizar el sistema, sin embargo, se descubre que la cantidad de características que permiten distinguir los diferentes tipos de instrumentos musicales en el mundo es relativamente reducida. Esto revela un cierto grado de restricción en las posibilidades que ofrece el diseño organológico en su conjunto.

Esta restricción es detectable si se compara la similitud de instrumentos creados independientemente en distintos puntos del mundo. América prehispánica, gracias a su aislamiento respecto del resto del mundo durante milenios, ofrece varios ejemplos indiscutibles, como son los tambores similares a los de África, los cascabeles similares a los europeos, o la kena semejante al sakuhachi japonés (ver Figura 6).

\section{FIGURA 6}

"Cascabel” (SH112.131.2) metálico prehispánico de Perú, similar a los usados en Europa. La convergencia de diseño organológico, en este caso, se debe a las restricciones del diseño sonoro (MCHAP 868).

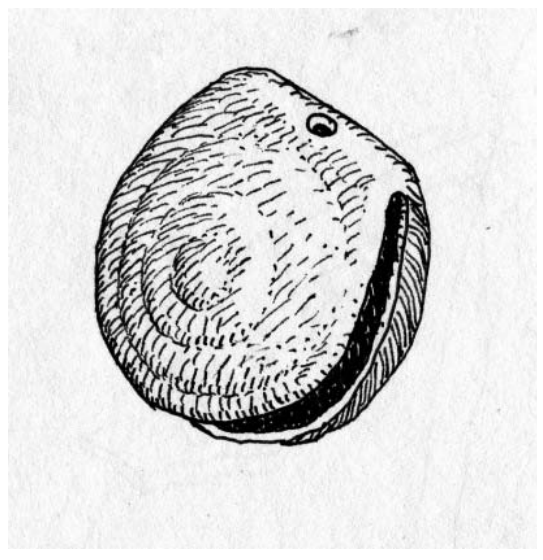




\subsubsection{La jerarquía de criterios clasificatorios en el sistema $\mathrm{SH}$}

El sistema SH está estructurado según los criterios diferenciadores entre los tipos de instrumentos musicales conocidos. Es posible distinguir entre características organológicas primarias, que tienen que ver directamente con el sonido, es decir, que definen las características del timbre, dinámica, tañido, intensidad, amplitud melódica, facilidad de ejecución y efectos sonoros, de otros que inciden secundariamente en el sonido, generalmente modulando su timbre al filtrarlo y aportarle resonancia. La tendencia general de la organología es que, a mayor incidencia directa en el sonido, son menores las variables involucradas. Entre las características organológicas primarias se encuentra un panorama reducido y preciso. A medida que uno se aproxima a las secundarias, estas se hacen más dispersas, difíciles de explicar y de agrupar.

\subsubsection{Características organológicas primarias}

En orden de importancia, tal como lo usa SH, estas características guardan relación con el manejo del timbre (lo que suena), la energía (lo que origina ese sonido) y la "humanidad" del sonido (cuán controlado está por el ejecutante, y en qué medida no es aleatorio o producido por factores no humanos). Dicho de otro modo: qué objeto suena, cómo se hace sonar y quién controla esa acción. Otros criterios organizativos primarios menos importantes son la cantidad de voces y la resonancia.

\subsection{Timbre: cualidad vibratoria del material}

El primer criterio usado en el sistema $\mathrm{SH}$ es diferenciar el cuerpo primario que vibra, para lo que distingue cuatro categorías: sólido (1, idiófono), membrana (2, membranófono), cuerda (3, cordófono) y aire (4, aerófono). No parece coherente el uso de criterios que se refieren tanto al estado de la materia (aire, que es un gas y no es sólido) como a formas estructurales específicas (cuerda, membrana $\left.{ }^{36}\right)$. No obstante, estas cuatro categorías son verdaderamente responsables de los cuatro tipos básicos de vibración sonora que ha conocido la humanidad durante siglos. Cada uno de ellos posee cualidades sonoras que se refieren principalmente al timbre, pero también a la dinámica, a la cualidad

36 Para ser preciso la membrana y la cuerda también son sólidas. Son sus diferencias de elasticidad las que los hacen totalmente diferentes en el ámbito organológico. Para solucionar esta inconsistencia, Schaffer (1936) opone "sólido" a "aire". Al primero lo separa en "no tensiles" y "flexibles y tensiles". La dificultad de ser preciso se revela aquí en que el opuesto a "sólido" es "gas", lo que no aporta a nuestra discusión, y el opuesto a "tensil y flexible" es "rígido", lo que es incompatible con la vibración necesaria del cuerpo de un idiófono. 
tonal (o atonal), y a las posibilidades de controlar esas variables. Cada uno de ellos muestra un complejo cuadro de posibilidades diferentes y propias. Estos cuatro criterios, los principales organizadores del sistema $\mathrm{SH}$, solo se ocupan una vez, a su inicio.

Un tema muy relacionado con estos cuatro criterios es la cualidad vibratoria de la materia prima. Sin embargo no es muy útil como criterio de clasificación y no son utilizados por SH. Es interesante constatar aquí también una severa restricción organológica: existe una sola materia prima vibrante en el aerófono, prácticamente una en los membranófonos y cordófonos tradicionales y unas pocas en idiófonos. En efecto, en el aerófono hay un solo material vibrante, el aire. La geometría del resonador es fundamental porque define el cuerpo vibrante, al delimitarlo, pero el material de que está hecho influye secundariamente. El recipiente es rígido, participando poco en el timbre del instrumento, lo que permite utilizar la cerámica y otros materiales que no son necesariamente buenos conductores del sonido.

El material de la membrana vibrante de los membranófonos es muy específico. Tradicionalmente era solo de cuero hasta mediados del siglo XX en que se añaden ciertos plásticos. Otros materiales no han dado resultado, por su fragilidad, como es el caso del papel o la tela que casi no han sido usados. El material del cuerpo influye secundariamente en el sonido. El material que excita la membrana (generalmente un percutor) importa menos que su dureza (por ejemplo un palo forrado en la punta con lana o con cuero, o con goma) y que la forma de tañer. Las cuerdas de los cordófonos también están restringidas a unos pocos materiales. Tradicionalmente se usó la tripa animal, utilizando la misma tecnología del arco de caza. Con menor frecuencia se usaron fibras animales o vegetales, más frágiles y menos homogéneas ${ }^{37}$. A partir del siglo XVIII, en que se inventa el trefilado, se comienza a usar también el metal, y en el siglo XX se añade el nylon. El material del cuerpo actúa secundariamente sobre el sonido, pero es más importante que en el membranófono, porque incide en la amplificación del débil sonido que emite la cuerda. La tendencia es a utilizar la madera como el material estructural, lo que permite combinar rigidez, maleabilidad, ensamblajes móviles (en clavijas), además de superficies y cajas con buenas cualidades de transmisión y amplificación de la vibración de la cuerda.

37 El arco musical, que permite una tensión débil en su cuerda, ha sido construido con diversos materiales, entre ellos cuerdas vegetales de cierta fragilidad, que se encuentran en diversos puntos del planeta. En cambio los cordófonos más desarrollados limitan los materiales a los que pueden soportar tensiones y ataques más agresivos, como la tripa. La seda es usada en Asia, extremo oriental, el cabello humano en diversas partes del mundo. 
En los idiófonos, donde lo que vibra es un trozo de material, en cambio, se advierten marcadas diferencias entre el metal, con sonidos como el gong, el platillo o la campana, y la madera, con sonidos como el xilófono o el teponaztli (ver Figura 7). Más escasos son los idiófonos de piedra, cristal y porcelana, su baja representatividad se debe asociar al hecho de que en ciertos casos no sean buenos conductores de las frecuencias que producen sonido o a la fragilidad del material con que están construidos, además de otros materiales cada vez menos representativos $^{38}$. El sistema de André Schaeffner (1936) lo usa como criterio subdivisorio, generando un panorama totalmente diferente al de SH y muy sugerente. No obstante tiene el defecto de generar grupos muy desiguales, uno grande relativo al metal, otro para la madera y una serie residual de jerarquías menores que se extiende, lo que hace al sistema muy inoperante. El sistema SH no lo utiliza; pero nosotros lo introdujimos excepcionalmente, para separar el tambor de hendidura (de madera) de la campana tubular (de piedra) en sus dos versiones, independiente (111.231.1-1/2) y en juego (111.232-1/-2), debido a la enorme distancia del diseño sonoro entre ambos tipos, a pesar de su semejanza de diseño estructural.

\section{FIGURA 7}

Teponaztli ("placas de percusión en juego, idioglotas". SH111.222) azteca de madera, provisto de dos lengüetas percutidas. Como en todos los idiófonos, el sonido tiene las características del material del cual está construido (MCHAP 3733).

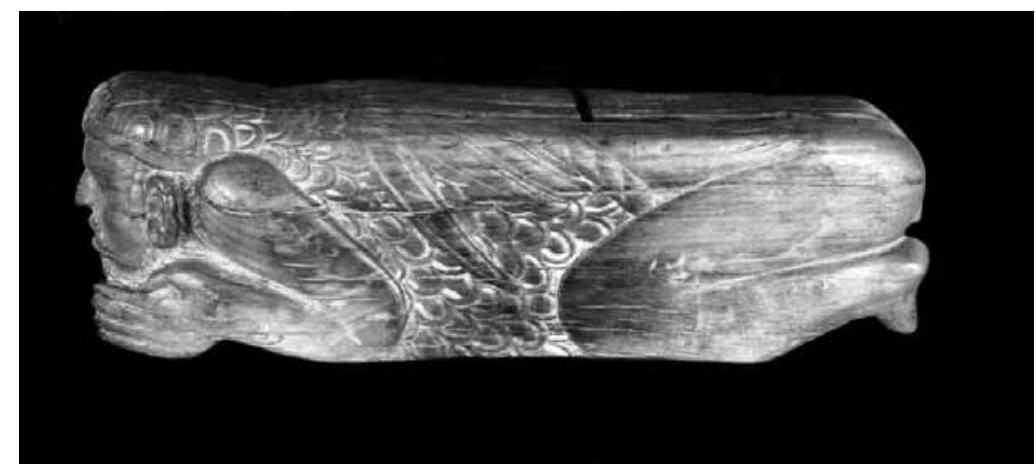

38 Entre los pueblos más apegados a la vida natural existe una cantidad de idiófonos confeccionados con material orgánico en su estado natural, tales como semillas, pupas de insectos, piedras, palos, etc. 


\subsection{Energía: tipo de excitación}

A partir de la segunda división el sistema SH opta por las formas de excitación del material vibrante para clasificar cada grupo, con excepción de los cordófonos, que presentan muchas variedades de tensión, largo, material, cantidad de cuerdas y de resonadores, de lo que surgen grupos muy diferentes. A partir de la tercera división, el sistema opta por criterios diferentes para cada grupo (geometría del cuerpo, variedad de materiales, modos de excitación). No obstante, el tipo de energía que pone en vibración el instrumento musical es el criterio más ampliamente usado en todas las subdivisiones.

La segunda división tanto de idiófonos como de membranófonos diferencia cuatro tipos básicos de excitación en que la energía se transmite por golpe (11 y 21), por punteo con el dedo (12 y 22), por frotación (13 y 23) y por soplo (14 y 24). El mismo criterio se usa en los cordófonos, en la cítara de caja (314.122$1 /-2 /-3 /-4)$ y parcialmente en el laúd de caja de mango añadido (321.322-1/-2). Esta tendencia, en que cada instrumento musical recibe un tipo de excitación específico, no ocurre en el resto de los cordófonos, en que es frecuente la utilización de más de un tipo de excitación para un mismo instrumento.

En los idiófonos se diferencia también el sacudimiento/raspadura/separación (112-1/-2/-3) y en los membranófonos frotado con palo/con cuerda/con la mano $(23-1 /-2 /-3)$.

Entre los aerófonos tres tipos de excitación específicos definen los grupos principales: en las trompetas (423) el aire es excitado por la vibración del labio del ejecutante; en los caramillos (422), por la vibración de lengüetas y en las flautas (421) el aire es excitado por soplo contra un filo. La vibración resultante no es fácil de explicar, ya que interviene una compleja mecánica de fluidos con fenómenos de turbulencia. En la subdivisión de las trompetas hay un pie forzado introducido por nosotros: (423.3) que se refiere no a cromatismo como los grupos (423-1/-2), sino a aspirado, un sistema de tañido opuesto al del resto de las trompetas (que es soplado) y que no fue conocido por Sachs-Hornbostel. Optamos por esta incongruencia formal, para no variar el sistema $\mathrm{SH}$ original $^{39}$ (ver Figura 8).

Otros criterios de excitación más complejos y oscuros son poco usados: de desviación (411), interrupción (412) y de alteración ${ }^{40}$ (413), de explosión (413.1), de vibración (413.2), de ruido (413.3), o bien autófono (412.1), no autófono (412.2), o lengüeta de entrechoque (412.11), batiente (412.12), libre (412.13) y de cinta (412.14).

39 Correcto sería soplado (423.1) y aspirado (423.2), pero esto modifica toda la numeración posterior, lo cual se evita, como se explicó en la introducción, ya que incide en la estructura misma del sistema de clasificación y produce una asimetría hacia un grupo muy particular.

40 El criterio "de explosión" utilizado por SH lo tuvimos que ampliar para introducir nuevos casos en que no existen criterios fáciles para describir el tipo de excitación. Elegimos el término "de alteración" que, si bien es ambiguo, sirve para dejar abierta la puerta a una gama de instrumentos de muy difícil clasificación. 


\section{FIGURA 8}

Nolkin ("trompeta de aspiración”, SH423.3) mapuche (MCHAP 2545).
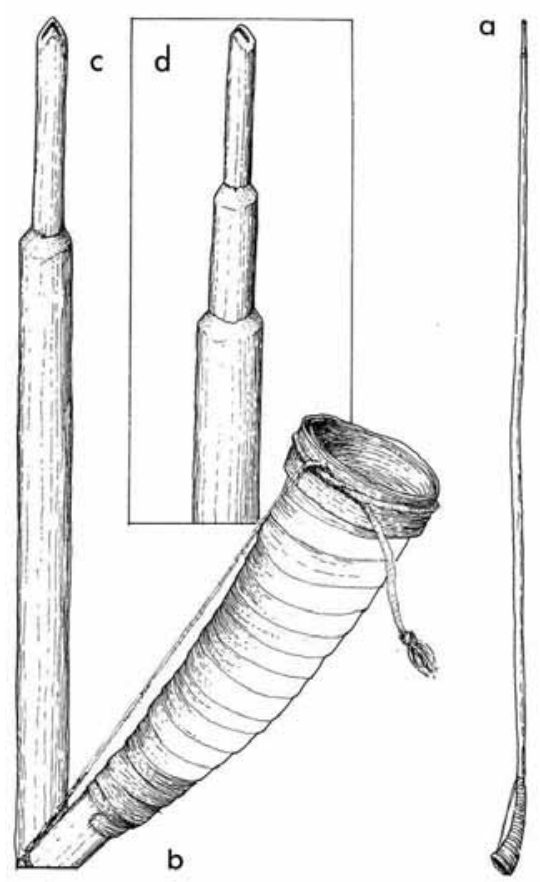

\subsection{Control}

Todo sonido se origina de un movimiento. El mayor o menor control del instrumentista sobre ese movimiento define qué tan "humano" (en el sentido de transmisor de emociones) o tan "natural" (en el sentido de reflejar la naturaleza mecánica del fenómeno) es ese sonido. El control directo es más fructífero musicalmente, pero requiere mayor destreza para lograr precisión. El control indirecto es más rígido pero asegura un resultado más homogéneo y seguro.

Se advierten ciertas tendencias culturales al respecto. En Europa hay una acentuada tendencia a preferir el control indirecto, lo que minimiza las variaciones individuales, como en la flauta dulce (donde el aeroducto asegura un control del sonido) o el tambor percutido con palo (de golpe más parejo que la mano) o la invención del teclado (que asegura la afinación de todas las escalas), tendencia que lleva finalmente a los instrumentos mecánicos (pianola, organillo), los que prescinden del ejecutante. En América indígena, por el contrario, se prefiere el control directo, usando la variación individual como valor estético, en la kena (flauta sin aeroducto), en las orquestas de flautas al unísono (en que las diferencias 
individuales enriquecen la melodía), en el azar del movimiento de idiófonos (campanillas adosadas al vestido) (ver Figura 9) o en la maraka que responde tanto a movimientos muy descontrolados como a otros muy controlados. En África y Asia también se encuentran algunas tendencias al control directo, como en el del tambor tocado con la mano y en los cordófonos de afinación sensibles a la presión de la mano, como el Koto y Sitar.

\section{FIGURA 9}

Recreación de un rey Chimú del Norte de Perú, de hace aproximadamente 700 años, recubierto de placas de oro ("sonaja de paño" SH112.113) que producen un suave sonido metálico con el movimiento del cuerpo (dibujo de José Pérez de Arce).

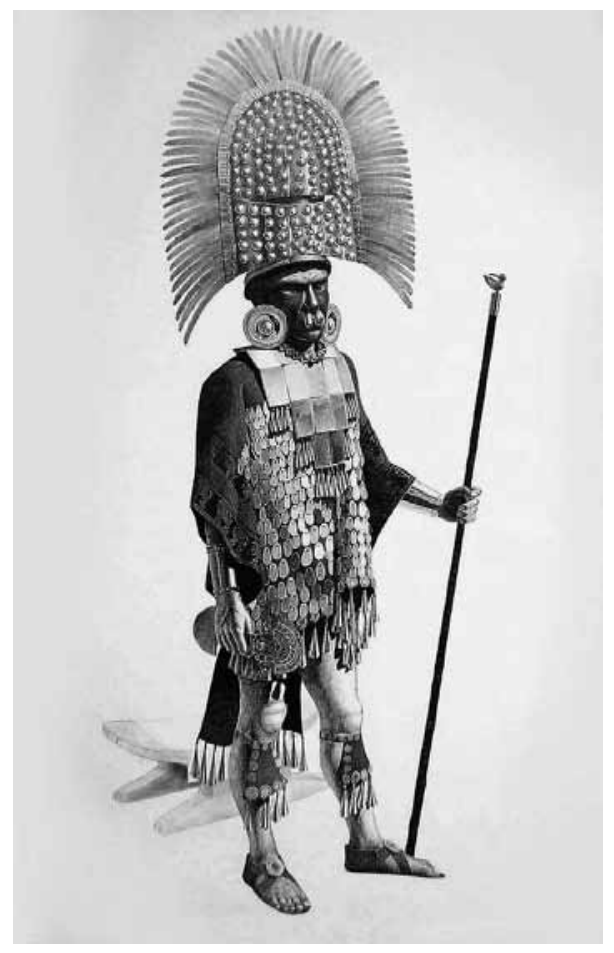

SH usa este criterio en idiófonos, con diferentes acepciones: golpe directo/ indirecto (11-1/-2); entrechoque/percusión (111-1/-2); campana con percutor/ con badajo (111.242.12 -1/-2); uso de mano o pie (la mano posee mucho más control que el pie) (111.221-1/-2), (111.231-1/-2), (111.211-1/-2/-3) y articulado (en que la transmisión del golpe es rígida) o en racimo (en que es flexible) 
(111.112-1/-2) y, por último, la trasmisión y multiplicación de la vibración ( maraka $\sin$ /con obstrucción interna 111.131.1-1/-2).

En los aerófonos la clasificación sería teóricamente más exacta si diferenciara la excitación labial directa (trompeta) e indirecta (flautas y caramillos), pero eso modificaría toda la estructura subsiguiente sin aportar significativamente al sistema. Distingue, en cambio, la ausencia o presencia de aeroducto $(421.1-1 /-2)^{41} \mathrm{sin} / \mathrm{con}$ boquilla (caracol, tuba, corno). Nosotros separamos las ocarinas de soplo directo de las botellas silbadoras de soplo indirecto (421.221.41-1/-2), (421.222.4-1/-2). Otros dos casos especiales de control son desplazamiento/giratorio (412.2-1/-2), ocarina $\sin /$ con variación tonal continua (421.221.411.-1/-2) y con agujeros/ vara/válvula (423.2-1/-2/-3).

A pesar de la importancia del golpe directo con la mano en los membranófonos, este no se considera porque su uso es transversal a todo el grupo. Se diferencia solamente entre golpe directo o indirecto en una ocasión (21-1/-2). En los cordófonos no se usa este criterio, ya que el grado de control depende más del intérprete que del sistema empleado para excitar el instrumento musical, como sucede a modo de ejemplo en el arco, en que el control es indirecto pero puede llegar a ser extraordinariamente preciso.

\subsection{Polifonía: la multiplicación del sonido}

El concepto de varias voces, no en la acepción de la polifonía europea, sino en una mucho más amplia, que incluye la posibilidad de varios sonidos, ya sea simultáneos o sucesivos, sirve para definir las categorías independiente/en juego en una cantidad de idiófonos y aerófonos: (111.11-1/-2), (111.12-1/-2), (111.211/-2), (111.22-1/-2), (111.23-1/-2), (111.241.-1/-2), (111.242.-1/-2), (133.-1/-2), (412.12-1/-2), (412.13-1/-2), (421.11-1/-2), (421.12-1/-2), (421.21-1/-2), (421.22$1 /-2),(422.1-1 /-2),(422.2-1 /-2 /),(422.3-1 /-2)$. El uso de dos hileras de tubos en la flauta de Pan (421.112.2-1/-2) afecta la resonancia, es decir, la cantidad de sonidos simultáneos (ver Figura 10).

La tendencia entre los idiófonos es que cada instrumento emita un tono, por eso su unión en juego es muy fructífera. En los aerófonos, además de este artificio, la geometría del resonador permite controlar con precisión el tono y variarlo mediante cambios en la presión del flujo de aire, o mediante agujeros que se obturan con los dedos. SH distingue la existencia o ausencia de agujeros de digitación y relega el número de agujeros a un sistema de división común (/1,/2, etc.). La ausencia de agujeros no significa ausencia de variación tonal, como ocurre en algunas flautas andinas que utilizan solo la presión de aire para obtener series

41 En Perú prehispánico se encuentran ejemplares que combinan ambos tipos (con ausencia o presencia de aeroducto), pero en embocaduras separadas el instrumento no puede ser tañido simultáneamente con ambas embocaduras, por lo tanto su definición cambia según se use. 


\section{FIGURA 10}

Siku ("flauta de Pan cerrada de caña con resonador, de uso colectivo". SH421.112.222) usada en Cariquima. Se observa el corte en diagonal de los tubos resonadores, que producen armónicos ligeramente desiguales respecto de los tubos cerrados, generando la riqueza timbrearmónica requerida por el conjunto.

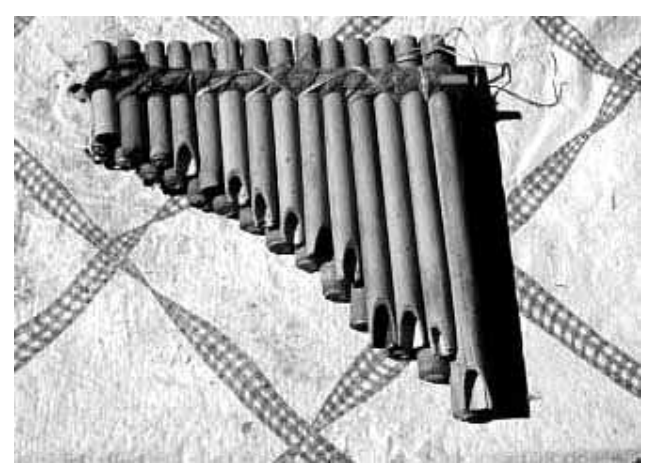

de sonidos amplias. Esta evidencia, junto a la presencia de muchas familias organológicas andinas que presentan un continuo entre 0 y varios agujeros, sugiere que es más lógico relegar también la ausencia de agujeros al sistema de división común, agregando/ 0 a la serie. Esto elimina alguna de las subdivisiones más bajas del sistema SH (421.211.1-1/-2), (421.221.1-1/-2), (421.221.3-1/-2), (421.221.41/-2), (421.222.1-1/-2), (421.222.4-1/-2), (422.121.-1/-2), (422.211.1/2), lo que en todo caso no altera el sistema. También se logra la variación tonal en flautas de fondo móvil (421.121.3-1/-2), con la obturación de la ventana (421.221.41-1/-2) y en trompetas, con el uso de dispositivos para lograr un cromatismo tonal (423.2) mencionado respecto del control.

En el cordófono la cuerda tensa vibra con una geometría muy precisa, lo que permite afinar con precisión. La altura del sonido es muy sensible al cambio de tensión. La tendencia es a controlar la tensión mediante clavijas manuales que permiten cambiar la afinación rápidamente y con precisión, lo que implica un gran dominio artesanal mecánico y estructural ${ }^{42}$. También es común acortar las cuerdas manualmente ("pisarlas", como en la guitarra). Estos criterios no se reflejan en el sistema SH porque son transversales a la muestra, excepto en el caso específico del arpa con clavija manual o con pedal. El recurso de multiplicar cuerdas es tendencia transversal en todo el grupo, lo que explica por qué solamente se usa

42 Este dominio artesanal mecánico y estructural fue muy desarrollado en Europa, desde los artificios mecánicos romanos en adelante, lo que explica el gran desarrollo del rubro cordófonos en esa región. En América prehispánica, en cambio, en que la mecánica se evitaba y el desarrollo estructural buscaba la mayor simplicidad orgánica, el cordófono no se desarrolló. 
como criterio en instrumentos simples (311.11-1/-2), (311.12-1/-2), (314.2-1/-2). También se usa sin o con división de la cuerda en el arco musical, lo que implica una o dos voces simultáneas: (311.121.1-1/-2), (311.121.22-1/-2), (311.122.-1/-2), y en las arpas con afinación fija o variable que implica una o más escalas: (322.21/-2), o serie diatónica/cromática, que se refiere a lo mismo (322.21-1/-2). El palo musical se distingue por uno/varios resonadores, lo que implica una polifonía de resonancia: (311.22-1/-2).

En los membranófonos la tendencia es a producir un tono de altura indeterminada. Excepcionalmente se utilizan métodos para precisar la afinación o variarla con métodos citados en la división común final. Otra tendencia transversal es a formar orquestas con varios instrumentos que aportan a la riqueza rítmica, por lo que hay solo dos ejemplos del criterio solo/en juego (211.1-1/-2), (211.212.$1 /-2)$. También se diferencia una/dos membranas, lo que incide en la resonancia (la segunda membrana generalmente no se tañe: 211.21-1/-2), (211.31-1/-2). El uso del bordón, que añade resonancia a la segunda membrana, se considera en un caso (211.312.-1/-2).

\subsubsection{Características organológicas secundarias}

A medida que se avanza en el sistema SH hacia las subdivisiones menores, se encuentran criterios clasificatorios cada vez más particulares y difíciles de definir y de agrupar. Una parte de ellos se puede relacionar con la geometría del resonador. Un caso especial lo constituye el criterio sin o con resonador en los aerófonos (4-1/-2), en que la geometría del resonador es una característica organológica primaria, ya que afecta directamente la formación del sonido primario. En el resto de los casos la geometría del resonador modula el sonido de modos diferentes, lo que genera una multitud de casos particulares. En los idiófonos se distinguen sin/con resonador y (en combinación con el control) resonador de caja/bucal; también resonador de palo/placa/canaleta/vaso/peine/tubo, y entre los vasos, gong/campana/platillo/caja; resonador abierto/cerrado. Este último criterio es usado en cuatro familias de aerófonos, si bien es difícil de aplicar, y solo en uno de membranófonos. En los cordófonos se distinguen resonadores de tubo entero/ medio tubo/cáscara/caja/tubo; en el arco musical y la cítara de caja se distinguen sin/con resonador. En los aerófonos se da otro tanto entre de caracol/de tubo cilíndrico/cónico/recto/curvo y en las flautas de Pan, tubo simple/complejo. Entre los membranófonos se distingue el resonador: cilíndrico/barril/doble cono/reloj de arena/cónico/copa/semiesférico/tubular/marco/grande/chico y en mirlitones, con/sin resonador.

El resto de los criterios es aún más difícil de definir, ya que combinan la geometría del resonador con otros factores, tales como la resonancia directa o indirecta en idiófonos (raspador de palo/tubo/vaso/rueda), la geometría estructural (cítara de palo/tubo; balsa/cáscara/marco; laúd de arco/mango/lira); la geometría del portacuerda (arco musical/cítara de palo rígido/arco-palo); la transmisión de la 
vibración (tambor frotado con palo atravesado/atado/fijo/medio libre/libre, o frotado con cuerda fija/giratoria; sonaja de hilera/marco/vaso/péndulo/deslizamiento/soga/palo/paño); el material (castañuela/címbalo).

Los criterios restantes son aún más particulares, con una incidencia en el sonido difícil de evaluar. Un criterio es el de heteroglota o idioglota, que diferencia instrumentos construidos a partir de un trozo de material de aquellos construidos agregando partes, el que se aplica a la placa de percusión, al arco musical, al birimbao, y a la cítara de tubo, de balsa y de medio tubo. Otro criterio es la posición que adopta el instrumento para tañerlo. Se distinguen aerófonos de posición longitudinal y traverso, a los que se puede agregar con aeroducto externo e interno, y flautas de Pan en forma de balsa o de paquete. También se distinguen las campanas asentada y colgante, tambores con y sin mango, y finalmente, laúd/ arpa/laúd-arpa. Otros criterios, aún más difíciles de definir respecto de su incidencia en el sonido son caja de percusión simple/compuesto, cordófono simple y compuesto, de mango atravesado o añadido, desunido o unido, arpa de mástil o de marco, de arco de ángulo.

\subsubsection{División común}

El criterio de la "división común", que surge de la necesidad de incluir elementos de gran importancia organológica pero transversales a toda la muestra, es un problema que SH resolvió dejándolo como opción adaptable al final del criterio de identificación.

La división común de los idiófonos se refiere a mecanismos que pueden modificar la capacidad interpretativa (con teclado/con acción mecánica). Son invenciones europeas, una mecanización del movimiento que reaparece en cordófonos $(-8,-9)$ y aerófonos $(-8,-9)$. En los membranófonos la división común se refiere a sistemas de ensamblaje parche/cuerpo (-6 a -9). Se incluyen los sistemas de variación de tensión del parche durante la ejecución ( -5 y subdivisiones, con la inclusión de los sistemas mecánicos antes confinados a -91), ya que amplían drásticamente la capacidad expresiva del instrumento. En los cordófonos la división común se refiere a sistemas de excitación que cambian la dinámica del sonido $(-2,-5,-6,-9)$. En los aerófonos esta división se refiere a un depósito auxiliar para soplar $(-6)$ y a los sistemas auxiliares para modificar la altura del sonido $(-7,-8,-9 ; / 0$ a/5).

\section{CONCLUSIONES}

Tras hacer un breve recorrido histórico por el desarrollo de los sistemas de clasificación hemos realizado una evaluación de los beneficios de cada uno de ellos, destacando la utilidad metodológica que brinda hasta hoy el sistema desarrollado por Curt Sachs y Erick von Hornbostel. A pesar de haber sido creado en 1914 
bajo criterios científicos diferentes a los de hoy, este sistema es de gran ayuda como herramienta metodológica para el estudio de instrumentos musicales, sobre todo bajo ciertas circunstancias. $\mathrm{Al}$ aproximarse a los instrumentos musicales vernaculares o arqueológicos entendidos como producciones tecnológicas de culturas que no corresponden a la tradición occidental, es necesario contar con herramientas adecuadas que nos permitan comprender el universo sonoro al cual nos enfrentamos, para así distinguir los elementos característicos de estos artefactos culturales. La primera fortaleza del sistema SH es basarse en criterios de producción sonora que emanan del objeto, lo que nos permite una mirada centrada en el desarrollo de tendencias asociadas a las tecnologías del sonido. Esto permite entender sus cambios y modificaciones en el tiempo y espacio a pesar de carecer de datos contextuales, lo cual es habitual, por ejemplo, en el estudio de la organología prehispánica, en que se carece frecuentemente de datos de fechamiento y cultura asociada. En esos casos, este método proporciona una alternativa de análisis que en el mejor de los casos se puede afinar mediante el estudio de eventuales continuidades etnográficas. Por otra parte, en aquellos casos de instrumentos que están en uso por comunidades culturalmente ajenas a la occidental, permite tener conciencia del límite que significa considerar solo aspectos tecnológicos frente a procesos de performances culturales que abordan un complejo conjunto de elementos destinados a estimular sentidos que van más allá de lo estrictamente sonoro (desplazamientos, colores, olores, sensaciones, emociones y afectividades). El sistema SH nos permite concentrar la atención en el diseño sonoro del objeto, con abstracción de los parámetros culturales que explican el objeto inserto en su contexto. Esto constituye una útil herramienta para definir un campo que es difícil, complejo y muchas veces elusivo, y por lo mismo que ha sido frecuentemente mal abordado en la discusión de objetos sonoros ajenos a la cultura del investigador. Es así como hemos distinguido un conjunto de características que se han definido como organológicas, diferentes a otras que atañen a un aspecto de diseño no sonoro (visual, formal, material, etc.), las cuales conforman una herramienta muy útil de interpretación de la realidad cultural. El sistema SH está apuntando a ese segmento muy específico y elusivo de la cultura. Creemos que este es su mayor aporte, como hemos podido comprobar en nuestras investigaciones.

El énfasis en esta mirada sobre lo tecnológico, al ser aplicada a un universo de artefactos que abarca desde lo arqueológico hasta la continuidad de tradiciones en la etnografía, nos permite distinguir elementos de tendencia y permanencia. Estas cualidades son de singular interés para poder visualizar de modo genérico los atributos asociados con las búsquedas en la tecnología del sonido. Esto permite considerar a gran escala el desarrollo en el tiempo y distribución en el espacio de tradiciones culturales distinguibles a partir del sonido. En tal sentido, si el sonido constituye solo una parte de complejas manifestaciones culturales, la aproximación tecnológica a este nos proporciona luces acerca de verdaderas puntas de iceberg 
respecto de lo que la música perteneciente a culturas arqueológicas ya extintas pudo haber sido.

En segundo lugar, nos parece que el recorrido por los criterios de clasificación que desarrollaron Sachs y Hornbostel en su propuesta nos permite conocer los modos de producción de sonido según la tecnología que presentan los artefactos sonoros o instrumentos musicales a nivel global. Al desmembrar y reconocer los atributos de cada uno de los aspectos que definen las subdivisiones tales como timbre, cualidad vibratoria del material; energía, tipo de excitación; control y polifonía, nos encontramos con varios rasgos que se destacan como organizadores de la organología a nivel mundial. Algunos de ellos son transversales a todas las culturas del mundo (los niveles primeros de subdivisión), mientras hay otros más complejos, variados y diferenciados culturalmente (a medida que se desciende hacia los niveles inferiores de subdivisión). Este tema, sin ser un objetivo propuesto específicamente por el trabajo de $\mathrm{SH}$, resulta, analizado separadamente, un valioso aporte a la musicología comparada y a los fundamentos teóricos de la organología, junto con transformarse en un aliado poderoso para poder interpretar objetos lejanos culturalmente sin caer en etnocentrismos que pueden ser difíciles de detectar. En nuestro análisis hemos podido distinguir los atributos organizadores de la organología y ejemplificar cada caso con la organología americana, la que era el segmento más ajeno al conocimiento de sus autores, Sachs y Hornbostel. En este sentido destacamos el conocimiento que se puede desprender del ejercicio de incluir nuevas variedades organológicas en el sistema, lo que transforma este método en un instrumento de análisis de mayor utilidad.

En tercer lugar nos parece muy relevante la cualidad dinámica que brinda este método mediante su sistema jerárquico determinado por el atributo del árbol filogenético. Este permite la inclusión de nuevas cualidades tecnológicas, por una parte, y hace posible su fácil incorporación a sistemas de clasificación basados en sistemas digitales, lo que es una gran ventaja para las instituciones que trabajan con sistemas de archivos culturales a gran escala. Considerando que la rigidez de un artículo en papel no constituye el mejor soporte ante las dinámicas posibilidades que brindan los diseños sonoros, vislumbramos las posibilidades que se pueden generar ante la sistematización y correlación de información organológica en bases de datos que puedan surgir con la actual tecnología digital. Destacamos en este sentido la inventiva de estos científicos de principios del siglo pasado, quienes desarrollaron una propuesta de jerarquización de gran utilidad para los problemas de registro, manejo de datos y correlación de los mismos y la perspectiva de generación de nuevos conocimientos.

Con el fin de contribuir en este proyecto centenario, esperamos que se generen en otras latitudes del globo aportes como este siguiendo el espíritu integrador que el sistema propone en la perspectiva de correlacionar y comprender el complejo universo del sonido y el entendimiento de las tecnologías asociadas a su producción. Respecto de los aportes e inclusiones que se pueden generar, se debe subrayar 
la necesidad de una continua revisión e inserción de nuevas categorías según la investigación de instrumentos musicales crece y genera nuevos contenidos para la región, a partir del estudio de la tradición del sonido en América y específicamente en el área Sur Andina. En los últimos trabajos que hemos realizado respecto de los tubos complejos, hemos podido acceder al uso de tecnologías de escáner y observar variantes morfológicas en las soluciones tecnológicas de estos tubos, las cuales sin lugar a dudas están ligadas a sutilezas en las búsquedas sonoras que nos permite aportar a subdivisiones organológicas muy particulares que se integran al sistema SH y que permitan su comparación universal. En esta fase dicha aproximación exploratoria está en proceso de análisis. La intención es realizar este tipo de pruebas sobre un mayor universo de instrumentos para así establecer nuevas subcategorías en esta división.

Todos los factores que hemos reseñado en estas conclusiones tienen una incidencia particularmente fecunda en el estudio de la organología precolombina, en la que el principal escollo ha sido la falta de antecedentes culturales para evaluar, cuantificar e interpretar un enorme corpus de objetos clasificados como instrumentos musicales. Si bien la especificidad de este material nos ha obligado a crear nuevas categorías para describirlos, las que eran desconocidas a SH, esta modificación consideramos que ayuda a que el método pueda ser aplicado con propiedad en la región, y que permita fomentar el estudio de tradiciones sonoras, que en su mayoría esperan ser descubiertas.

Ante la continuidad en la evaluación, modificaciones y aplicación que el sistema ha alcanzado a nivel europeo en la actualidad, creemos que esta propuesta significa un aporte a nivel regional. No obstante, se debe tener presente la gran tarea que falta por hacer en la investigación y registro del complejo universo sonoro que caracteriza a nuestro continente. Destacamos, en este sentido, la importancia de que continúe el desarrollo de líneas de investigación de modo de avanzar en la recopilación e integración de nuevos datos al sistema. A esto se agrega la necesidad de desarrollar proyectos que suministren plataformas para establecer diálogos con otros investigadores que desde la perspectiva de la organología continúan generando aportes.

\section{BIBLIOGRAFÍA}

\section{Adams Hoover, Cynthia}

1996 "Las colecciones de instrumentos musicales un desafío especial", Museum Internacional, XLVIII/189, pp. 4-5.

Agricola, Martin

1529 Musica instrumentalis deudsch. Wittenberg: Georg Rhau.

ARETZ, IsABeL

1967 Instrumentos musicales de Venezuela. Venezuela, Estado de Sucre: Editorial Universitaria Oriente. 


\section{BARCLAY, RoBERT}

1997 The Care of Historical Musical Instruments. Recuperado de www.cimcim.icom. museum/iht/ (4 de marzo, 2006).

Baumann, Max Peter

2001 "Bolivia, II Traditional music", The New Grove Dictionary of Music and Musicians. Segunda edición. Editado por Stanley Sadie. Volumen III. Londres: Oxford University Press, pp. 823-830.

\section{Bessaraboff, Nicolas}

1941 Ancient European Musical Instruments. An Organological Study of the Musical Instruments in the Leslie Lindsey Mason Collection at the Museum of Fine Arts. Boston, Cambridge, Massachusetts: Harvard University Press.

BIOT, EDOUARD (1803-1850, traductor)

Le tcheou-Li ou rites des Tcheu. Recuperado de http:/ / www.uqac.uquebec.ca/zone30/ Classiquesdessciencessociales/index.html (18 de diciembre, 2010).

Bolaños, César, Josafat Roel Pineda, Fernando García, Alida Salazar.

1978 Mapa de los instrumentos musicales de uso popular en el Perú: clasificación y ubicación geográfica. Lima: Instituto Nacional de Cultura, Oficina de Música y Danza.

Both, AdJE

2001 “Die Musikkultur des Azteken”, Berliner Gesellschaft für Anthropologie, Ethnologie und Urgeschichte. Volumen XXII. Berlin. pp. 43-48.

Cavour Aramaya, Ernesto

1994 Instrumentos musicales de Bolivia. La Paz: Editoral Amayo.

2003 Diccionario enciclopédico de los instrumentos musicales de Bolivia. La Paz: Editorial Amayo.

Dräger, Hans Heinz

1948 Prinzip einer Systematik der Musikinstrumente. Kassel: Bärenreiter-Verlag.

EBERT, JaMES

1979 "An Ethnoarcheological Approach to Reasessing the Meaning of Variability in Stone Tool Assemblages, en Carol Kramer (editora). Ethnoarchaeology : Implications of Ethnography for Archaeology. Nueva York: Columbia University Press, pp. 59-76.

Grebe, María Ester

1971 "Clasificación de instrumentos musicales", RMCh, XXV/113-114 (enero-junio), pp. 18-34.

Gudemos, Mónica

1988 Antiguos sonidos. El material arqueológico musical del Museo Dr. Eduardo Casanova. Jujuy, Argentina: Imprenta Zissi.

1998 “Campanas arqueológicas de metal del noroeste argentino”, Anales, $\mathrm{N}^{\circ} 6$. Madrid: Museo de América, pp. 111- 146.

GunjI, Sumi

1996 "La interpretación de instrumentos musicales: una colección universitaria en el Japón”, Museum International, XLVIII/189. París, pp. 6-8.

Heyde, Herbert

1975 Grundlagen des natürlichen systems der Musikinstrumente. Leipzig: Deutscher Verlag der Wissenschaften Leipzig. 
HODDER, IAN

1982 Symbols in Action. Ethnoarcheological Studies of Material Culture. Cambridge: Cambridge University Press.

Hood, MantLE

1971 The Ethnomusicologist. Nueva York: McGraw-Hill.

IzIKovitz, KARL GUSTAV

1935 Musical and Other Sound Instruments of the American Indians - a Comparative Ethnography Study. Göteborg: Eleanders Boktryckeri Acktiebolag.

Jiménez Borja, Arturo

1950-1951 "Instrumentos musicales peruanos", sobretiro de la Revista del Museo Nacional de Lima, tomo XIX-XX. Lima: Museo Nacional de Lima, pp. 37-190.

LAWSON, Graeme

2004 "Music, Intentionality and Tradition: Identifying Purpose, and Continuity of Purpose, in the Musicarchaeological Record", en Ellen Hickmann y Ricardo Eichmann (editores). Vorträge des 3. Symposiums der Internationalen Studiengruppe Musikarchäologie in Kloster Michaelstein, 9-16 junio, 2002. Rahden/Westfalia: Verlag Marie Leidorf, pp.61 -97.

MAHILLON, Victor

1880 Catalogue descriptif et analytique du Musée Instrumental du Conservatoire Royal du Bruxelles. Ghent, Bélgica: A. Hoste.

Malm, William Paul

1974 “Computer Aid in Musical Instrument Research", Festschrift to Ernst Emsheimer. Estocolmo: Hilleström, pp. 119-121.

Mendívil, Julio

2000 "La musicología alemana en la actualidad", Boletín de la Asociación Argentina de Musicología, XV/3, $\mathrm{N}^{\circ}$ 46, pp. 17-18.

2002 "Flutes and Food for the Ancestors: from the Tradition of Discoveries to the Discovery of Traditions in Archaeomusicology". No editado. Colonia.

MERSENNE, Marin

1636 Traité de l'harmonie universelle. París: Sebastian Cramoisy.

Montagu. Jeremy

2009 "It's time to look at Hornbostel-Sachs again", Muzyka, No 1, pp. 7-27.

Myers, Arnold

1989 "Cataloguing Standards for Instrument Collections", CIM-CIM Newsletter, No XIV. Gran Bretaña: Universidad de Edinburgo, pp. 14-28.

Ortiz, Fernando

1952 Los instrumentos de la música afrocubana. La Habana: Dirección de Cultura del Ministerio de Educación.

Pérez de Arce, José

1998 "El sonido rajado; una historia milenaria”, Valles, Revista de Estudios Regionales, III/3. La Ligua, Chile: Museo de la Ligua, pp. 141-150.

2000 "Sonido Rajado, Historical Approach", Galpin Society Journal, N LIII. Oxford: Oxford University Press, pp. 233- 251. 
2001 "Campanas metálicas Santamarianas", RMCh, LX/196 (julio-diciembre), pp. 59-74.

2003 "El guitarrón chileno: una revisión organológica". Trabajo presentado al II Congreso Chileno de Musicología, enero 2003. Santiago: Sociedad Chilena de Musicología. Manuscrito.

2004 "Etnographic Analogies between South Andean Patterns of Dance-Music Traditions and their Prehispanic Evidence", en Ellen Hickmann y Ricardo Eichmann (editores). Music-Archaeological Sources: Finds, Oral Transmission, Written Evidence, Studien zur Musikarchäologie IV, Orient-Archäologie, 15. Rahden/Westfalia: Verlag Marie Leidorf GmbH, pp. 279-287.

2013 "Flautas akonkawa”, Boletín del Museo Chileno de Arte Precolombino, № 18 (en Prensa). Puppo, Giancarlo

1979 Arte argentino antes de la dominación hispana. Buenos Aires: Hualfin Edicolor S.A.

Reinecke, Hans Peter

1974 "Einige Bermerkungen zur methodologischen Basis instrumentaler Forschung", Festschrift to Ernst Emsheimer. Estocolmo: Hilleström, pp.176-179.

SACHS, CURT, Erich Moritz von Hornbostel

1914 "Systematik der Musikinstrumente", Berliner Gesellschaft für Anthropologie, Ethnologie und Urgeschichte, XLVI/4-5. Braunschweig: Limbach, pp. 553- 590.

SCHAEFFNER, ANDRÉ

1936 Origine des instruments de musique. París: Payot.

STEVENSON RoBert

1968 Music in Aztec and Inca Territory. Berkeley y Los Angeles: University of California Press.

STOCKMANN, ERICH

1971-1972 "The Diffusion of Musical Instruments in an Inter- Ethnic Process of Comunication", Yearbook of the International Folk Music Council, volumen III, pp. 128-137.

Trichet, Pierre

ca. 1640-1957 Traité des instruments de musique. François Lesure (editor). Neuillysur-Seine: Societé de Musique d'Autrefois.

Vega, CARlos

1946 Los instrumentos musicales aborígenes y criollos de Argentina. Buenos Aires: Centurión.

VELÁsQuez, RobERTo

2003 Ehekachichtli. An Ancient Noise Generator with Tubular Windway, Whistle of Air, Whistle of Wind, Whistle of the Death,Aerophone of Double Diaphragm or Aerophone with air Spring. Recuperado de http://www.tlapitzalli.com/mctlapitzali/aire/ehekae.html (15 de noviembre de 2010).

Wachsmann, Klaus, Margaret J. Kartomi

2001 "Instruments, classification of. 1. Introduction: the classification system of Hornbostel and Sachs", The New Grove Dictionary of Music and Musicians. Segunda edición. Editado por Stanley Sadie. Volume XII. Londres: Oxford University Press, pp. 418-419. 


\section{APÉNDICE \\ Adaptación del sistema de clasificación organológica Sachs-Hornbostel}

Clasificación SH - metodología

A continuación se presenta la adaptación del sistema de clasificación organológica Sachs-Hornbostel a partir de la traducción hecha por Carlos Vega. Se mantuvieron los lineamientos generales, se interpretaron las explicaciones de un modo más coherente y fácil de seguir, y se agregaron algunos nombres genéricos y algunas nuevas categorías. En las notas se trascribe el texto de Vega, para los efectos de comparación. En los títulos de cada especie se trató de evitar la cadena de nombres asociados (idiofono de golpe indirecto - vasos de entrechoque de madera) por un nombre que sintetice la especie (castañuela, en ese ejemplo), de modo de ampliar los ejemplos dados por Vega en tal sentido. Para este efecto se mantiene la definición de la especie entre paréntesis, y se destaca su nombre específico. Debido a que los instrumentos musicales normalmente aparecen en forma independiente, esta característica no se indica como tal. No obstante si los instrumentos aparecen en juegos, entonces esta característica se señala de manera explícita.

Los nombres de clasificación y sus explicaciones aparecen en negro.

Los ejemplos de cada tipología aparecen en gris.

La cursiva representa los textos que fueron reformulados en esta versión.

La negrita representa las nuevas categorías incorporadas.

En rojo, las nuevas categorías incorporadas por Bolaños et al 1978.

En la sección de notas al pie aparecen referencias de las nuevas categorías incorporadas y comentarios respecto de éstas.

\section{IDIÓFONO.}

El sonido se produce por vibración de un cuerpo sólido. Instrumento y cuerpo sonante son una misma cosa; no son imprescindibles partes componentes. El material en que está construido el instrumento (como tendencia: metal, madera, piedra) incide directamente en el sonido. ${ }^{l}$

11 IDIÓFONO DE GOLPE.

El instrumento se hace sonar golpeándolo con otro objeto. ${ }^{2}$

111 IDIÓFONO DE GOLPE DIRECTO.

El instrumento es percutido directamente por el ejecutante. Se obtienen golpes aislados, netos e inconfundibles. ${ }^{3}$

$\begin{array}{lllll}1 & 1 & 1 & 1 & 1 \\ \text { IDIÓFONO DE ENTRECHOQUE. }\end{array}$

Dos o más partes sonoras son golpeadas entre sí. ${ }^{5}$

$\begin{array}{lllllll}1 & 1 & 1 & 1 & 1 & \text { PALOS DE ENTRECHOQUE. }\end{array}$

$\begin{array}{lllllll}1 & 1 & 1 & 1 & 1 & 1 & 1\end{array}$ (palos de entrechoque independientes ${ }^{7}$ ) o CLAVES.

Piedras entrechocadas (Oceanía, mapuche), maderas entrechocadas (África), iaf-iaf (ramas sacudidas), waiki (lanzas) y palituwe (palo de "chueca") mapuches, taka tika y mazo, Perú.

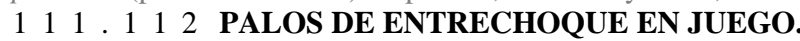

$\begin{array}{lllllllllll}1 & 1 & 1 & 1 & 1 & 1 & 2 & \text {. } & 1 & \text { PALOS DE ENTRECHOQUE ARTICULADO. }\end{array}$

Claves articuladas (Rusia).

$\begin{array}{llllllllll}1 & 1 & 1 & 1 & 1 & 1 & 2 & 2 & 2 & \text { PALOS DE ENTRECHOQUE EN RACIMO. }\end{array}$

Palmas, Alarma de monasterio (Europa), flechas, bambú hendido (Oceanía), palmas de entrechoque (Perú).

$\begin{array}{lllllll}1 & 1 & 1 & 1 & 1 & \text { PLACA DE ENTRECHOQUE. } & \mathbf{8}\end{array}$

$\begin{array}{lllllll}1 & 1 & 1 & 1 & 1 & 2 & 1\end{array}$ PLACA DE ENTRECHOQUE (independiente).

Par de claves de hueso o madera (Egipto, Australia), tijeras, topos metálicos (Perú), escudo y espada (Europa, África).

$\begin{array}{llllllll}1 & 1 & 1 & 1 & 2 & 2 & \text { PLACAS DE ENTRECHOQUE EN JUEGO. }\end{array}$

Placas colgantes, látigo de placas, matraca de placas (Asia).

111.13 CANALETAS DE ENTRECHOQUE. ${ }^{9}$

(Birmania).

\footnotetext{
${ }^{1}$ Vega: El material del instrumento que produce el sonido gracias a su rigidez y elasticidad, sin tener necesidad de cuerdas o membranas tendidas.

${ }^{2}$ Vega: El instrumento se pone en vibración mediante la percusión.

${ }^{3}$ Vega: El ejecutante hace el mismo movimiento que el golpe: no se toman en consideración los medios mecánicos, si existen,, como los badajos, las teclas, las cuerdas, y otras cosas de esta índole. Lo decisivo es que el ejecutante puede producir golpes aislados, netos e inconfundibles y que el instrumento esté preparado para esta especie de percusión. Ver nota 4 y 49.

${ }^{4}$ Vega: Idiófono de entrechoque o castañuela. En rigor, el entrechoque es un tipo de golpe indirecto, ya que no es la mano la que golpea, sino la que mueve el conjunto para que se entrechoquen sus partes del mismo modo que la familia (112). La diferencia, sin embargo, es que en este grupo se entrechocan generalmente dos elementos, y por lo tanto el resultado sonoro tiende a producir sonidos aislados, netos e inconfundibles, que justifican su permanencia en esta familia. Ver nota 3. El nombre castañuela lo reservamos para una subespecie.

${ }^{5}$ Vega: Dos o más partes sonoras coordinadas, son golpeadas una contra la otra.

${ }^{6}$ Vega: Palos de entrechoque o castañeteo de palos; Annam, India, Islas de Marshall.

${ }^{7} \mathrm{La}$ tendencia organológica es a los instrumentos independientes, siendo los en juego la excepción. Por esto en adelante usaremos el

descriptor "independiente" entre paréntesis, lo cual significa que, salvo indicación contraria, se subentiende este estado.

${ }^{8}$ Vega: Placas de entrechoque o castañeteo de placas; China e India.

${ }^{9}$ Vega: Canaletas de entrechoque o castañeo de canaletas.
} 


\section{APÉNDICE}

Adaptación del sistema de clasificación organológica Sachs-Hornbostel

111.14 VASOS DE ENTRECHOQUE. ${ }^{\mathbf{1 0}}$

Se considera vaso aun a la más pequeña excavación en una tabla.

111.141 (vasos de entrechoque de madera) o CASTAÑUELA.

Vasos naturales y excavados. Castañuela (España). ${ }^{11}$

111.142 (vasos de entrechoque de metal) o CIMBALOS. ${ }^{\mathbf{1 2}}$

Vasos doblados hacia fuera. Par de platillos (Europa, Perú, Chile), címbalo y crótalo (Medio Oriente y

Asia), dos cucharas entrechocadas (Perú, Chile).

111 . 143 (vasos de entrechoque de bivalvo) o CADACADA.

Dos conchas de ostión (mapuche).

$\begin{array}{lllll}1 & 1 & 1 & 2 & \text { IDIOFONO DE PERCUSIÓN. }\end{array}$

El sonido se obtiene golpeando el instrumento con un objeto. ${ }^{13}$

$\begin{array}{llllll}1 & 1 & 1 & 2 & 1 & \text { PALO DE PERCUSIÓN. }\end{array}$

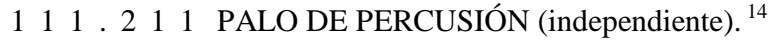

$\begin{array}{llllllllllll}1 & 1 & 1 & . & 2 & 1 & 1\end{array}$. 1 PALO PERCUTIDO CON OTRO PALO.

El palo que golpea es menor: si son de igual tamaño, es (111.111). Tambor de tinaja, yunque, triangulo, raíces de árbol golpeadas (Perú).

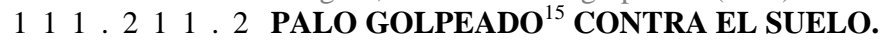

El palo es golpeado con la mano contra el suelo. Bastón de ritmo; kiyaya, vara de alcalde, champi (Perú), lanzas (N. Britania), palos (Australia).

$\begin{array}{lllllllllllll}1 & 1 & 1 & 2 & 1 & 1 & 3 & \text { PALO PATEADO. }\end{array}$

Palo flexible golpea contra el suelo al ser pateado. Palo de baile (Amazonía).

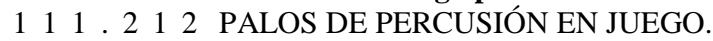

Varios palos de percusión de diferente altura tonal se unen en un instrumento. Xilófono (África, Asia). ${ }^{16}$

$\begin{array}{llllll}1 & 1 & 1 & 2 & 2 & \text { PLACA DE PERCUSIÓN. }\end{array}$

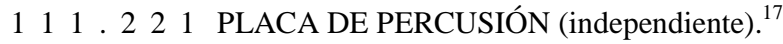

$\begin{array}{llllllll}1 & 1 & 1 & 2 & 2 & 1\end{array}$. 1 PLACA GOLPEADA.

Flexatón, serrucho, zapato de taconeo, espada (Europa); piedra sonora, matraca de tabla, escudo

$\begin{array}{lllllllll}1 & 1 & 1 & 2 & 2 & 1 & . & 2 & \text { PLACA PATEADA. }\end{array}$ golpeado (África, Oceanía); tormento (Chile) ${ }^{18}$; remo golpeado sobre tinaja (Perú).

Piedra, tabla (Oceanía); vapen (suelo pateado, mapuche).

$\begin{array}{lllllll}1 & 1 & 1 & 2 & 2 & 2 & \text { PLACAS DE PERCUSIÓN EN JUEGO. }{ }^{19}\end{array}$

$\begin{array}{lllllllllll}1 & 1 & 1 & 2 & 2 & 2\end{array}$. 1 PLACAS DE PERCUSIÓN EN JUEGO IDIOGLOTA.

Placas recortadas. Teponatzli (México).

$\begin{array}{lllllll}1 & 1 & 1 & 2 & 2 & 2 & 2\end{array}$. 2 PLACAS DE PERCUSIÓN EN JUEGO HETEROGLOTA.

Litófonos (China); xilófono (África); metalófono (Asia sudoriental). Corabici, dos palos de distinto tamaño sobre resonador (Perú).

$\begin{array}{lllllll}1 & 1 & 1 & 2 & 3 & \text { TUBO DE PERCUSIÓN. }\end{array}$

$\begin{array}{lllllll}1 & 1 & 1 & 2 & 3 & 1 & \text { TUBO DE PERCUSIÓN (independiente). }{ }^{20}\end{array}$

$\begin{array}{llllllll}1 & 1 & 1 & 1 & 2 & 3 & 1\end{array}$. 1 TUBO GOLPEADO CON LA MANO, CON PALO O CONTRA EL SUELO.

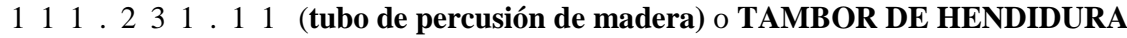

Tubo de madera o caña, generalmente con corte o hendidura longitudinal. Tambor de hendidura (África, Amazonía); bastón rítmico de caña (Amazonía, Hawai); wampo (mapuche)

Dyadiko, tronco pateado, Tuntui, tintili, tambor de tronco hueco, mortero colectivo de madera (Perú).

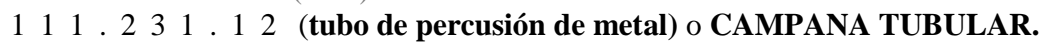

Sin cortes o hendiduras. Campana tubular.

$\begin{array}{lllllll}1 & 1 & 1 & 2 & 3 & 1\end{array} .2$ (tubo de percusión golpeado o pateado) o TUBO DE RITMO.

Se golpea contra el piso. Tubo de ritmo. Judsocona, ilicaida, de bambú; bastón de madera (Perú).

\footnotetext{
${ }^{10}$ Vega: Vasos de entrechoque o castañeteo de vasos.

${ }^{11}$ Vega: Castañuelas; Vasos de castañeteo naturales y excavados.

${ }^{12}$ Vega: Platillos; Vasos de castañeteo doblados hacia fuera.

${ }^{13}$ Vega: Se golpea el instrumento con un objeto que no da sonido (mano, barajo, palillo) o se golpea el instrumento mismo contra tal objeto (cuerpo, suelo).

${ }^{14}$ Vega: Japón, Annam, Balcanes. También los triángulos pertenecen a esta categoría.

${ }^{15}$ A falta de un vocablo específico, se usa "golpeado" para referirse a una acción manual, contrapuesta a "pateado", con el pie.

${ }^{16}$ Vega: Todos los xilófonos, si sus componentes sonoros son biplanos.

${ }_{17}^{17}$ Vega: En la iglesia cristiana oriental.

${ }^{18}$ El tormento consta de muchas placas pero al no tener afinación no se consideran en juego.

${ }^{19}$ Vega: Litófonos(China), también la mayoría de los metalófonos.

${ }^{20}$ Vega: Tambor de madera, campanas de tubo.
} 


\section{APÉNDICE}

Adaptación del sistema de clasificación organológica Sachs-Hornbostel

$\begin{array}{llllll}1 & 1 & 1 & 2 & 3 & 2 \\ \text { TUBOS DE PERCUSIÓN EN JUEGO. } & & \\ & & \end{array}$

$\begin{array}{lllllllllll}1 & 1 & 1 & 2 & 3 & 2 & \end{array}$ TAMBORES DE HENDIDURA EN JUEGO.

Aron, maguare, juarai, kömögbua, papana, pamuko, dos tambores (masculino y femenino Perú).

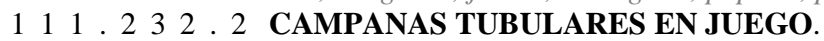

Campanas de tubo, xilófono de tubos (Europa).

$\begin{array}{llllll}1 & 1 & 1 & . & 4 & \text { VASO DE PERCUSIÓN. }\end{array}$

$\begin{array}{lllllll}1 & 1 & 1 & 2 & 4 & 1 & \text { (Vaso de percusión central) o } \mathrm{GONG}^{22}\end{array}$

Las vibraciones disminuyen hacia el borde, donde se sujeta.

111.241 .1 GONG (independiente). ${ }^{23}$

Gong metálico (Asia).

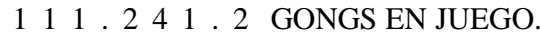

Juego de gong (Asia sudoriental), tambor de tonel metálico (Caribe),

111.242 (Vaso de borde golpeado) o CAMPANA. ${ }^{24}$

Las vibraciones disminuyen hacia el centro, donde se sujeta.

$\begin{array}{llllllll}1 & 1 & 1 & 2 & 4 & 2\end{array} .1$ CAMPANA (independiente)

$\begin{array}{lllllllll}1 & 1 & 1 & 2 & 4 & 2 & 1 & 1 & 1 \\ \text { CAMPANA DE ASIENTO. } & & \\ & \end{array}$

El vaso se asienta en un cojín o similar.

$\begin{array}{lllllllllll}1 & 1 & 1 & 2 & 4 & 2 & 1 & 1 & 1 \\ \text { CAMPANA ASENTADA. }\end{array}$

El vaso tiende a la forma tubular (China, Indochina, Japón). Cencerro manual (Sudamérica).

$\begin{array}{lllllllllll}1 & 1 & 1 & 2 & 4 & 2 & 1 & 1 & 2 & \text { PLATILLO ASENTADO. }\end{array}$

El vaso tiene forma de plato extendido (Europa).

111.242 .12 CAMPANA COLGANTE. ${ }^{26}$

El vaso se cuelga del vértice.

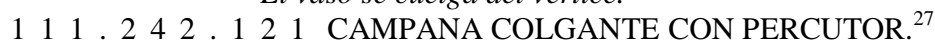

Con percutor suelto.

$\begin{array}{llllllllllll}1 & 1 & 1 & 2 & 4 & 2 & 1 & 2 & 1\end{array} .1$ CAMPANA PERCUTIDA.

Campana metálica (universal), campanillas (Europa).

$\begin{array}{llllllllll}1 & 1 & 1 & 2 & 4 & 2 & 1 & 2 & 1\end{array} .2$ PLATILlO PERCUTIDO.

En la batería actual, universal.

111.242 .122 CAMPANA CON BADAJO. ${ }^{28}$

La campana tiene badajos colgantes en su interior.

$\begin{array}{lllllllllllll}1 & 1 & 1 & 2 & 4 & 2 & .1 & 2 & 2\end{array} .1$ CAMPANA DE UN BADAJO.

Campana de metal (Europa, Asia); esquila (Perú).

$\begin{array}{lllllllllll}1 & 1 & 1 & 2 & 4 & 2 & 1 & 2 & 2\end{array}$ (Campana con varios badajos) o CENCERRO.

Cencerro de madera (universal), de metal (Andes).

111.242 .2 CAMPANAS EN JUEGO. ${ }^{29}$

Campanilla múltiple (Europa, Bali); carillón (Europa); juego de vasos con agua (India).Campanas de iglesias (Europa, universal).

$\begin{array}{llllll}1 & 1 & 1 & 2 & 4 & 3 \\ \text { CAJA DE PERCUSIÓN. } & \text { 30 }\end{array}$

La vibración se distribuye por todo el cuerpo, se sostiene de cualquier parte.

$\begin{array}{lllllllllll}1 & 1 & 1 & 2 & 4 & 3\end{array}$. 1 CAJA DE PERCUSIÓN SIMPLE.

La misma caja hace de resonador. Cajón peruano, caja de arpa o guitarra percutida (Andes Sur); jarra cerámica percutida (universal).

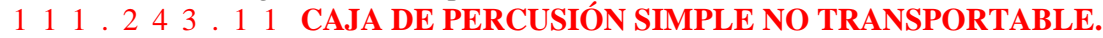

Tamborete, cajón, caja de arpa o guitarra percutida (Perú, Argentina, Chile); jarra cerámica percutida (universal).

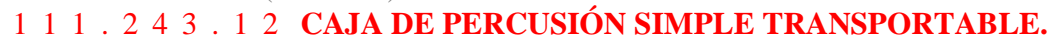

Caja, cajita, caparazón de tortuga percutido (Perú).

\footnotetext{
${ }^{21}$ Vega: Tubo fono, xilófono de tubos.

${ }^{22}$ Vega: Gongs, Las vibraciones aumentan en dirección al vértice.

${ }^{23}$ Vega: Asia del sur y del este; también en los llamados tambores de metal, mejor dicho gongs de caldera, pertenecen a este lugar.

${ }^{24}$ Vega: Campanas. Las vibraciones disminuyen hacia el vértice.

${ }^{25}$ Vega: Asentadas. El vaso esta encima de la mano o una almohada; la abertura está dirigida hacia arriba, China, Indochina, Japón.

${ }^{26}$ Vega: Colgantes. La campana está colgada del vértice.

${ }^{27}$ Vega: Id. con percutor. Sin badajo fijo, sino con percutor suelto.

${ }^{28}$ Vega: Id. con badajo: La campana tiene un badajo fijo. El badajo implica un golpe indirecto, por lo tanto este instrumento debiera estar entre los idiófonos de golpe indirecto (112). Sin embargo la similitud entre las campanas con y sin badajo hacen más fácil identificarlas como subdivisión de un mismo grupo. Por otra parte los sonidos de la campana con badajo tienden a ser más bien aislados y definidos (como en la campana de iglesia católica) o en grupos rítmicos bien definidos (como en el cencerro de madera), si bien esto exige cierta pericia y control. Ver nota 3.

${ }^{29}$ Vega: Campanas en Juegos (La subdivisión correspondiente).

${ }^{30}$ Nueva categoría. Bolaños et al 1978 la ponen como 111.25, nos parece más útil ponerla como parte de los vasos, para incorporar ejemplos más universales.
} 


\section{APÉNDICE \\ Adaptación del sistema de clasificación organológica Sachs-Hornbostel}

$\begin{array}{lllllllll}1 & 1 & 1 & . & 2 & 4 & 3 & . & 2 \\ \text { CAJA DE PERCUSIÓN COMPUESTA. }\end{array}$

Recipiente boca abajo sobre agua en otro recipiente (África, Latinoamérica); kuivitun (mapuche);

tinya acuática (Perú).

112 IDIOFONO DE GOLPE INDIRECTO.

El movimiento del ejecutante se trasmite indirectamente, el instrumento posee varios elementos que percuten produciendo grupos de sonidos complejos más que golpes aislados. ${ }^{\mathbf{3 1}}$

$\begin{array}{lllll}1 & 1 & 2 & 1 & 1 \\ \text { (Idiófono de sacudimiento) o SONAJA. }\end{array}$

El ejecutante sacude el instrumento. ${ }^{32}$

$\begin{array}{llllll}1 & 1 & 2 & 1 & 1 & 1 \\ \text { SONAJA DE HILERA. }\end{array}$

Cuerpos sonoros perforados unidos en hileras se entrechocan. ${ }^{33}$

$\begin{array}{lllllll}1 & 1 & 2 & 1 & 1 & 1 & \text { SONAJA DE SOGA. }\end{array}$

Los cuerpos sonoros son unidos por una cuerda. ${ }^{34}$ Collares de valvas, semillas u otros (América, chunan (mapuche), churo, zacapa (Perú); hileras de campanillas de entrechoque; chanrara, bakich, bisha, misha, shakap, firisai, quiriraji, uirisai, yeshyeshllem, sakapaxi, lanakostakitsi, tsaiwaiwue, köyehu, patakura, shakapa, kayonothe, aru, shakap, peetai, awanketai, nunkutai, viciriji, tsompirontsi, chaje, sonajeros de semillas, de pezuñas, de caracoles, de muelas de animales, de élitros de coleópteros, huesos, picos de pájaro, y cascabeles (Perú).

$\begin{array}{llllll}1 & 1 & 2 & 1 & 1 & 2 \\ \text { SONAJA DE PALO. }\end{array}$

Los cuerpos sonoros son unidos por un palo o aro ${ }^{35}$. Sistro de madera (Samoa); espuela (Europa, América), llol llol y platería (mapuche); chapitas, tentem, tabas, corona con sonajero (Perú).

$\begin{array}{llllllll}1 & 1 & 2 & 1 & 1 & 3 & \text { SONAJA DE PAÑO. } & \\ & 36\end{array}$

Los cuerpos sonoros son unidos a un paño. Brazaletes, perneras (universal); ornamentos metálicos en vestimenta (prehispánico, Perú); maichiles, morisca, comocomo, pataku, kunkuakachumtai, matinhue, siog 'koy, de caracol, semillas, élitros de coleóptero (Perú).

$\begin{array}{llllll}1 & 1 & 2 & 1 & 2 & \text { SONAJA DE MARCO. }\end{array}$

Cuerpos sonoros fijos a un marco lo golpean. ${ }^{37}$

$\begin{array}{lllllll}1 & 1 & 2 & 1 & 1 & 2 & 1\end{array}$ SONAJA DE PÉNDULO.

Los cuerpos sonoros cuelgan del marco. ${ }^{38}$

$\begin{array}{llllllll}1 & 1 & 2 & 1 & 2 & 1\end{array}$. 1 PALO SONAJERO.

Palo con cuerpos sonoros colgados. Bastón sonaja (Andes), matraca procesional de tabla,

Monapue, guadae, arupaweru (Perú).

$\begin{array}{lllllllll}1 & 1 & 2 & . & 1 & 2 & 1 & \text {. } & \text { PLACA SONAJERO. }\end{array}$

Placa con cuerpos sonoros colgados. Escudo de danza con sonaja de anillos (África); vestimentas y objetos rituales metálicos con sonajas (Perú prehispánico); sonajas de marco y de horqueta, taqlla, (Perú).

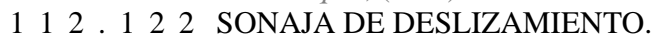

Cuerpos sonoros se deslizan dentro de cuerpos no sonoros o a la inversa ${ }^{39}$. Anklung (Java); sistro metálico con palos (Medio Oriente, Europa).

$\begin{array}{llllll}1 & 1 & 2 & 1 & 1 & 3 \\ \text { SONAJA DE VASO. }\end{array}$

Objetos encerrados en un vaso o colgantes por fuera del vaso entrechocan y golpean el vaso. ${ }^{40}$

\footnotetext{
${ }^{31}$ Vega: El ejecutante no hace ningún movimiento de golpe; la percusión se origina indirectamente, principalmente como consecuencia de un movimiento de otra índole que hace el ejecutante; el instrumento está destinado a hacer oír complejos de sonidos o ruidos, no golpes aislados.

${ }_{32}$ Vega: El ejecutante hace un movimiento de sacudimiento.

${ }^{33}$ Vega: Autófonos perforados se unen en hileras y chocan uno contra el otro en el sacudimiento.

${ }^{34}$ Vega: Los cuerpos sonoros son puestos en hileras en una cuerda. Collares de valvas en hileras.

${ }^{35}$ Vega: Los cuerpos sonoros son puestos en hilera en un palo o aro. Sistro con anillos.

${ }^{36}$ Bolaños et al 1978 la llaman de "hileras múltiples".

${ }^{37}$ Vega: Los cuerpos sonoros se fijan en un objeto y golpean contra este.

${ }^{38}$ Vega: Los cuerpos sonoros cuelgan libremente del marco. Escudo de danza con sonaja de anillos.

${ }^{39}$ Vega: Cuerpos que no suenan se deslizan de un lado a otro dentro de cortes o perforaciones de un cuerpo que suena y lo ponen en vibración, o cuerpo que suenan se deslizan de un lado a otros en cortes de un cuerpo que no suena y son puestos en vibración por este en cada deslizamiento. Anklun (más moderno).Sistro con palo. Este es un grupo de definición compleja, con objetos extraños, de difícil comprensión cuando se analizan fuera de contexto.

${ }^{40}$ Vega: Los cuerpos sonoros están encerrados en un vaso y chocan unos contra otros, contra la pared del vaso o, generalmente de ambas maneras. N.B. la sonaja que se haya en el río Benue hecho [a] con una calabaza con mango, en la cual los cuerpos sonoros no están encerrados en el interior, sino anudados en la parte exterior de una red que recubre la calabaza, se tiene que considerar como variedad de la sonaja de vasos. Capsulas de frutas con granos de semillas, cascabeles con bolitas sueltas encerradas que golpean.
} 


\section{APÉNDICE \\ Adaptación del sistema de clasificación organológica Sachs-Hornbostel}

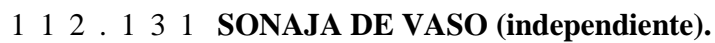

$\begin{array}{lllllllll}1 & 1 & 2 & 1 & 3 & 1\end{array} .1$ (Sonaja de vaso cerrado) o MARAKA. ${ }^{41}$

Vaso sin aberturas (aberturas pequeñas no se toman en cuenta), con numerosas partículas que se entrechocan en el interior, o con objetos colgantes por fuera.

$\begin{array}{lllllllllllllll}1 & 1 & 2 & 1 & 1 & 3 & 1 & 1 & 1 & 1 & \text { MARAKA SIN OBSTRUCCIÓN INTERNA. }\end{array}$

Capsulas de frutas con semillas, calabaza (Sudamérica; wada mapuche; karacachi (Perú); caparazón de tortuga (Norteamérica); de madera (Norteamérica, Perú); de cuero (Norteamérica, excepcional mapuche); de cestería (Andes, África); de cuerno (Perú); toonhfu, burero, cavalle, shacate, buriburiti, maraka, riariaera, pueru, de calabaza; sanabi, de semilla, sonaja de cerámica (Perú).

$\begin{array}{lllllllllll}1 & 1 & 2 & .1 & 3 & 1 & 1 & 2 & \text { MARAKA CON OBSTRUCCIÓN INTERNA. }\end{array}$ Varillas o placas interiores retardan o modifican el entrechoque entre las partículas Palo de agua (Colombia); maraka con púas (Argentina).

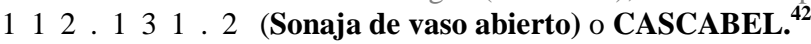

Vaso, generalmente con la abertura en la base, con una o más partículas que entrechocan en el interior.

$\begin{array}{lllllllllll}1 & 1 & 2 & 1 & 3 & 1 & 2 & 1 & \text { CASCABEL en soga. }\end{array}$ Cascabel metálico (universal); cerámica (México); semillas (Andes).

$\begin{array}{llllllll}1 & 1 & 2 & 1 & 3 & 1\end{array} .22$ CASCABEL en paño. morisca, cascabeles de polaina (Perú).

$\begin{array}{lllllllll}1 & 1 & 2 & 1 & 3 & 1 & 2 & 3 & \text { CASCABEL en mango. }\end{array}$ Kaskawilla (mapuche)

$\begin{array}{lllllll}1 & 1 & 2 & 1 & 3 & 2\end{array}$ (Sonaja de vaso adosada a un artefacto) o VASO SONAJA.

La sonaja forma parte de un objeto utilitario (recipiente u otro) que actúa como resonador. El contenido del recipiente influye en el sonido. Puede tener o no abertura ${ }^{43}$. Tumi sonaja, botella sonaja, vaso sonaja, jarro sonaja (Andes).

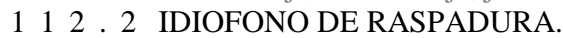

El ejecutante raspa un cuerpo dentado con un palo o similar. ${ }^{44}$

112.21 PALO RASPADO. ${ }^{45}$

Se raspa un palo dentado con otro palo.

$\begin{array}{llllll}1 & 1 & 2 & 2 & 1 & 1 \\ \text { PALO RASPADO SIN RESONADOR. }\end{array}$

Palo o hueso dentado (universal), quijada o cacharaina (Perú, Chile). ${ }^{46}$

112.212 PALO RASPADO CON RESONADOR.

Palo dentado y calabaza (África); hueso dentado sobre recipiente (México); caja con nervadura superior dentada (China).

$\begin{array}{llllll}1 & 1 & 2 & 2 & 2 & \text { TUBO RASPADO. }\end{array}$

Güiro, de calabaza o de caña (Perú)

$\begin{array}{llllll}1 & 1 & 2 & 2 & 3 & \text { VASO RASPADO }\end{array}$

Se raspa un vaso que tiene la superficie surcada (Caribe, Congo). ${ }^{48}$

112.24 (Raspadura de rueda) o CARRACA.

Una rueda dentada cuyo eje sirve de mango es raspado por una lengüeta dentro de un marco, que gira alrededor del mismo mango. (Europa), matraca (Perú, Chile). ${ }^{49}$

\footnotetext{
${ }^{41}$ Bolaños et al 1978 lo dividen en "con agarradero", "sin agarradero" y "colgante”. Nos parece que nuestra proposición separa más nítidamente grupos organológicos contrastados.

${ }^{42}$ La diferencia entre abierto y cerrado puede ser mínima, pero como categoría organológica es muy importante. Bolaños et al 1978 proponen la subcategoría 112.133: sonajero de vaso colgante subdividido en "campanitas" y "cascabeles", pero no aclaran por qué separan estas "campanitas" de las" campanas" (111.242). Al subdividir el "cascabel" lo hacen en tres categorías: "independiente", "en fila" y "en fila múltiple". Nosotros lo redujimos a "'en soga" y "en paño", para ser coherentes con nuestra nomenclatura, incorporando el único caso de "independiente" que ellos presentan dentro de "en paño", que nos parece más coherente, y añadimos "en mango" para incluir el importante aporte mapuche, muy diferenciable organológicamente.

${ }^{43} \mathrm{La}$ apertura tiende a ser una rajadura inferior, y la(s) partícula(s) tiende(n) a ser una, grande.

${ }^{44}$ Vega: El ejecutante produce directa o indirectamente un movimiento de raspadura: un cuerpo que no suena pasa por un cuerpo dentado que suena y es levantado alternativamente por los dientes y lanzado a la superficie; o un cuerpo elástico que suena, corre por encima de un cuerpo dentado que no suena y recibe de este modo una serie de golpes. Este grupo no debe confundirse con los idiófonos de frotación.

${ }^{45}$ Vega: De palillos. Se raspa con un palillo dentado o con un bastoncito.

${ }^{46}$ Vega: Sudamérica, India, arco musical dentado, Congo. Bolaños et al 1978 clasifican la cacharanina como "con resonador".

${ }^{47}$ Vega: Usambra y este de Asia (Tiger).

${ }^{48}$ Vega: Sudamérica y Congo.

${ }^{49}$ Vega: Una rueda dentada cuyo eje sirve de mango y una lengüeta dentro de un marco, que puede girar libremente alrededor del mismo mango; durante la rotación la lengüeta pega contra los dientes de la rueda. Europa e India.
} 


\section{APÉNDICE \\ Adaptación del sistema de clasificación organológica Sachs-Hornbostel}

$\begin{array}{lllll}1 & 1 & 2 & 3 & 3 \\ \text { IDIOFONO DE SEPARACIÓN. }\end{array}$

Compás elástico cuyas puntas se separan con un palo y vuelven a chocar (China, Malaca, Persia, Balcanes) ${ }^{50}$.

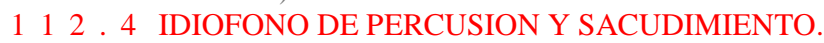

El golpe hace vibrar el instrumento. Quijada de equino raspada o golpeada (África y Los Andes); tranatrana (mapuche); cacharaina (Perú, Chile).

12 IDIOFONO DE PUNTEO. ${ }^{51}$

Se puntea una lengüeta elástica fija en un extremo.

121 IDIOFONO DE PUNTEO EN FORMA DE MARCO.

La lengüeta oscila dentro de un marco rígido. ${ }^{52}$

121.1 (Idiófono de punteo con resonador de caja) o CRICRI.

La lengüeta esta recortada en un tubo o similar ${ }^{53}$.

121.2 (Idiófono de punteo con resonador bucal) o BIMBIRIMBAO.

La lengüeta unida a un marco necesita la boca como resonador. ${ }^{54}$

$\begin{array}{lllll}1 & 2 & 1 & 2 & 1 \\ \text { BIMBIRIMBAO IDIOGLOTA. }\end{array}$

La lengüeta está recortada en el marco (Asia sudoriental); ${ }^{55}$ cauca (Perú).

121.22 BIMBIRIMBAO HETEROGLOTA. ${ }^{56}$

La lengüeta está unida al marco. ${ }^{57}$ Trompe (mapuche, aymara).

122 (tabla) o PEINE PUNTEADO ${ }^{58}$

Varias lengüetas asociadas a una tabla como dientes de peine.

122.1 PEINE PUNTEADO HETEROGLOTA. ${ }^{59}$

Con lengüetas unidas a la tabla.

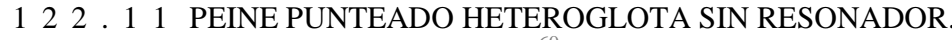
Zansa de tabla (Sudáfrica). ${ }^{60}$

122.12 PEINE PUNTEADO HETEROGLOTA CON RESONADOR. Zansa con caja (África). ${ }^{61}$

122.2 (Peine punteado idioglota) o CAJITA DE MUSICA. ${ }^{62}$

Con lengüetas recortadas. Un cilindro con clavos puntea las lengüetas (Europa).

13 IDIOFONO FROTADO. ${ }^{63}$

El instrumento se pone en vibración por frotación de su superficie.

$\begin{array}{llll}1 & 3 & 1 & \text { PALO FROTADO. } \\ & 64\end{array}$

$\begin{array}{llll}1 & 3 & 2 & \text { PLACA FROTADA. } \\ & 65\end{array}$

Serrucho frotado (Perú, Chile).

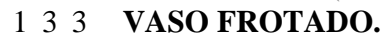

$\begin{array}{lllll}1 & 3 & 3 & . & 1\end{array}$ VASO FROTADO (independiente).

Caparazones de tortugas (Brasil); teteco (Perú).

$\begin{array}{lllll}1 & 3 & 3 & 2 & \text { VASOS FROTADOS EN JUEGO. }\end{array}$

Glass harmonica (Estados Unidos). ${ }^{66}$

14 IDIOFONO SOPLADO. ${ }^{67}$

$\mathrm{El}$ instrumento se pone en vibración por soplo.

\footnotetext{
${ }^{50}$ Vega: Instrumentos en forma de compás elástico cuyas puntas se tocan; esas puntas se separan con fuerza con un palito y después vuelven a chocar causa de su elasticidad. China (huan t’u) Malaca, Persia (qâsik), Balcanes.

${ }^{51}$ Vega: Idiófonos de punteado. Lengüetas, es decir, plaquitas elásticas, fijas por un extremo, son encorvadas y luego vuelve a su posición inicial a causa de su elasticidad.

${ }_{52}$ Vega: La lengüeta oscila dentro de un marco o de una manija.

${ }^{53}$ Vega: La lengüeta está recortada en un palito de modo que tiene en este su resonador. Melanesia.

${ }^{54}$ Vega: La lengüeta está colocada en un marco en forma de palito o de placa y necesita la boca como resonador.

${ }^{55}$ Vega: La lengüeta está recortada en la materia del marco y unida a el por la raíz. Indochina, Indonesia, Melanesia.

${ }^{56} \mathrm{SH}$ incluyen los subgrupos (121.221) bimbirimbao heteroglota independiente y (121.222), bimbirimbao heteroglota en juego.

${ }^{57}$ Vega: La lengüeta esta fija al marco.

${ }^{58}$ Vega: En forma de tabla o peine punteado. Las lengüetas están atadas a una tabla o recortadas en una tabla como dientes de peine.

${ }^{59}$ Vega: Con lengüetas atadas.

${ }^{60}$ Vega: Todas las zansas de una tabla simple.

${ }^{61}$ Vega: Todas las zansas con caja o plato bajo la tabla.

${ }^{62}$ Vega: Con lengüetas cortadas: cajitas de música.

${ }^{63}$ Vega: Idiófono de frotación se pone en vibración el instrumento por frotación.

${ }^{64}$ Vega: (131.1) independiente, sin ejemplos conocidos y (131.2) en juego, que subdivide en (131.21) directo y (131.22) indirecto (violín de clavos y Chladnis Euphon).

${ }^{65}$ Vega: (132.1) independiente (serrucho frotado) y (132.2) en juego (Neumenklemburgo).

${ }^{66}$ Vega: Verillón.

${ }^{67}$ Vega: Idiófono de soplo. Se pone el instrumento en vibración por soplo.
} 


\title{
APÉNDICE
}

\section{Adaptación del sistema de clasificación organológica Sachs-Hornbostel}

\author{
141 PALO SOPLADO. ${ }^{68}$ \\ Idiófono soplado en forma de palo o bastón. \\ 142 PLACA SOPLADA. ${ }^{69}$ \\ Idiófono soplado en forma de placa. Piano cantor (Europa).
}

DIVISIÓN COMÚN FINAL DE LOS IDIOFONOS.

-8 con teclado; celesta, carillón con teclado (Europa).

-9 con acción mecánica; carillón mecánico, caja de música (Europa).

\section{MEMBRANÓFONO.}

Las membranas estiradas rígidamente, son las productoras del sonido. Es preciso un cuerpo rígido que reciba la tensión sin deformarse y un sistema de ensamblaje que mantenga la tensión en la membrana.

21 MEMBRANOFONO DE GOLPE.

Se golpean las membranas.

211 MEMBRANOFONO DE GOLPE DIRECTO. ${ }^{70}$

El ejecutante golpea la membrana con la mano o con un objeto.

211.1 (Membranófono de golpe directo semiesféricos) o TIMBAL. ${ }^{71}$

Con el cuerpo de forma semiesférica o de plato. El plato es cerrado: pequeñas aberturas no se toman en

cuenta. La forma se refiere a la cavidad interior, no a la forma exterior.

$2 \quad 11.11$ TIMBAL (independiente).

Cuerpo de madera (universal); kultrún (mapuche); timbal de pie (África, Europa). ${ }^{72}$

211.12 TIMBALES EN JUEGO.

Par de timbales unidos (Asia occidental). ${ }^{73}$

211.2 (Membranófono tubular) o TAMBOR.

El cuerpo tiene forma de tubo. El alto es mayor que el radio de la membrana.

$\begin{array}{lllllll}2 & 1 & 1 & 2 & 1 & \text { TAMBOR CILÍNDRICO. }\end{array}$

No se toma en cuenta el afinamiento de los extremos ni los aros de cabeza ni las irregularidades menores, por ejemplo del tronco ahuecado. ${ }^{74}$

$2 \begin{array}{llllll}2 & 1 & 1 & 2 & 1 & 1\end{array}$ TAMBOR CILÍNDRICO DE UN PARCHE. ${ }^{75}$

$\begin{array}{lllllllll}2 & 1 & 1 & 2 & 1 & 1\end{array}$. 1 TAMBOR CILÍNDRICO ABIERTO, DE UN PARCHE.

El extremo opuesto al cuero está abierto (Malaca, México); bongó (América); nuvuichiavatovan de tronco (Perú).

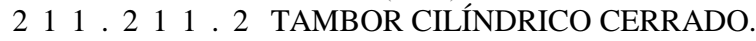

El extremo opuesto al cuero está cerrado. Si el interior es semiesférico, es timbal (India occidental).

211.212 TAMBOR CILÍNDRICO DE DOS PARCHES. ${ }^{76}$

El tambor tiene dos membranas útiles (que pueden ser golpeadas).

$\begin{array}{lllllllll}2 & 1 & 1 & 2 & 1 & 2\end{array} .1$ TAMBOR CILÍNDRICO DE DOS PARCHES (independiente).

$\begin{array}{lllllllllll}2 & 1 & 1 & 2 & 1 & 2 & . & 1 & 1 & \text { TAMBOR CILÍNDRICO GRANDE DE DOS PARCHES. } & \end{array}$

El parche tiene más de $20 \mathrm{~cm}$. de diámetro (una mano extendida).

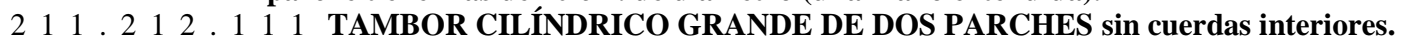

Tambor militar (Europa); kakekultrun (mapuche); wankara, aru, tambora, tarola, tampu, tampur, tambun, tampora, tambor de tronco ahuecado, sipitundu, tundu, xnjaansoni, juaitdiru, kon, fosxtoki, sixtoki, ticatadamanaja, tutu, toeto, kaxa, ixanagé, richuvu, richunuvuu, wasiona, toonto, tutu, lema, tampor (Perú); bombo (Perú, Argentina).

$\begin{array}{lllllllllll}2 & 1 & 1 & 2 & 1 & 2 & 1 & 1 & 2 & \text { TAMBOR CILÍNDRICO GRANDE DE DOS PARCHES con cuerdas interiores }\end{array}$ Algunos kakekultrun (williche, Chile); bombo de baile chino (Chile).

$\begin{array}{llllllll}2 & 1 & 1 & 2 & 1 & 2 & .1 & 2 \\ \text { TAMBOR CILÍNDRICO PEQUEÑO DE DOS PARCHES. }\end{array}$ El parche mide menos de $20 \mathrm{~cm}$. diámetro (una mano extendida). Caja, tinya (Perú, Argentina, Chile).

\footnotetext{
${ }^{68}$ Vega:). En bastones o palos (141.1) independiente, sin ejemplos conocidos y (141.2) en juego (piano eólico).

${ }^{69}$ Vega: (142.1) independiente, no conocido, y (142.2) en juego (piano cantor).

${ }^{70}$ Vega: El ejecutante mismo hace el movimiento del golpe; no se tienen en cuenta articulaciones mecánicas intermediarias, palillos conjuntos de teclas, etc., si existen. Los tambores que suenan únicamente por sacudimiento no entran aquí.

${ }^{71}$ Vega: Semiesféricos o en forma de plato (timbales-timbal) El cuerpo es de forma semiesférica o de plato.

${ }^{72}$ Vega: El timbal europeo.

${ }^{73}$ Vega: Los pares de timbales del Asia occidental siempre unidos.

${ }^{74}$ Vega: Diámetro de la mitad y diámetro terminal son iguales; el afinamiento de los extremos no se toma en cuenta; tampoco los aros de cabeza.

${ }^{75}$ Vega: De un cuero.

${ }^{76}$ Vega: De dos cueros.

${ }^{77}$ Tanto esta subdivisión como la (211.212.12) que se diferencian por tamaño, se basa en un criterio arbitrario pero permite subdividir un grupo muy numeroso y variado en América, que tiene correlato en las subdivisiones vernáculas. Nueva categoría.
} 


\section{APÉNDICE \\ Adaptación del sistema de clasificación organológica Sachs-Hornbostel}

$\begin{array}{llllllll}2 & 1 & 1 & 1 & 2 & 1\end{array} .2$ TAMBORES CILÍNDRICOS EN JUEGO, DE DOS PARCHES.

Tuntún, tambora, par de tambores de tronco ahuecado de diferente tamaño, tamporo de varios

tamaños (Perú).

211.22 TAMBOR EN FORMA DE BARRIL. ${ }^{78}$

El diámetro medio es más grande que el diámetro terminal, de perfil curvo (Asia, África); tumbadora (América).

211.23 TAMBOR EN FORMA DE DOBLE CONO. ${ }^{79}$

El diámetro medio es más grande que los diámetros terminales; de perfil romboidal (India).

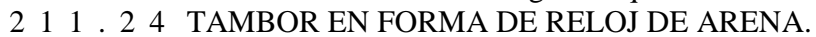

El diámetro del medio es más chico que los diámetros terminales (Asia), ${ }^{80}$ unu tinya (Perú, Arica prehispánico).

211.25 TAMBOR CÓNICO.

Los diámetros terminales son notablemente desiguales; las desigualdades pequeñas no se pueden tener en cuenta porque son inevitables (Asia, África), ${ }^{81}$ tambor de botija, tumba (Perú).

211.26 TAMBOR DE COPA.

El cuerpo consiste en una media esfera o cilindro con un pie más delgado. Si el interior es cerrado, es timbal (211.1) o tambor cerrado (211.211.2) (Medioriente, Norte del África). ${ }^{82}$

211.3 (Membranófono de marco) o CAJA. ${ }^{83}$

La altura del cuerpo es igual o inferior al radio de la membrana.

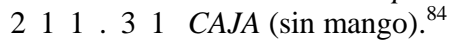

211.311 CAJA DE UN PARCHE. ${ }^{85}$

Pandereta o pandero (Norteamérica, Perú, Chile).

211.312 CAJA DE DOS PARCHES. ${ }^{86}$

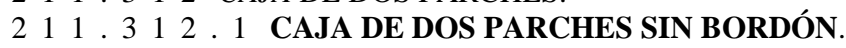

Bordón es un elemento que vibra junto al parche (universal); caja, tinya, tamborcito, didin (Perú, Argentina, Bolivia, Chile).

211.312 .2 CAJA DE DOS PARCHES CON BORDÓN. ${ }^{87}$

211.32 CAJA CON MANGO.88

(Europa, América), caja roncadora (Perú); caja carnavalera (Argentina).

En el marco hay un mango en el sentido del diámetro (Norteamérica).

212 MEMBRANOFONO DE GOLPE INDIRECTO. ${ }^{89}$

El tambor es sacudido; el sonido resulta del entrechoque de objetos encerrados o atados. El sonido es confuso,

no nítido ${ }^{90}$. (Subdivisión como la de los tambores de golpe directo).

$\begin{array}{llllll}2 & 1 & 2 & 1 & \text { TIMBAL SONAJA. }\end{array}$

Kultrún (usado ocasionalmente como sonajero, mapuche).

$\begin{array}{llllll}2 & 1 & 2 & 2 & 2 & \text { TAMBOR SONAJA. }\end{array}$

$\begin{array}{lllll}2 & 1 & 2 & . & 3 \\ \text { CAJA SONAJA. }\end{array}$

22 MEMBRANOFONO PUNTEADO.

Bajo el centro del cuero hay una cuerda anudada; esta cuerda se puntea y ella transmite vibraciones al cuero ${ }^{91}$. (India). ${ }^{92}$

\footnotetext{
${ }^{78}$ Vega: Barril. El diámetro medio es más grande que el diámetro terminal; el cuerpo esta abovedado. Asia, África, Antiguo México.

${ }^{79}$ Vega: Doble cono. El diámetro medio es más grande que los diámetros terminales; el cuerpo tiene una pared recta, con una línea de perfil quebrada Indias anteriores (Mrdanga, Banyâ, pakhavâja).

${ }^{80}$ Vega: Asia, Melanesia, África oriental.

${ }^{81}$ Vega: India.

${ }^{82}$ Vega: El cuerpo del tambor consiste en una parte principal de en forma de media esfera o cilindro y de una parte añadida mas delgada. Modificaciones de la forma fundamental, como las que existen especialmente en indonesia, no cambia el concepto, siempre que no se llegue a la forma cilíndrica. Darabuckle.

${ }^{83}$ Vega: De marco. La altura del cuerpo es, a lo sumo igual al radio del cuero. N.B. El tambor militar europeo tiene su origen, aun en sus ejemplares más chatos, en el tambor cilíndrico; por eso no se cuenta entre los tambores de marco.

${ }^{84} \mathrm{La}$ tendencia de las cajas en el mundo es a carecer de mango. Salvo indicación contraria, se entiende su ausencia.

${ }^{85}$ Vega: De un cuero.

${ }^{86}$ Vega: De dos cueros.

${ }^{87}$ Nueva categoría.

${ }^{88}$ Vega: 211.321 De un cuero. Esquimales. 211.322 De dos cueros. Tibet.

${ }^{89}$ Vega: [de golpe indirecto]. tambores sonajeros (subdivisión como la de los tambores de golpe directo). El tambor es sacudido; la percusión se realiza por golpeteo de las bolitas atadas o encerradas, o por cosa análoga Indias, Tibet.

${ }^{90}$ Los objetos encerrados en los membranófonos andinos, de significado ritual o mágico, que suenan ocasionalmente de modo semejante al bordón, no entran dentro de esta categoría, a no ser de que el ejecutante los sacuda como sonajero.

${ }^{91}$ Este tipo de instrumento actúa como cordófono: suena como tal, se tañe como tal y cumple las funciones de éstos. Sin embargo, la inexistencia de un sistema de tensión (que aquí cumple el brazo del ejecutante) obligaría a crear una jerarquía nueva entre los cordófonos, opuesta a (31) y (32), lo cual obliga a cambiar todo el sistema subsiguiente. Para evitar esta situación optamos por dejarlo como está.

${ }^{92}$ Vega: India (Copî-yantra, Anandalahahi).
} 


\section{APÉNDICE \\ Adaptación del sistema de clasificación organológica Sachs-Hornbostel}

23 (Membranófono de frotación) o TAMBOR FROTADO.

El cuero se pone en vibración por fricción.

231 TAMBOR FROTADO CON PALO.

Un palo unido al cuero se frota, o frota al cuero.

231 . 1 TAMBOR FROTADO CON PALO ATRAVESADO.

El palo penetra en el cuero.

231.11 TAMBOR FROTADO CON PALO ATRAVESADO FIJO.

El palo no puede moverse; se frota solamente el palo (África).

231.12 TAMBOR FROTADO CON PALO ATRAVESADO MEDIO LIBRE.

El palo puede moverse solamente un poco; la mano frota al palo y el palo al cuero (África).

231 . 13 TAMBOR FROTADO CON PALO ATRAVESADO LIBRE.

El palo se mueve y frota el cuero (Europa). ${ }^{93}$

231 . 2 TAMBOR FROTADO CON PALO SUPERPUESTO. ${ }^{94}$

El palo está atado encima del cuero parado de punta (Europa).

232 TAMBOR FROTADO CON CUERDA.

Una cuerda unida al cuero se frota.

232 . 1 TAMBOR FROTADO CON CUERDA FIJA.

El tambor esta inmóvil.

232.11 TAMBOR FROTADO CON CUERDA FIJA, DE UN CUERO.

Europa, África.

231.12 TAMBOR FROTADO CON CUERDA FIJA, DE DOS CUEROS.

232 . 2 TAMBOR FROTADO CON CUERDA GIRATORIA.

El tambor gira y la cuerda se frota en una muesca del mango que hace de eje (Europa, India, África oriental).$^{95}$

233 TAMBOR FROTADO A MANO. ${ }^{96}$

Se frota el cuero con la mano. Pandereta de cueca (Chile).

24 (Membranófono de soplo) o MIRLITON.

La membrana se pone en vibración por soplo o por emisión de sonidos o palabras ${ }^{97}$ (Europa, África occidental), hoja de árbol (Ecuador). 98

241 MIRLITON SIN RESONADOR. ${ }^{99}$

Papel de seda sobre un peine (Europa), hoja vegetal o plástica sobre los labios cuando vibra al cantar (al tañerla es aerófono libre, lengüieta labial). Tajitu, hoja vegetal (Perú)

242 MIRLITON CON RESONADOR. ${ }^{100}$

La membrana está en el interior de un tubo caja (África). Wititi, gamitara (Perú).

DIVISIÓN COMÚN FINALDE LOS MEMBRANOFONOS.

-5 Con posibilidad de variar la tensión durante la ejecución. ${ }^{101}$. Esta acción permite modular la altura tonal y crear melodías, ya sean afinadas con precisión o no (sensación de timbre de rango tonal).

-51 Tensión manual en membrana. El centro del parche tiene un material adherido que permite definir el tono. La mano, al presionar el parche, eleva ese tono (tabla hindú).

-52 Abertura en cuerpo. Una abertura lateral del cuerpo es obturada con la mano alterando la altura del tono. (timbal maya).

-53 Tensión atadura.

-531 Sin maquinaria. Una correa presiona la atadura, elevando la altura del tono (tambor parlante hindú).

-532 Con maquinaria.

-5321 Sin pedales (tambor europeo).

-5322 Con pedales (timbal de maquina).

\footnotetext{
${ }_{93}^{93}$ Vega: El palo se mueve libremente; no se frota el palo, sino que el palo excluidamente frota el cuero. Venezuela.

${ }^{94}$ Vega: Con palo atado encima.

${ }^{95}$ Vega: El tambor gira y la cuerda se frota en una muesca del mango. Waldteufel (Europa, India, África oriental).

${ }_{97}^{96}$ Sería más correcto subdividir en frotado directo (a mano) versus frotado indirecto (con palo o cuerda).

${ }^{97}$ Vega: la membrana no da ningún sonido propio, sino que modifica la voz. Sin embargo la hoja de árbol soplada emite sonidos propios.

${ }^{98}$ Vega: membranófonos de voz humana. (Mirlitones). La membrana se pone en vibración por la emisión de sonidos o palabras; el cuero no da ningún sonido propio, sino que modifica la voz. Europa, África occidental.

${ }^{99}$ Vega: "Mirlitones libres". Se influye directamente sobre la membrana, sin que el viento se acumule en un depósito. El papel de seda encima de un peine.

${ }^{100}$ Vega: Mirlitones de tubos y vasos. La membrana está en el interior de un tubo caja. África; también las flautas de Asia oriental en las cuales un agujero lateral obturado con una membrana pegada, representa contaminaciones con el principio de Mirlitón de tubos.

${ }^{101}$ Nueva categoría. Incluimos esta sección debido a la incidencia en la música que tiene la acción de modular los tonos del instrumento.
} 


\section{APÉNDICE \\ Adaptación del sistema de clasificación organológica Sachs-Hornbostel}

-6 Cuero pegado.

-7 Cuero clavado. Excepcional, kultrún y kakekultrún mapuche histórico.

-8 Cuero atado.

-81 Atadura de soga o correa. ${ }^{102}$

-811 Atadura simple. ${ }^{103}$ Las ataduras corren de cuero a cuero en zig-zag o forman una red sin utilizar ninguno de los dispositivos que siguen (Universal).

-812 Atadura con ligadura de tensión. Sogas transversales tensan las ataduras (Ceilán, kultrún mapuche). ${ }^{104}$

-813 Con anillos de tensión. Pequeños anillos o presillas unen cada dos ataduras, tensándolas (Europa, India). ${ }^{105}$

-814 Con cuñas de tensión. Entre la pared del tambor y las ataduras se calzan cuñas cuya posición puede regular la tensión ${ }^{106}$ (India, Indonesia, África).

82 Atadura soga-cuero. Las sogas están atadas abajo de un cuero que no suena (África). ${ }^{\mathbf{1 0 7}}$

83 Atadura soga-tabla. Las sogas están atadas abajo de una tabla (Sumatra). ${ }^{\mathbf{1 0 8}}$

84 Atadura soga-rodete. Las sogas están atadas bajo de un rodete (África). ${ }^{109}$

85 Atadura soga-cinturón. Las sogas están atadas abajo a un cinturón de otro material (India).

86 Atadura de soga-estaca. Las sogas están atadas abajo de estacas que están metidas en el costado del cuerpo (África).

-9 cuero apretado. Sobre el borde de la piel hay un anillo que lo ciñe. ${ }^{110}$

91 Apretamiento de soga (Andes). ${ }^{11}$

92 Apretamiento de arco (África). ${ }^{112}$

\section{CORDÓFONO.}

Una o varias cuerdas estiradas rígidamente son las productoras del sonido. Es preciso, al igual que en los membranófonos, un cuerpo rígido que reciba la tensión sin deformarse y un sistema de ensamblaje que resista esa tensión. ${ }^{113}$

31 (Cordófono simple) o CÍTARA.

El instrumento consiste en un porta-cuerdas solo, o con un cuerpo de resonancia separables sin destruir la tensión de la cuerda. ${ }^{114}$

311 CÍTARA DE PALO.

El porta-cuerdas tiene forma de palo o una tabla puesta de filo. ${ }^{115}$

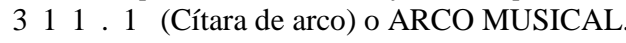

El porta cuerdas es un palo flexible (y curvo).

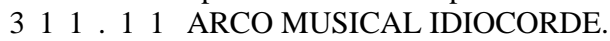

La cuerda ha sido desprendida de la corteza del palo y queda sujeta al arco en los extremos.

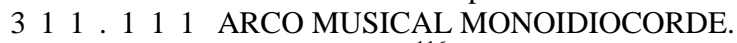

De una cuerda ${ }^{116}$ (Nueva Guinea, Togo)

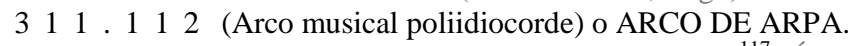

Varias cuerdas sobre un puente dentado ${ }^{117}$ (África occidental).

$\begin{array}{llllll}3 & 1 & 1 & 1 & 2 & \text { ARCO MUSICAL HETEROCORDE. }\end{array}$

La cuerda es añadida al arco. ${ }^{118}$

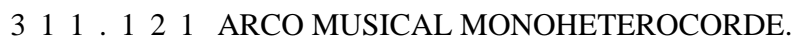

El arco tiene una sola cuerda de materia extraña a la del arco.

$\begin{array}{lllllllll}3 & 1 & 1 & 1 & 2 & 1\end{array}$. 1 ARCO MUSICAL MONOHETEROCORDE (sin resonador). ${ }^{119}$

\footnotetext{
${ }^{102}$ Vega: Las ataduras corren de cuero a cuero o forman una red sin utilizar ninguno de los dispositivos que siguen.

${ }^{103}$ Vega: Sin aparato especial de tensión.

${ }^{104}$ Vega: Bandas transversales se colocan en el dispositivo para estirar.

${ }^{105}$ Vega: Las ataduras corren en zig-zag; cada dos tiros se unen por medio de un pequeño anillo o presilla.

${ }^{106}$ Vega: Entre la pared del tambor y las ataduras se calzan cuñas cuya posición puede regular el dispositivo de tensión.

${ }^{107}$ Vega: Las sogas están atadas abajo a un cuero que no se utiliza.

${ }^{108}$ Vega: Las sogas están atadas abajo a una tabla suplementaria.

${ }^{109}$ Vega: Las sogas están atadas bajo de un rodete añadido.

${ }^{110}$ Vega: África.

${ }^{111}$ Vega: Tambor europeo.

${ }^{112}$ Vega: Timbal de máquina. Además subdivide esta categoría en (921) Sin maquinaria, (922) Con maquinaria,( 9221) Sin pedales, (9222) Con pedales, que nosotros incluimos en (-532), (-5321/2)

${ }^{113}$ Vega: Una o varias cuerdas están tendidas entre puntos fijos.

${ }^{114}$ Vega: El instrumento consiste en un porta-cuerdas solo, o en un porta-cuerdas y un cuerpo de resonancia en cohesión inorgánica, separables sin destrucción del aparato musical.

${ }^{115}$ Vega: El porta-cuerdas tiene forma de palo; también las tablas puestas de filo pertenecen a ésta.

${ }^{116}$ Vega: El arco tiene una sola cuerda del mismo palo.

${ }^{117}$ Vega: El arco tiene varias cuerdas del palo propio, conducidas sobre un puente dentado.

${ }^{118}$ Vega: La cuerda es de otra materia que el arco.
} 


\section{APÉNDICE \\ Adaptación del sistema de clasificación organológica Sachs-Hornbostel}

La boca [humana] no se considera como resonador. ${ }^{120}$

$\begin{array}{llllllll}3 & 1 & 1 & 1 & 2 & 1 & 1 & 1\end{array}$ ARCO MUSICAL MONOHETEROCORDE SIN DIVISIÓN DE LA CUERDA. ${ }^{121}$

(África); kinkelkawe frotado de hueso, paupawen golpeado de madera y chinko soplado por viento de madera, (mapuches); kauka, tumag, tumank, tomangu, kabana, tsayantar, petont, tontorenzi, piompirintzi, pegombirinchi, yosokopi, jijiti, trompa, junoranti, yoiri, catiruhuu, tin, oxri (Perú).

$\begin{array}{llllllll}3 & 1 & 1 & 1 & 2 & 1\end{array} .12$ ARCO MUSICAL MONOHETEROCORDE CON DIVISIÓN DE LA CUERDA. ${ }^{122}$ Un hilo abraza la cuerda y la divide en dos partes (África Sudecuatorial).

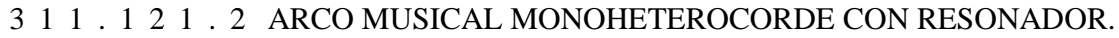

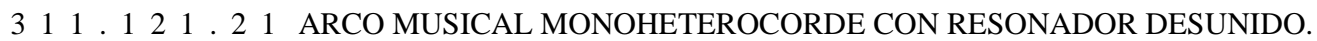
El resonador está unido al arco de manera provisoria (Borneo) con división de hilo (Tanzania), Arco musical sobre un recipiente (Sudáfrica).

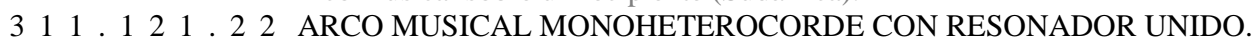

El resonador esta fijo permanentemente al arco. Borneo.

$\begin{array}{lllllllll}3 & 1 & 1 & 1 & 2 & 1 & 2 & 2 & 1\end{array}$ ARCO MUSICAL MONOHETEROCORDE CON RESONADOR UNIDO SIN DIVISIÓN DE LA CUERDA ${ }^{123}$.

(Sudáfrica); con clavija para afinar (India, Tailandia).

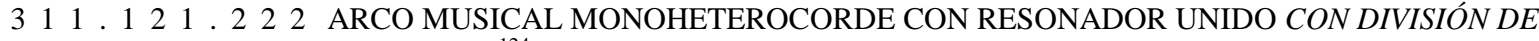
LA CUERDA. ${ }^{124}$

Un hilo u otro elemento divide la cuerda en dos. Con hilo (África); el resonador divide (Kenia); un palo divide (Molucas).

311.122 ARCO MUSICAL POLIHETEROCORDE.

$\mathrm{El}$ arco tiene varias cuerdas de otra materia que el cuerpo.

$\begin{array}{lllllll}3 & 1 & 1 & 1 & 2 & 2 & 1\end{array}$ ARCO MUSICAL POLIHETEROCORDE SIN DIVISIÓN DE LA CUERDA. ${ }^{125}$

(Oceanía) con clavijas para afinar (Tailandia).

$\begin{array}{lllllll}3 & 1 & 1 & 1 & 2 & 2 & \text { ARCO MUSICAL POLIHETEROCORDE CON DIVISIÓN DE LA CUERDA. } \\ & & \end{array}$

311.2 CITARA DE PALO RÍGIDO. ${ }^{127}$

El porta-cuerdas es rígido.

$\begin{array}{lllllll}3 & 1 & 1 & 2 & 1 & \text { ARCO-PALO MUSICAL. }\end{array}$

El porta-cuerdas tiene un extremo flexible y curvo. Los palos musicales con dos extremos flexibles y curvos se incluyen entre los arcos musicales (Indochina).

311.22 PALO MUSICAL. ${ }^{128}$

Un palo rígido soporta las cuerdas. El bastón de caña hueco por casualidad es cítara de palo; si la cavidad del tubo se usa como resonador, es cítara de tubo.

$\begin{array}{llllll}3 & 1 & 1 & 2 & 2 & 1\end{array}$ PALO MUSICAL SIN RESONADOR O CON UN RESONADOR. ${ }^{129}$

(India, Célebes); charrango de palo, de tabla o de árbol (mapuche).

311.222 PALO MUSICAL CON VARIOS RESONADORES. ${ }^{130}$

(India).

312 CÍTARA DE TUBO.

El porta-cuerdas es un tubo. ${ }^{131}$

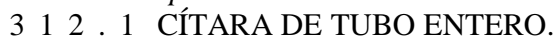

$\begin{array}{llllll}3 & 1 & 2 & 1 & 1 & 1 \\ \text { CÍTARA IDIOCORDE DE TUBO. }\end{array}$

Cuerda recortada. (África, Indonesia); de una cuerda (N Britania); de varias cuerdas (N Guinea,

Yugoeslavia), otta, titiri (Perú).

312.12 CÍTARA HETEROCORDE DE TUBO. ${ }^{132}$

\footnotetext{
119 Salvo definición contraria, se entiende que la opción válida es "sin resonador".

${ }^{120}$ Vega: N.B. si se emplea un resonador no unido al aparato mismo, el instrumento pertenece al $n^{\circ} 311.121 .21$. La boca [humana] no se considera como resonador.

${ }^{121}$ Vega: Sin corredera vocal. África (Ganza, Samuius, To).

${ }^{122}$ Vega: Con corredera. Una corredera de hilo abraza la cuerda y la divide en dos partes. África sudecuatorial (N'kungo,Uta).

${ }^{123}$ Vega: Sin corredera. Sudáfrica (Hade,Thomo).

${ }^{124}$ Vega: Con corredera. Sudáfrica y Madagascar (Gubo, Hungo, Bobre).

${ }^{125}$ Cambiamos "corredera vocal" por "división de la cuerda". Vega: Sin corredera vocal. Oceanía (Kalove).

${ }^{126}$ Vega: Con corredera vocal. Oceanía (Pagolo).

${ }^{127}$ Vega: Palos musicales.

${ }^{128}$ Vega: Palos musicales verdaderos. N.B. Los bastones de caña que están huecos por casualidad pertenecen por eso, no a las citaras de tubos, sino a las citaras de palos; pero los instrumentos en los cuales se usa la cavidad del tubo como resonador verdadero, son citaras de tubos, como, por ejemplo, el arpa neomexicana.

${ }^{129}$ Vega: Con una sola calabaza como resonador. India (Tuila), Célebes (Suleppe).

${ }^{130}$ Vega Con varias calabazas como resonador. India (Vînâ).

${ }^{131}$ Vega: El porta-cuerdas es una tabla abovedada en sentido del ancho.

${ }^{132} \mathrm{SH}$ mencionan dos subdivivisiones de cítara heterocorde de tubo: (312.121) de tubo simple y (312.122) tubo en que en el espacio internudal del bambú está metido en una hoja de palmera atada en forma de recipiente (Timor).
} 


\section{APÉNDICE}

Adaptación del sistema de clasificación organológica Sachs-Hornbostel

$\begin{array}{llll}3 & 1 & 2 & 2 \\ \text { CÍTARA DE MEDIO TUBO. }\end{array}$

Las cuerdas corren sobre el lado convexo de una canaleta.

$\begin{array}{lllll}3 & 1 & 2 & 2 & 1\end{array}$ CÍTARA IDIOCORDE DE MEDIO TUBO.

Cuerda recortada.

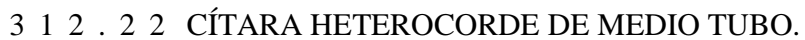

313 CÍTARA DE BALSA.

Cuerda atada. K'in, Koto (Asia Occidental).

El porta-cuerdas está formado de cortes de caña ligados entre sí en forma de balsa.

$\begin{array}{lllll}3 & 1 & 3 & 1 & 1 \\ \text { CÍTARA IDIOCORDE DE BALSA. }\end{array}$

Cuerda recortada (India, África central). ${ }^{133}$

$\begin{array}{lllll}3 & 1 & 3 & 2 & 2 \\ \text { CÍTARA HETEROCORDE DE BALSA. }\end{array}$

314 CÍTARA DE TABLA.

Cuerda atada (África). ${ }^{134}$

El porta-cuerdas es una tabla; también el suelo se considera como tal.

314.1 CÍTARA DE TABLA, CON CUERDAS PARALELAS. ${ }^{135}$

El plano de las cuerdas corre paralelo al porta-cuerdas.

314.11 CÍTARA DE TABLA, CON CUERDAS PARALELAS, SIN RESONADOR.

(Borneo, África).

314.12 CÍTARA DE TABLA, CON CUERDAS PARALELAS, CON RESONADOR.

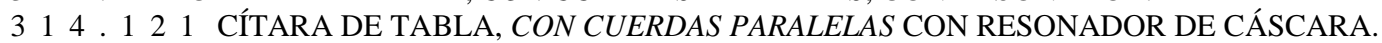

El resonador es una cáscara de fruta o de forma semejante (África). ${ }^{136}$

314.122 (cítara de tabla, con cuerdas paralelas con caja de resonancia) o CÍTARA DE CAJA

El resonador está compuesto de tablas. ${ }^{137}$

$\begin{array}{lllllll}3 & 1 & 4 & 1 & 2 & 2\end{array} .1$ CÍTARA DE CAJA PERCUTIDA.

Salterio (Europa, Medio Oriente, India); clavicordio, piano (Europa).

$\begin{array}{llllllll}3 & 1 & 4 & 1 & 2 & 2 & 2 & 2 \\ \text { CÍTARA DE CAJA PULSADA. }\end{array}$

Salterio clavecín, espineta (Europa).

$\begin{array}{llllllll}3 & 1 & 4 & 1 & 2 & 2\end{array} .3$ CÍTARA DE CAJA FROTADA.

$\begin{array}{llllllll}3 & 1 & 4 & 1 & 2 & 2\end{array} .4$ CÍTARA DE CAJA SOPLADA.

Arpa eólica (Europa).

314.2 CÍTARA DE TABLA DE CUERDAS VERTICALES. ${ }^{138}$

El plano de las cuerdas corre verticalmente respecto al porta-cuerdas.

314.21 CÍTARA DE TABLA DE UNA CUERDA VERTICAL. ${ }^{139}$

Una cuerda sujeta al suelo, resonador excavado en el suelo (África, Sudeste asiático).

314.22 CÍTARA DE TABLA DE VARIAS CUERDAS VERTICALES. ${ }^{140}$

315 CÍTARA DE CÁSCARA.

Las cuerdas corren sobre la abertura de una cáscara (África). ${ }^{141}$

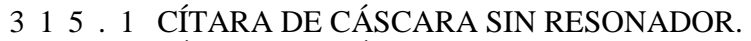

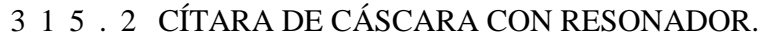

316 CÍTARA DE MARCO.

La cáscara está unida a una calabaza o semejante.

Las cuerdas están tendidas dentro de un marco.

316 . 1 CÍTARA DE MARCO SIN RESONADOR.

Quizá entre los salterios de la Edad Media.

316.2 CÍTARA DE MARCO CON RESONADOR.

(África occidental). ${ }^{142}$

32 CORDÓFONO COMPUESTO.

El instrumento consiste en un porta-cuerdas y un cuerpo de resonancia en coherencia orgánica, inseparables sin destrucción del aparato sonoro.

\footnotetext{
${ }^{133}$ Vega: India, Guinea superior, Congo central.

${ }^{134}$ Vega: Territorio del norte de Nyassa.

${ }^{135}$ Vega: De tablas verdaderas.

${ }^{136}$ Vega: El resonador es una cáscara de fruta o cosa semejante; luego, un producto natural, o - si se hace artificialmente - tallado.

Territorio de Nyassa.

${ }^{137}$ Vega: Cítara, Hackbrett, piano.

${ }^{138}$ Vega: De tablas (falsas).

${ }^{139}$ Vega: De suelo. El porta-cuerdas es el suelo; una cuerda. Malaca, Madagascar.

${ }^{140}$ Vega: De arpa.

${ }^{141}$ Vega: África oriental [ex] alemana.

${ }^{142}$ Vega: Entre los Kru, África occidental (Kani).
} 


\section{APÉNDICE \\ Adaptación del sistema de clasificación organológica Sachs-Hornbostel}

321 (cordófono compuesto de cuerdas paralelas) o LAÚD.

El plano de las cuerdas corre paralelo a la tapa.

$\begin{array}{llll}3 & 2 & 1 & 1\end{array}$ LAÚD DE ARCO.

Cada cuerda tiene su propio portador flexible (África). ${ }^{143}$

321.2 (laúd de yugo) o LIRA.

El porta-cuerdas es un yugo de dos brazos con travesaño. ${ }^{144}$

321.21 LIRA DE CÁSCARA.

Como resonador sirve una cáscara natural o tallada (Medio Oriente, Europa del sur, Norte de África). ${ }^{145}$

321.22 LIRA DE CAJA.

Como resonador sirve una caja hecha de tablas (Europa, Medio Oriente, Norte de África). ${ }^{146}$

321.3 LAÚD DE MANGO.

El porta-cuerdas es un mango (o más). No se tienen en cuenta mangos secundarios como, por ejemplo en la prasârinî vînâ de India ni el yugo de adorno de las guitarras-liras. ${ }^{147}$

321.31 LAÚD DE MANGO ATRAVESADO. ${ }^{148}$

El mango atraviesa el cuerpo de resonancia.

321.311 LAÚD DE CÁSCARA, DE MANGO ATRAVESADO.

El cuerpo de resonancia es una cáscara natural o tallada pulsado (Medio Oriente, N África) frotado

(África, Medio Oriente, Asia sudoriental). ${ }^{149}$

321.312 (Laúd de caja, de mango atravesado) o GUITARRA DE PICO.

El cuerpo de resonancia es una caja de tablas. Frotado (África, Medio Oriente). ${ }^{150}$

321.313 LAÚD DE TUBO, DE MANGO ATRAVESADO.

El mango atraviesa un tubo. Frotado (China). ${ }^{151}$

321.32 LAÚD DE MANGO AÑADIDO.$^{152}$

El mango está tallado o añadido como cuello al cuerpo de resonancia.

321.321 LAÚD DE CÁSCARA, DE MANGO AÑADIDO

Los laúdes cuyo cuerpo está hecho de trozos o astillas imitando las cáscaras (Europa, Medio Oriente, Asia Oriental) ${ }^{153}$

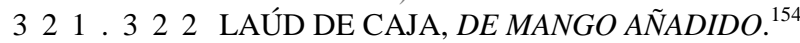

$\begin{array}{lllllll}3 & 2 & 1 & 3 & 2 & 2\end{array} .1$ (laúd pulsado de caja, de mango añadido) o GUITARRA.

Guitarra, mandolina (España, América); cavaquiña (Brasil); requinto, bandola, bandurria, tiple (Perú); charango (Bolivia); guitarrón (Chile).

$\begin{array}{llllll}3 & 2 & 1 & 3 & 2 & 2\end{array}$ (laúd frotado de caja, de mango añadido) o VIOLÍN,

322 ARPA.

Violín; viola da gamba; kitag, aravir, kitiar, kampana (Perú).

El plano de las cuerdas es vertical respecto a la tapa y la línea en que se sujetan las puntas inferiores de las cuerdas corre en dirección al cuello.

322 . 1 ARPA ABIERTA O DE MÁSTIL. ${ }^{155}$

El arpa no tiene estaca anterior.

322.11 ARPA DE ARCO.

De cuello flexible ${ }^{156}$ (Birmania, África).

322.12 ARPA DE ÁNGULO.

El cuello rígido esta en ángulo respecto del cuerpo (Europa Sur, África, Asia sudoriental). ${ }^{157}$

322.2 ARPA DE MARCO.

$\mathrm{El}$ arpa tiene una estaca anterior.

${ }^{143}$ Vega: África (Akam, Kalangu, Wambi).

${ }^{144}$ Vega: El porta-cuerdas es un yugo de dos brazos con travesaño, colocado en el plano de la tapa.

${ }^{145}$ Vega: Lira, lira del África occidental.

${ }^{146}$ Vega: Kithara, Crwth.

${ }^{147}$ Vega: El porta-cuerdas es un simple mango. No se tienen en cuenta mangos secundarios como, por ejemplo en la Prasârinî Vînâ India. También pertenecen a ésta los laúdes cuyo encordado está repartido en varios cuellos - como el arpa-lira - y laúdes - por ejemplo, las guitarras-liras - en los cuales el yugo tiene valor de adorno.

${ }^{148}$ Vega: De pico. El mango está puesto diametralmente a través del cuerpo de resonancia.

${ }^{149}$ Vega: Persia, India e Indonesia.

${ }^{150}$ Vega: Egipto (Rebâb).

${ }^{151}$ Vega: El mango esta puesto diametralmente a través de un tubo. China e Indochina.

${ }^{152}$ Vega: De cuello.

${ }^{153}$ Vega: Mandolín, Tiorba, Balalaika.

${ }^{154}$ Vega: De cuello, de caja o guitarras de cuello. N.B. Los laúdes cuyo cuerpo está hecho de rozos o astillas imitando las cáscaras, se incluyen entre los laúdes de cáscaras. Violín, Gamba, Guitarra.

${ }^{155}$ de mástil sugiere la existencia de una estaca anterior la que, justamente, por su ausencia caracteriza este grupo. Por eso añadí la palabra "abierto" que me parece más descriptiva.

${ }_{156}^{15}$ Vega: El cuello se curva alejándose del cuerpo.

${ }^{157}$ Vega: El cuello está quebrado; se aleja del cuerpo. Siria; Egipto y Corea antiguos. 


\title{
APÉNDICE
}

\section{Adaptación del sistema de clasificación organológica Sachs-Hornbostel}

\author{
322.21 ARPA DE MARCO DE AFINACIÓN FIJA. ${ }^{158}$ \\ Todas las arpas de la Edad Media. \\ $\begin{array}{lllllll}3 & 2 & 2 & 2 & 1 & 1 & \text { ARPA DE MARCO DIATÓNICA. }\end{array}$ \\ (Europa, Andes, Paraguay).

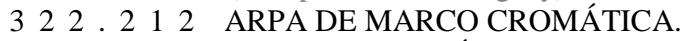 \\ $\begin{array}{lllllll}3 & 2 & 2 & 2 & 1 & 2\end{array} .1$ ARPA CROMÁTICA CON UN PLANO DE CUERDAS. \\ (Europa). \\ $\begin{array}{llllll}32 & 2 & 2 & 1 & 2\end{array} .2$ ARPA CROMÁTICA CON DOS O MÁS PLANOS DE CUERDAS. ${ }^{159}$ \\ Arpa cromática de Lyon; de tres planos de cuerdas (Europa) \\ 322.22 ARPA DE MARCO DE AFINACIÓN VARIABLE. ${ }^{160}$ \\ La afinación de las cuerdas puede ser variada por un mecanismo. \\ 322.221 ARPA CON CLAVIJA MANUAL. ${ }^{161}$ \\ Las cuerdas cambian de afinación por acción manual. (Europa). \\ 322.222 ARPA CON PEDAL. \\ 323 LAÚD-ARPA. \\ Las cuerdas cambian de afinación por acción del pie. Arpa actual de concierto (Europa) \\ El plano de las cuerdas es perpendicular a la tapa, y la línea de inserción de las cuerdas paralelo al cuello; \\ puentecillo dentado ${ }^{162}$ (N. África, Camerún). \\ DIVISIÓN COMÚN FINAL. \\ - 4 Percutido con martillo o palitos. \\ - 5 Pulsado. ${ }^{163}$ \\ - 6 Punteado con plectro. \\ -7 Frotado. \\ - 71 Con arco. \\ - 72 Con rueda. \\ - 73 Con cinta. \\ - 8 Con teclado. \\ - 9 Con acción mecánica.
}

4 AERÓFONO.

El aire es puesto en vibración a través de un flujo continuo del mismo aire. ${ }^{164}$

41 AERÓFONO SIN RESONADOR. ${ }^{165}$

El aire vibrante no está limitado por el instrumento.

411 AERÓFONO DE DESVIACIÓN.

El viento choca contra un filo, (o un filo es movido a través del aire) y produce el sonido. ${ }^{166}$ Látigo, hoja de sable, zumbayllo zumba, waraka (Perú)

412 AERÓFONO DE INTERRUPCIÓN.

La corriente de viento sufre interrupción periódica, produciéndose un sonido.

412.1 (Autófono) o LENGÜETA.

El viento pone en vibración una laminilla e interrumpe periódicamente el aire, produciendo el sonido. ${ }^{167}$

$4 \begin{array}{llllll}4 & 2 & 1 & 1 & \text { LENGÜETAS DE ENTRECHOQUE. } & \\ & & \end{array}$

El viento hace que dos laminillas se abran y cierren periódicamente. Tallo de gramínea hendido

(Medioriente).

412.12 LENGÜETA BATIENTE.

El aire hace que una laminilla golpee un marco, interrumpiendo periódicamente el paso del aire. ${ }^{169}$

\footnotetext{
${ }^{158}$ Vega: Sin aparato para modificar la afinación.

159 Vega: Con dos palos de cuerdas cruzados.

${ }^{160}$ Vega: Con aparato para modificar la afinación. Las cuerdas pueden ser estiradas por un mecanismo.

${ }^{161}$ Vega: A mano. Hakeharfe, Harpe ditale, Harpinella.

${ }^{162}$ Vega: El plano de las cuerdas corre verticalmente con respecto a la tapa y la línea que toma las puntas inferiores de las cuerdas corre verticalmente con respecto a la dirección del cuello; puentecillo dentado.

${ }^{163}$ Vega: Ejecución digital.

164 Vega: El aire mismo es, principalmente, puesto en vibración. En todos los casos el sonido es producido, en última instancia, por vibración del aire. En los aerófonos el aire es excitado directamente para que produzca el sonido, y no secundariamente como ocurre con la vibración de cuerdas, membranas o cuerpos sólidos.

165 Vega: Aerófonos libres.

${ }^{166}$ Vega: El viento choca contra un filo, o un filo es movido por el aire; en los dos casos se realiza, según opinión moderna, un deslizamiento periódico del aire sobre los lados del filo.

${ }^{167}$ Vega: La corriente del viento choca contra una laminilla; ésta se pone en vibración e interrumpe a la corriente periódicamente. Pertenecen a esta clase también las lengüetas con sobrecubiertas, es decir, tubos cuyo contenido de aire no vibra principal, sino secundariamente; que no producen sonido por sí mismos, sino que amplifican y modifican el timbre del sonido. Generalmente se conocen las sobre-cubiertas por la falta de agujeros de obturar. Las flautas de lengüeta del órgano.

${ }^{168}$ Vega: Laminillas de entrechoque. Dos laminillas forman una hendidura que se cierra periódicamente durante la vibración.
} 


\section{APÉNDICE \\ Adaptación del sistema de clasificación organológica Sachs-Hornbostel}

412.121 LENGÜETA BATIENTE (independiente).

(Columbia Británica).

412.122 LENGÜETAS BATIENTES EN JUEGO.

Se incluyen las lengüetas con sobrecubiertas, es decir, tubos cuyo contenido de aire no vibra principal, sino secundariamente; amplificando y modificando el timbre del sonido. Generalmente se conocen las sobre-cubiertas por la falta de agujeros de obturar. Los más antiguos juegos de flautas de lengüeta del órgano (Europa).

412.13 LENGÜETA LIBRE.

El aire hace que la lengüeta se mueva a través de una abertura exactamente igual a su tamaño interrumpiendo periódicamente el paso del aire. ${ }^{170}$

$\begin{array}{lllllll}4 & 1 & 2 & 1 & 3 & 1 & \text { LENGÜETA LIBRE (independiente) }\end{array}$

El antiguo claxon de automóvil.

$\begin{array}{lllllll}4 & 1 & 2\end{array} .132$ LENGÜETAS LIBRES EN JUEGO.

Armonio, armónica de boca, acordeones (Europa, América); sheng (Extremo Oriente). ${ }^{171}$

412.14 LENGÜETA DE CINTA.

El viento choca contra el filo de una cinta extendida. ${ }^{172}$ (Columbia Británica).

412 . 15 LENGÜETA LABIAL.

Se sopla contra una lámina puesta entre los labios. Hoja vegetal o plástica (universal), tajitu (Perú).

$\begin{array}{lllll}4 & 1 & 2 & 2 & 2 \\ \text { AERÓFONO DE INTERRUPCION NO AUTÓFONO. }\end{array}$

La interrupción periódica del aire se realiza sin intervención del aire.

$\begin{array}{llllll}4 & 1 & 2 & 2 & 1 & \text { AERÓFONO DE DESPLAZAMIENTO. }\end{array}$

El interruptor se desplaza en su propio plano. Sirena de agujeros, sirena de ondas.

412.22 AERÓFONO GIRATORIO.

El interruptor gira alrededor de su eje. Palo zumbador con un hilo (Universal); toro bramador, palo

zumbador, tsixtsi, plumas zumbadoras asu, fugadi, boribori, weeka, piruru, hedzako, reexe, toomo, naibiti, fauniotatek, runrún, hehtaidi, bufuna, (Perú), disco zumbador con dos hilos (Sudáfrica). ${ }^{173}$

413 AERÓFONO DE ALTERACION ${ }^{174}$

$\begin{array}{lllll}4 & 1 & 3\end{array} .1$ AERÓFONO DE EXPLOSIÓN.

El aire recibe un único choque de condensación. Cerbatana.

$\begin{array}{llll}4 & 1 & 3\end{array} .2$ AERÓFONO DE VIBRACIÓN.

Una cañería ranurada transversalmente, al ser soplada, emite la serie armónica por vibración de la columna de aire.

$\begin{array}{llll}4 & 1 & 3 & 3 \\ \text { AERÓFONO DE RUIDO. }{ }^{175}\end{array}$

una pequeña cavidad con dos agujeros es introducida en la boca produciendo un ruido característico, aun no entendido acústicamente (universal). De piedra (prehispánico: México). De madera, corteza o caparazón de tortuga: Pitu, piat, bisutotoja (Perú).

42 AERÓFONO CON RESONADOR. ${ }^{176}$

El aire vibrante está limitado por el instrumento mismo.

421 (aerófono de filo) o FLAUTA.

Una corriente de aire choca contra un filo.

421 . 1 (Flauta sin aeroducto) o PITO. ${ }^{177}$

El ejecutante mismo produce con los labios la corriente de aire en forma de cinta.

421 . 11 PITO LONGITUDINAL.

El ejecutante sopla contra el borde agudo de la abertura superior de un tubo.

$\begin{array}{lllllllll}4 & 2 & 1 & 1 & 1 & 1 & \text { PITO LONGITUDINAL (independiente). }{ }^{178}\end{array}$

$\begin{array}{lllllllll}4 & 2 & 1 & 1 & 1 & 1 & 1 & 1 & \text { (pito longitudinal abierto) o KENA. } \\ & & \end{array}$

El extremo inferior de la flauta está abierto.

$\begin{array}{llllllllllll}4 & 2 & 1 & 1 & 1 & 1\end{array} .11$ KENA sin agujeros de digitación.

\footnotetext{
${ }^{169}$ Vega: La laminilla golpea un marco.

${ }^{170}$ Vega: La lengüeta se mueve a través de una abertura exactamente igual a su tamaño.

${ }^{171}$ Vega: N.B Si existen agujeros para los dedos como en el Sen chino, éstos no sirven para la modificación de la altura tonal y, en consecuencia, no pueden ser considerados como agujeros de obturar.

${ }^{172}$ Vega: El viento choca contra el filo de una cinta extendida. El fenómeno acústico no se ha investigado hasta ahora.

${ }^{173}$ Vega: Palo zumbador, Disco zumbador, Ventilador de alas.

${ }^{174}$ Vega: Aerófono de explosión. La existencia de casos que no caben en la definición "aerófonos de explosión” obliga a crear una división general para todos ellos, y evitar así la multiplicación de categorías dedicadas a casos particulares, las que pueden aumentar con el tiempo. Si bien el nombre "aerófonos de alteración" no nos parece bueno, es el mejor que encontramos.

${ }^{175}$ Nueva categoría. De gran importancia en Mesoamérica (ver Velásquez 2003) y se encuentra al parecer en todo el mundo; en Chile detectado en Linares.

${ }^{176}$ Vega: Instrumentos de soplo.

${ }^{177}$ Vega: Sin canal de insuflación.

${ }^{178}$ Vega: Aisladas.

${ }^{179}$ Vega: divide esta categoría en dos: 421.111.11 Sin agujeros (Bengala), y 421.111.12 Con agujeros. (En casi todo el mundo).
} 


\title{
APÉNDICE
}

\section{Adaptación del sistema de clasificación organológica Sachs-Hornbostel}

\author{
Piwilkawe (prehispánico: diaguita), tutuca de hueso (prehispánico: mapuche),

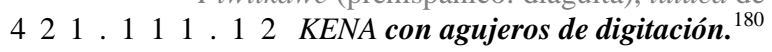 \\ Pinkulwe de caña (mapuche), kena de 3, a 9 agujeros de digitación: phalawata, mala-pusi-ppiani, \\ hilawata, quenacho, lawata, requiunto, pingollo, chaqallo, shilo, junjam, pijug, oja, wajia, tiripish, \\ peem, yakuch, pijug, gongonasi, perena, lauta, bilenja, kupim, noelo, spuxuna, pochiina, tsikaniu, \\ gagökato, dotdici, tepbi, pallot, soncari, cobwerentsi, sonkarinci, plawta, tumleji, totore, pifuana, \\ ta'kili, ksorkaxpo (Perú)
}

$\begin{array}{llllllllll}4 & 2 & 1 & 1 & 1 & 1\end{array}$. PITO LONGITUDINAL CERRADO.

El extremo inferior de la flauta está cerrado.

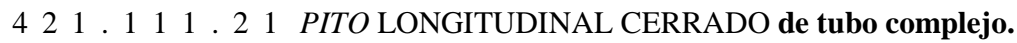
Pifilka (mapuche).

$\begin{array}{lllllllll}4 & 2 & 1 & 1 & 1 & 1 & 2 & 2 & \text { PITO LONGITUDINAL CERRADO de tubo simple. }\end{array}$

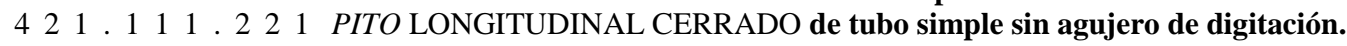

Piwilkawe (mapuche); kowi, paca de caña, (Perú).

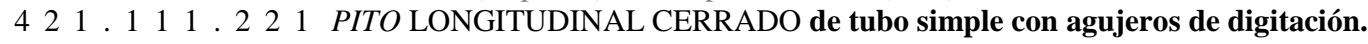

Piwulka, piwulka antropomorfa (premapuche; algunas presentan tubos adicionales al modo del piloilo).

421.112 (pitos longitudinales en juego) o FLAUTA DE PAN. ${ }^{181}$

Varias flautas longitudinales distintamente afinadas están unidas en un instrumento.

$\begin{array}{lllllllll}4 & 2 & 1 & 1 & 1 & 2\end{array} .1$ FLAUTA DE PAN ABIERTA. ${ }^{182}$.

Los tubos están abiertos. Se incluyen los tubos semicerrados.

$\begin{array}{llllllllll}4 & 2 & 1 & 1 & 1 & 2\end{array} .11$ FLAUTA DE PAN ABIERTA EN FORMA DE BALSA.

Las flautas se ligan una al lado de otra en hilera o metidas en una tabla (China).

$\begin{array}{llllllll}4 & 1 & 1 & 1 & 2\end{array} .12$ FLAUTA DE PAN ABIERTA EN FORMA DE PAQUETE.

Las flautas forman un atado redondo (Salomón, Archipiélago de Bismark).

$\begin{array}{lllllll}4 & 2 & 1 & 1 & 1 & 2\end{array} .2$ FLAUTA DE PAN CERRADA.

Los tubos están cerrados.

$\begin{array}{llllllllll}4 & 2 & 1 & 1 & 1 & 2 & . & 2 & 1 & \text { FLAUTA DE PAN CERRADA, DE UNA HILERA. }\end{array}$

$\begin{array}{lllllllllllllll}4 & 2 & 1 & 1 & 1 & 2 & 2 & 1 & 1 & \text { FLAUTA DE PAN CERRADA, DE UNA HILERA EN ESCALERA. } & \\ & & \end{array}$

Los tubos están ordenados de mayor a menor. Se incluyen los instrumentos que externamente tienen forma de balsa (con tubos de igual largo) pero cuyo largo interior está ordenado de mayor a menor.

$\begin{array}{lllllllllll}4 & 2 & 1 & 1 & 1 & 1 & 2 & . & 2 & 1 & 1\end{array}$. 1 FLAUTA DE PAN CERRADA, DE UNA HILERA EN ESCALERA, SOLISTA.

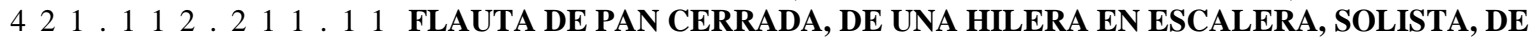
TUBO SIMPLE.

$\begin{array}{lllllllllllll}4 & 2 & 1 & 1 & 1 & 2 & 2 & 1 & 1\end{array} .111$ con corte en bisel.

la embocadura posee un corte en bisel. Zampoña de doble bisel, antara (Perú).

421.1122 .211 . 1112 sin corte en bisel.

Caña (Universal) siku, zampoña, antara, chacha, sarta, antecc, de 4 a 15 tubos (Bolivia,

Perú); teteco, niratuchi de 2 tubos; hetu de 2 a 3 tubos; orebi, siroro, tirhbakue 3 tubos; recarnets, totama 5 tubos; chofana 2 a 12 tubos; songari, tselo, de 3 a 13 tubos; tseko de 3 a 7 tubos; songarinchi de 4 a 6 tubos; yundadora 6 tubos; puicamanchi 7 y 8 tubos, kantash 8 tubos; hetupue, notiri, noxari, 10 tubos; seno, filo, urusa, yupana, 12 tubos; duunduumuta de 10 a 24 tubos (Perú).

$\begin{array}{lllllllllll}4 & 1 & 1 & 1 & 2 & 2 & 1 & 1\end{array} .12$ (Flauta de pan cerrada, de una hilera en escalera, solista, de tubo complejo) o ANTARA.

Son capaces de dar el llamado "sonido rajado"

$\begin{array}{lllllllllllll}4 & 2 & 1 & 1 & 1 & 2 & 2 & 1 & 1 & 1 & 2 & 1 & \text { ANTARA sin asa. }\end{array}$

Antara de cerámica (prehispánica; Paracas, Nazca)

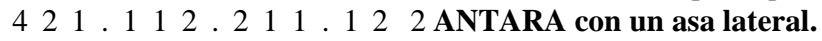

\footnotetext{
${ }^{180}$ Bolaños et al 1978 proponen subdivisiones según sin o con muesca / cantidad de agujeros de digitación / sin o con ag. Posterior / en algunos casos sin o con sonador. Sin embargo una gran cantidad de estas subdivisiones quedan vacías, por lo que no nos parece necesaria para nuestros propósitos.

${ }^{181}$ Vega: divide esta categoría en dos: 421.111.21 sin agujeros. (La llave hueca) y 421.111.22 Con agujeros. (Especialmente en Nueva Guinea).

${ }^{182}$ Bolaños et al 1978 insertan la categoría 421.111.2, medio tapadillo, de gran importancia en Perú. Hemos preferido dejarla fuera porque introduce un cambio importante en la numeración original, desvirtuando el uso universal que ha tenido el sistema SH hasta ahora, contra nuestro propósito. Creemos que este importante aporte debe explicitarse como parte de la categoría "abierta".

${ }^{183}$ Bolaños et al 1978 distinguen una categoría nueva como "rectangular", por la forma externa del instrumento, pero nos parece engañosa pues la conformación interna (organológica) sigue siendo en escalera, por eso no la hemos usado, sin desconocer su importancia regional como tipología.
} 


\section{APÉNDICE}

Adaptación del sistema de clasificación organológica Sachs-Hornbostel

Antara surandina (prehispánica, Tiwanaku, San Pedro, Santamaría, Diaguita, Aconcagua).

$\begin{array}{llllllllllll}4 & 2 & 1\end{array} .112 .211 .123$ ANTARA con un asa basal.

(premapuche).

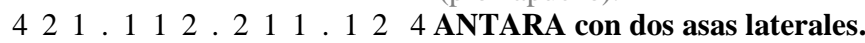

(premapuche).

$\begin{array}{lllllllllll}4 & 2 & 1 & 1 & 1 & 2 & . & 2 & 1 & 1\end{array}$. 2 FLAUTA DE PAN CERRADA, DE UNA HILERA EN ESCALERA, COLECTIVA.

Dos individuos tocan partes complementarias del mismo instrumento.

421.112 .211 .21 con corte en bisel.

La embocadura posee un corte en bisel. Antara menor (Perú).

$\begin{array}{llllllllllll}4 & 2 & 1 & 1 & 1 & 2 & 2 & 1 & 1 & 2 & 2 & \\ \text { sin corte en bisel. }\end{array}$

Siku, antara, antecc, phuco, pusa, de 5 a 12 tubos (Bolivia, Perú); laquitas (Chile); tabla siku de perfil rectangular (Perú).

$\begin{array}{lllllllll}4 & 2 & 1 & 1 & 1 & 2\end{array} .212$ FLAUTA DE PAN CERRADA, DE UNA HILERA EN ESCALERA ALTERNA.

los tubos se organizan de mayor a menor en dos series intercaladas

421.112 .212 .1 solista.

421.112 .212 .11 con corte en bisel. antara, parrilla de 8 a 30 tubos (Perú).

421.112 .212 .12 sin corte en bisel.

yuphana o rondadora de 29 y 32 tubos (Perú); rondadora (Ecuador).

421.112 .212 .2 colectivo.

$\begin{array}{llllllllll}4 & 2 & 1 & 1 & 1 & 2 & 2 & 1 & 3 & \text { FLAUTA DE PAN CERRADA, DE UNA HILERA EN DOBLE ESCALERA. }\end{array}$

Los tubos se disponen en forma de escaleras encontradas en forma de ala (se encuentran en los tubos menores) o en forma de pirámide invertida (se encuentran en los tubos mayores) (prehispánico Ecuador y Perú).

421.112 .213 (flauta de pan cerrada, de una hilera irregular) o PILOILO.

Los tubos se disponen de un modo irregular de acuerdo a su largo. Cada instrumento tiene una ordenación de tubos propia y distinta, de madera o piedra (prehispánico, mapuche).

$\begin{array}{lllllllll}4 & 2 & 1 & 1 & 1 & 2\end{array} .22$ FLAUTA DE PAN CERRADA, CON RESONADOR.

Una segunda hilera de tubos que no se soplan sirve como resonador, aumentando la respuesta tímbrica del instrumento. Normalmente el resonador es de tubo abierto, de igual longitud que el que se toca, pero los hay cerrados, de la mitad de tamaño; en ambos casos la respuesta es a una octava (puede ser desigualada).

421.112 .22 en escalera.

421.112 . 42121 solista.

Igual número de tubos que se tañen y resonadores antecc de chuncho de 5 y 7 tubos con resonador cerrado de mitad de tamaño, phuko de ayarichi y siku de 6 y 7 tubos con resonador

421.1122 .222 colectivo abierto de igual tamaño, tabla siku de perfil rectangular, 6 y 7 tubos (Perú).

Antecc de chuncho de 5 a 12 tubos (Perú).

$\begin{array}{lllllllll}4 & 2 & 1 & 1 & 1 & 2 & 2 & 3 & \text { FLAUTA DE PAN CERRADA, DE DOS HILERAS. }\end{array}$

Las dos hileras se tañen. Sikus modernos (S. XX), cromáticos. Piloilo (un caso único de dos

hileras en lados opuestos, premapuche).

421.12 (pito traverso) o FLAUTA TRAVERSA ${ }^{184}$

El ejecutante sopla contra el borde afilado de un agujero lateral del tubo.

421.1221 FLAUTA TRAVERSA (independiente) ${ }^{185}$

421 . 12 2 1 . 1 FLAUTA TRAVERSA ABIERTA. ${ }^{186}$.

(universal); pinkulwe (mapuche); kena traversa de 5 agujeros, palawita de 6 agujeros, pífano de 7 agujeros, pito de 8 agujeros, flauta de 9 agujeros (Perú).

421.121 .2 FLAUTA TRAVERSA SEMICERRADA. ${ }^{187}$

Con un agujero pequeño en el nudo terminal. N.O. de Borneo. Chuncho pito de 6 agujeros, traversera de 7 agujeros (Perú).

\footnotetext{
${ }^{184}$ Vega: Transversales.

${ }^{185}$ Vega: Aisladas.

${ }^{186}$ Vega divide en sin y con agujeros.

${ }^{187}$ Vega: Medio tapadillo.
} 


\title{
APÉNDICE \\ Adaptación del sistema de clasificación organológica Sachs-Hornbostel
}

\author{
421.1221 .3 FLAUTA TRAVERSA CERRADA. ${ }^{188}$ \\ $\begin{array}{lllllllll}4 & 2 & 1 & 1 & 2 & 1 & 3 & 1 & \text { FLAUTA TRAVERSA DE FONDO MÓVIL. } \\ & & \end{array}$ \\ Con tapón móvil (Malaca, Nueva Guinea); con bolita deslizante (Mesoamérica), \\ 421.121 .32 FLAUTA TRAVERSA CERRADA DE FONDO FIJO. \\ (Bengala, Malasia). De caña, pinkui, juam, tsabrak, nangku,tirotzi, puputsi, roxroko, penkoll, \\ jonkamentotzi, wa-koinarika, kurawi, boborara, auno (Peru) De caña cerrada en ambos extremos, \\ 421.122 FLAUTAS TRAVERSAS EN JUEGO. \\ embocadura central potamentosi (Perú), \\ 421.122 .1 FLAUTAS TRAVERSAS ABIERTAS EN JUEGO. \\ 421.122 .2 FLAUTAS TRAVERSAS CERRADAS EN JUEGO. ${ }^{190}$ \\ (Brasil) \\ 421.13 (Pito vascular) o FLAUTA GLOBULAR. ${ }^{191}$ \\ El ejecutante (o el aire) sopla contra el borde agudo de la abertura de un recipiente globular. La \\ geometría interior es la que define este grupo, no la exterior. cerámica (Sudamérica); piwullhue \\ (mapuche); toke (Perú); semillas (universal); batae, chiyumi, juido, cido, xroloxi, huiwe (Perú); de caracol \\ mutun (Perú); de cráneo de animal (Andes prehispánicos); de pinzas de cangrejo wawaako (Perú); trompo \\ zumbador, worampi, kantsupi, guatsoek, tolumpa, сhumu (Perú); flecha silbadora (prehispánica \\ Aconcagua); flecha zumbadora de caracol (Perú); trompo zumbador, tolumpa, chumuoaitoa, noago, \\ hotwidoje, puraraca, mokusitsapuraraka, sowiti, tsiyechi, runrún, dannenja, nguruyana, lomuni (Perú); \\ semillas de voleo (Perú); doble de cerámica havatachare (Perú).
}

421.2 (Flauta con aeroducto) o SILBATO. ${ }^{192}$

Una hendidura estrecha lleva la corriente de aire, en forma de cinta, contra el borde afilado.

421.21 SILBATO CON AERODUCTO EXTERNO. ${ }^{193}$

El aeroducto está afuera de la pared de la flauta; se cuenta entre éstos también el canal formado por el plano oblicuo de la pared y un anillo ceñido arriba o de modo semejante.

$\begin{array}{lllllll}4 & 2 & 1 & 2 & 1 & 1 & \text { SILBATO CON AERODUCTO EXTERNO (independiente). }{ }^{194}\end{array}$

421.211 .1 SILBATO ABIERTO CON AERODUCTO EXTERNO. ${ }^{195}$

Sin agujeros (China, Borneo). Con agujeros (Indonesia).

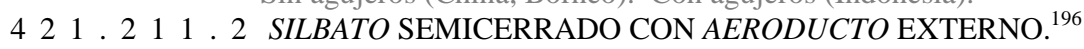

Malaca.

421.211 .3 SILBATO CERRADO CON AERODUCTO EXTERNO. ${ }^{197}$

421.212 SILBATOS EN JUEGO, CON AERODUCTO EXTERNO.

Tibet.

421.22 SILBATO CON AERODUCTO INTERNO. ${ }^{198}$

El canal está en el interior del tubo. Se incluyen las flautas cuyo aeroducto está formado por un taco (nudo, resina) en el interior del tubo y por una tapa ajustada encima por afuera (caña, madera, cuero).

421.2221 SILBATO CON AERODUCTO INTERNO (independiente). ${ }^{199}$

$\begin{array}{lllllll}4 & 2 & 1 & 2 & 2 & 1\end{array}$. 1 (Silbato abierto con aeroducto interno) o FLAUTA DE PICO. ${ }^{200}$

De madera (Europa); de cerámica (Mesoamérica). Pito de 1 agujero; rehue, flauta de 2 agujeros; shainti 3 agujeros; pincullo, flauta, rayan y chisga pinkillo, tepedehue, shoncate, pinkawe, hetowo, totajetu, de 4 agujeros; tsuntyenyuu de 4, 5, 6 agujeros; tarka de 5, 6, 7 agujeros; ndundu, pífano, lolina, de 6 agujeros; khoana, tarjka, de 7 agujeros (Perú)

421.221 . 2 SILBATO SEMICERRADO CON AERODUCTO INTERNO. ${ }^{201}$

India e Indonesia flauta de 2 agujeros; pura, umi, flauta de 3 agujeros; pifa, pincullo, flauta, pito, pífano flautín, pinkillo, pincollo, pfukullu, tokana de 4 agujeros, pinkillo, flauta, pincollo, tocoro,

\footnotetext{
${ }^{188}$ Vega: Tapadillo.

${ }^{189}$ Vega divide "con agujero "y "sin agujeros", subdividido a su vez en "de fondo fijo" y "de fondo móvil". Al eliminar la primera subdivisión se elimina un división "sin agujero, de fondo fijo", que carece de ejemplos conocidos.

${ }^{190}$ Vega: Tapadillo. Entre los Siusi, N.O. del Brasil.

${ }^{191}$ Vega: Vasculares, sin pico desarrollado. El cuerpo de la flauta no es un tubo, sino un vaso. Karajá (Brasil), Bajiote (Congo interior).

${ }^{192}$ Vega: Con canal de insuflación. Una hendidura estrecha lleva la corriente de aire, en forma de cinta, contra el borde afilado de un corte lateral.

${ }^{193}$ Vega: Con canal externo.

${ }^{194}$ Vega: Aisladas.

${ }^{195}$ Vega: Abiertas. Divide en dos categorías: 421.211.11 Sin agujeros (China Borneo) y 421.211.12 Con agujeros (Indonesia).

${ }^{196}$ Vega: Medio Tapadillo.

${ }^{197}$ Vega: Tapadillo.

${ }^{198}$ Vega: Con canal interno. El canal está en el interior del tubo. Pertenecen a esta clase también las flautas cuyo canal está formado por un taco (nudo, resina) en el interior del tubo y por una tapa ajustada encima por afuera (caña, madera, cuero).

${ }^{199}$ Vega: Aisladas.

${ }^{200}$ Vega: Abiertas. Divide en dos categorías: 421.221.11 Sin agujeros (Pitos de señales europeos) y 421.221.12 Con agujeros (Blockflöte).

${ }^{201}$ Vega: Medio Tapadillo.
} 


\section{APÉNDICE}

\section{Adaptación del sistema de clasificación organológica Sachs-Hornbostel}

tiama de 5 agujeros, pinkillo, toccana, pito pinkuillo, charca, awilcuchi de 6 agujeros; flauta, wiswillo de 7 agujeros; pastora, flauta, pinkillo de 8 agujeros (Perú).

421.221 .3 SILBATO CERRADO CON AERODUCTO INTERNO. ${ }^{202}$

Pitos de señales sin agujeros (Europa, América); lawata, novenanteq de 4 agujeros (Perú).

421.221 .4 (silbato vascular con aeroducto interno) u OCARINA. $^{203}$

Generalmente de cerámica. En muchos casos es imposible definir si el aeroducto es interno o externo, por lo cual se considerarán todos del mismo modo (aeroducto interno), aunque tengan un aeroducto incorporado a la pasta antes de cocer. ${ }^{204}$

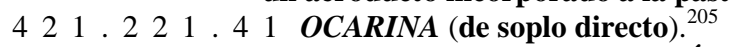

$\begin{array}{lllllllllll}4 & 2 & 1 & 2 & 2 & 1 & 4 & 1 & 1 & \text { OCARINA SIN VARIACIÓN TONAL CONTINUA. }\end{array}$

Pueden existir agujeros de digitación. Cerámica (Andes y Mesoamérica). Resonador sin agujeros; silbato, ocarina, pululu con agujeros (Perú).

$\begin{array}{lllllllll}4 & 2 & 1 & 2 & 2 & 1\end{array} .412$ OCARINA CON VARIACIÓN TONAL CONTINUA.

Es posible variar la altura del sonido de modo gradual obturando un agujero de digitación grande, o largo, o la ventana con la mano o la boca. De metal para señales (Europa); de cerámica prehispánica (Mesoamérica).

421.221 .42 (ocarina de soplo indirecto) o BOTELLA SILBADORA.

La ocarina se halla unida a una botella o similar provista de vasos comunicantes: el aire es empujado por el líquido que contiene, produciendo el sonido. Botella silbadora (Andes,

Mesoamérica).

421.222 SILBATOS EN JUEGO, CON AERODUCTO INTERNO.

421.221 . 4 SILBATOS ABIERTOS EN JUEGO, CON AERODUCTO INTERNO. ${ }^{206}$

Interior tubular. Cerámica (Mesoamérica), madera (Europa del Este). De tubo abierto; gaita con 5/0 y 6/0 agujeros (en un tubo); dathadi 2/0 agujeros; kena con 3/3 agujeros; gaita con 5/5 agujeros; flauta doble con 7/7 agujeros en cada tubo; de hueso con 1/1 agujeros (Perú).

421.222 . 2 SILBATOS SEMICERRADOS, EN JUEGO, CON AERODUCTO INTERNO. ${ }^{207}$

Interior tubular. Juego de flautas de caña, de órgano.

421.222 . 3 SILBATOS CERRADOS, EN JUEGO, CON AERODUCTO INTERNO. ${ }^{208}$

Interior tubular. Juego de órgano labiales de tapadillo.

421.222 .4 OCARINAS EN JUEGO.

Interior globular.

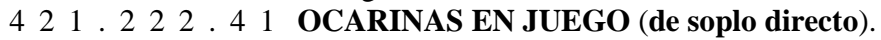

De cerámica prehispánicas (Andes, Mesoamérica). Resonador sin agujeros (Perú).

$\begin{array}{lllllll}42 & 1 & 2 & 2 & 4 & 2 & \text { (ocarinas en juego de soplo indirecto) o BOTELLA SILBADORA MULTIPLE. }\end{array}$

Descripción similar a (421.221.412). Botella silbadora de varios silbatos prehispánica (Ecuador, Perú).

422 (aerófono de lengüeta) o CARAMILLO.

El viento entra a través de laminitas que pone en vibración, haciendo a su vez vibrar la columna de aire..$^{209}$

422.1 (caramillo de dos lengüeta) u OBOE.

Posee dos cañitas vibrantes (la mayoría de los casos un tallo aplastado). ${ }^{210}$

422.11 OBOE (independiente) ${ }^{211}$

422.1111 OBOE DE TUBO CILÍNDRICO. ${ }^{212}$

Oboe de madera (Europa sur y Medio Oriente). Cincosinati (Perú).

422.112 OBOE DE TUBO CÓNICO.

Oboe europeo. Chirimía (Perú).

\footnotetext{
${ }^{202}$ Vega: Tapadillo. Vega Agrega a esta categoría 421.221.31 Sin agujeros que se divide en: 421.221.311 De fondo fijo (pitos de señales europeos) y 421.221.312 De fondo con tapón (Stempelpfeifen).

${ }^{203}$ Nueva categoría, de gran importancia en América precolombina.

${ }^{204}$ Vega: 421.221.41 Sin agujeros. Flautillas de arcilla zoomorfas (Europa, Asia). 421.221.42 Con agujeros. Ocarina.

${ }^{205}$ Se considerará la opción "de soplo directo" como la normal, salvo indicación contraria.

${ }^{206}$ Vega: Abiertas. Divide en dos categorías: (421.222.11) Sin agujeros (Juego de órgano labiales abiertos) y (421.222.11) Con agujeros (Flageolet doble).

${ }^{207}$ Vega: Medio Tapadillo.

${ }^{208}$ Vega: Tapadillo.

${ }^{209}$ Vega: El viento tiene acceso o entrada por descargas a la columna de aire que se tiene que poner en vibración, por medio de laminitas vibrantes añadidas al instrumento.

${ }_{210}^{21}$ Vega: El caramillo tiene una cañita con lengüetas de entrechoque (la mayoría de los casos un tallo aplastado).

${ }^{211}$ Vega: Aisladas.

${ }^{212}$ Vega: Divide en dos categorías: 422.121.1 Sin agujeros (Columbia británica) y 422.121.2 Con agujeros (Aulós. Cuero corvo Krummhorn).
} 


\section{APÉNDICE}

\section{Adaptación del sistema de clasificación organológica Sachs-Hornbostel}

\subsection{OBOES EN JUEGO.}

422.121 OBOES EN JUEGO DE TUBO CILÍNDRICO.

Doble aulós (Grecia).

422.122 OBOES EN JUEGO DE TUBO CÓNICO.

(India).

422.2 (Caramillo de una lengüeta) o CLARINETE. ${ }^{213}$

Posee una laminilla vibrante.

421.21 CLARINETE (independiente). ${ }^{214}$

$4 \begin{array}{llllll}4 & 2 & 2 & 1 & 1 & \text { CLARINETE DE TUBO CILÍNDRICO. } \\ & 215\end{array}$

Clarinete idioglota de caña (Amazonía Brasil, Colombia); ruuhuitu, (Perú); clarinete idioglota y heteroglota de madera (Europa, Asia).

422.212 CLARINETE DE TUBO CÓNICO. Saxofón (Europa); oboe de madera (Europa, Asia).

422.22 CLARINETES EN JUEGO.

Clarinete doble (universal).

422.3 CARAMILLO DE LENGÜETA LIBRE.

La lengüeta se mueve a través de una abertura exactamente de su tamaño. Si no existen agujeros, pertenece a las lengüietas libres de marco (412.13) (India).

422.31 CARAMILLO DE LENGÜETA LIBRE. (Independiente). ${ }^{216}$

422.32 . CARAMILLOS EN JUEGO, DE LENGÜETA LIBRE. ${ }^{217}$

423 (Aerófono de vibración labial) o TROMPETA. ${ }^{218}$

Los labios vibrantes del ejecutante, ponen en vibración la columna de aire.

$\begin{array}{lllll}4 & 2 & 3\end{array} .1$ TROMPETA NATURAL.

Sin mecanismo para modificar la altura del sonido.

423.11 CARACOL TROMPETA.

Una concha sirve como trompeta.

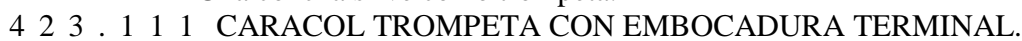

$\begin{array}{llllllllllll}4 & 2 & 3 & 1 & 1 & 1 & 1 & 1 & \text { SIN BOQUILLA. }\end{array}$

(Asia, América); pututu, churu, quipakugku, kachu, wacrawitsi, (Perú)

$\begin{array}{lllllllll}4 & 2 & 3 & 1 & 1 & 1 & 1 & 2 & \text { CON BOQUILLA. }\end{array}$

(Asia, América). Pututu (Perú).

423.112 CARACOL TROMPETA CON EMBOCADURA LATERAL.

(Oceanía).

423.12 TROMPETA DE TUBO.

$\begin{array}{lllllll}4 & 2 & 3 & 1 & 2 & 1 & \text { TROMPETA LONGITUDINAL. }\end{array}$

La abertura de soplo está en dirección al eje.

423.121 .1 (Trompeta longitudinal de tubo recto) o TUBA. ${ }^{219}$

El tubo no es ni curvo ni quebrado.

$\begin{array}{lllllllll}4 & 2 & 3 & 1 & 2 & 1 & 1 & 1 & \text { TUBA SIN BOQUILLA. }\end{array}$

De caña (Sudamérica); trutruca (mapuche); punati, perutiati, coxiri, cashtaina, yaixjina (Perú); de cerámica (Andes prehispánicos); de madera, toxcu (Perú, andes prehispánicos, Europa, Oceanía); metal (Europa); trutruca y klarin metalico (mapuche); de corteza (Perú); de plástico, trutruca plástica, (mapuche); de calabaza matti phusaña (Perú) y hueso (Andes prehispánicos); de hojas (Andes sur), kullkull (mapuche). De piel de quirquincho (Perú); de cola de lagarto, de cola de carachupa (Perú); bajón (trompeta múltiple, Bolivia),

423.121 .12 TUBA CON BOQUILLA.

Pampa corneta, trompeta, huarajo, kañari, Perú.

$\begin{array}{lllllll}4 & 2 & 1 & 2 & 1\end{array} .2$ (Trompeta longitudinal de tubo curvo) o CORNO.

El tubo es curvo o quebrado.

$\begin{array}{llllllll}4 & 2 & 3 & 1 & 2 & 1 & 2 & 1 \\ \text { CORNO SIN BOQUILLA. }\end{array}$

Cuerno animal (Europa, Asia, Sudamérica); kullkull (mapuche, Chile); pututo (Andes). Poro, oututo, wagra, pucu, kachu, wacrawitsi, tiorensi, kowi (Perú).

\footnotetext{
${ }^{213}$ Vega: Clarinetes. El caramillo tiene una laminilla batiente.

${ }^{214}$ Vega: Aislados.

${ }^{215}$ Vega: Divide en dos categorías: 422.211.1 Sin agujeros (Columbia Británica) y 422.211.12 Con agujeros (Clarinete Europeo).

${ }^{216}$ Vega: Aisladas.

${ }^{217}$ Vega: Dobles.

${ }^{218}$ Vega: Por medio de los labios vibrantes del ejecutante, el viento entra por descargas a la columna de aire que hay que poner en vibración.

${ }^{219}$ Habría sido mejor separar según la forma del tubo, cilíndrica o cónica (igual que en las trompetas cromáticas). Esto incide en la tímbrica y las posibilidades musicales del instrumento, más que por la forma recta o curva, que no incide salvo en su transporte y maniobrabilidad. Dejamos, sin embargo, esta división intocada por respeto al sistema original.
} 


\title{
APÉNDICE \\ Adaptación del sistema de clasificación organológica Sachs-Hornbostel
}

\author{
423.121 .22 CORNO CON BOQUILLA. \\ Metal (Europa). Pututo, wagra, sokos (Perú).
}

423.1222 TROMPETA TRAVERSA.

La abertura de soplo está a un lado.

423.122 .1 TUBA TRAVERSA.

Caña erke (Noroeste argentino, Perú); de cerámica (Perú); con boquilla: mamac, llungur, pucu y kepa,

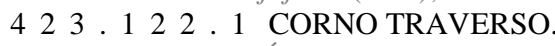

jojore (Perú); trutruca y klarin traverso (mapuche, Chile).

423.2 TROMPETA CROMÁTICA.

Con sistema para cambiar la altura del sonido.

$\begin{array}{lllll}4 & 2 & 3 & 2 & 1\end{array}$ TROMPETA CROMÁTICA CON AGUJEROS.

Cornetto renacentista (Europa).

423.22 TROMPETA DE VARA.

El tubo puede ser alargado desplazándose dentro de otro tubo (Europa). ${ }^{220}$

$\begin{array}{lllll}4 & 2 & 3 & 3 & \\ \text { TROMPETA DE VALVULA. }\end{array}$

El tubo se alarga o acorta por conexión o desconexión de tubos adicionales (Europa).

423.231 (Trompeta de válvula de tubo cónico) o CORNETÍN.

El tubo es de forma cónica.

423.232 (Trompeta de válvula de tubo cilindro-cónico) o TROMPA.

El tubo es principalmente de forma cónica.

423.233 (Trompeta de válvula de tubo cilíndrico) o TROMPETA.

El tubo es principalmente de forma cilíndrica.

\section{$\begin{array}{lllll}4 & 2 & 3 & 3\end{array}$ TROMPETA DE ASPIRACIÓN.}

El aire es aspirado en vez de soplado. El sonido es diferente en dinámica y en su registro, más agudo.

Nolkiñ (mapuche, Chile).

DIVISIÓN COMÚN FINAL.

- 6 Con depósito para el viento.

- 61 Rígido.

- 62 Flexible gaitas y semejantes, provistos de saco con varios clarinetes u oboes (Europa),

- 7 Con cierre de agujeros.

- 71 Con aparato de válvulas.

- 72 Con aparato de cinta.

- 8 Con teclado. Órgano (Europa).

- 9 Con tracción mecánica. Organillo (Europa).

En el caso de aquellos aerófonos con agujero, se especifica la cantidad de éstos del siguiente modo:

$/ 0$, Sin agujeros. ${ }^{221}$

/1, Un agujero.

/2, Dos agujeros.

13, Tres agujeros.

14 Cuatro agujeros.

15 Cinco agujeros.

\footnotetext{
${ }^{220}$ Vega: El tubo puede ser alargado por tradición de las varas [tubos secundarios] dentro de las vainas. Sacabuche Europeo.

${ }^{221}$ Nueva categoría. Vega parte esta subdivisión de la división común desde un agujero (/1) en adelante. Al añadir el equivalente a sin agujeros (/0) se simplifica la definición de todos los grupos en que el sistema se divide entre sin agujeros y con agujeros. Esta división no necesariamente significa que unos tengan posibilidades melódicas y los otros no, ya que hay muchos casos de flautas andinas que se tocan con presión de aire, obteniendo la serie armónica aun sin contar con agujeros, pudiendo tocar melodías de muchas notas. Debido a esto, propongo que la existencia o no de agujeros se plantee como una opción común.
} 